\title{
Contributions to risk management
}

\author{
On the balance between \\ value creation and protection
}

by

\section{Henrik Langdalen}

\author{
Thesis submitted in fulfilment of \\ the requirements for the degree of \\ PHILOSOPHIAE DOCTOR \\ $(\mathrm{PhD})$

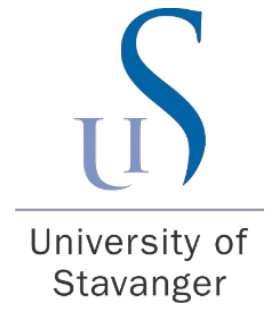

Faculty of Science and Technology Department of Safety, Economics and Planning 2020 
University of Stavanger

NO-4036 Stavanger

NORWAY

www.uis.no

C2020 Henrik Langdalen

ISBN:978-82-7644-940-2

ISSN:1890-1387

PhD: Thesis UiS No. 533 


\section{Preface}

This thesis is submitted for partial fulfilment of the requirements for the degree of Philosophiae Doctor $(\mathrm{PhD})$ at the University of Stavanger, Faculty of Science and Technology, Norway. The research presented was performed in the period from May 2017 to April 2020. This $\mathrm{PhD}$ thesis is funded by the Norwegian Ministry of Education and Research. The financial support is gratefully acknowledged.

This $\mathrm{PhD}$ project has been research on safety economics, with a special emphasis on risk management and the balance between different concerns. The main goal was to contribute to new knowledge in risk management. It became clear early on that the focus area should be the balance between value creation and protection, but the actual result of the research is a product of a three-year long process, in which the research and researcher matured and developed. The resulting research is influenced by my belief that there is great value in working across disciplinary boundaries, utilising the best of different perspectives.

I would like to express my deepest thanks to my supervisor and coauthor, Professor Eirik Bjorheim Abrahamsen. You have provided me with excellent guidance, support, patience and help, for which I will forever be grateful. Your knowledge, openness and positive attitude have been decisive factors in my ability to carry out this project. Thank you for giving me a phone call in February 2017 and providing me with this opportunity. It has been a true pleasure working with you. Thank you!

I would also like to thank my co-supervisor, Associate Professor II Håkon Bjorheim Abrahamsen. You have provided me with the best of guidance on the papers we have written together. Your positive attitude and critical questions have been inspiring and motivating, which has taken me and my work a step further. 
My deepest thanks go also to my co-supervisor, Associate Professor Jon Tømmerås Selvik. You have provided me with excellent guidance and support throughout the period, for which I will forever be grateful. Your knowledge and positive attitude have been invaluable. It has been a pleasure working with you. Thank you!

My gratitude also goes to the other co-authors for your contributions to the papers. Senior Researcher Hans Petter Lohne at NORCE, thank you for letting me join the P\&A project and for your thorough and constructive feedback on our paper. Dr Leif Inge K. Sørskår, thanks for many good discussions, collecting the data and allowing me on board the HEMS study. Associate Professor Sissel H. Jore, thank you for helping me with the introduction to the security world. Associate Professor Stephen J. M. Sollid, you have my thanks for your support and comments. PhD Student Kristen Rasmussen, thanks for the collaboration on the HEMS paper. Many thanks go also to the other co-authors, with whom I have had the pleasure of collaborating.

Linda March, at The Good English Company, deserves a special thanks for excellent proofreading of my work. My gratitude goes also to the staff and $\mathrm{PhD}$ coordinators at the Faculty of Science and Technology for all help and assistance throughout the period.

To my fellow PhD students, thank you - I know that I am not the most outgoing person and not exactly a "world champion in small talk", but I have truly enjoyed my time at UiS and you have all contributed to making these three years unforgettable.

Finally, to Helene, thank you very much for your support and patience, during my time as unemployed throughout the last period of the $\mathrm{PhD}$. You are the best!

Henrik Langdalen

Stavanger, April 2020 


\section{Summary}

The overall objective of this thesis is to contribute to new knowledge in risk management. More concretely, the research relates to one of the main tasks of risk management: to obtain an appropriate balance between value creation on the one hand and protection on the other

Risk management is considered to be all activities and measures carried out to manage the risk. The main purpose is to support the balancing of the conflicts inherent in exploring opportunities, creating values and development, on the one hand, and avoiding losses and accidents on the other. Many of the situations we face, however, involve high risk and uncertainty, making it challenging to predict the outcomes of our decisions and to obtain an appropriate balance between different concerns such as risk and socioeconomic profitability. Various strategies can form the basis for supporting risk management and decision-making under uncertainty, using different tools and approaches. To adequately inform the decision-makers about the risks and uncertainties, we need to make sure that the strategy we apply, and the approaches and principles that follow, are appropriate for the decision-making context and capable of capturing the relevant uncertainties. This is not straightforward, and there is a need to continuously develop the approaches we use to support the decision-makers. At the same time, we need to acknowledge the fact that the tools we use are just tools, with strong limitations. The quality of the produced decision support, then, relates to the quality of the background knowledge, on which the analyses and evaluations are based. To obtain good quality background knowledge, however, is not always straightforward.

The thesis contributes to this end by exploring approaches, principles and underlying ways of thinking related to how we can obtain the appropriate balance between value creation and protection, and by producing new knowledge to support that balance in a specific domain. The scientific 
contribution of the thesis consists of seven papers. The content and contribution of the seven papers are summarised in the following.

In risk management, different strategies can be applied to support the tasks. The strategy refers to the underlying way of thinking and the principles that follow. Amongst the principles, ALARP is central. According to the ALARP principle, risks should be reduced to a level that is As Low As Reasonably Practicable, meaning that risk-reducing measures should be implemented unless the costs are grossly disproportionate to the obtained benefits. By large, however, observations from the industry and literature indicate that analysts focus on single measures in isolation when using the ALARP principle to support decision-making. This underlying way of thinking might lead to misguided decisions: it does not consider that safety measures do not always give the intended effect, as offset effects can occur, and the weight given to the cautionary principle might be inappropriate, given the decision-making context. Paper I discusses and illustrates the importance of systems thinking when using the ALARP principle to guide decision-making under uncertainty. Systems thinking has a role to play, as it enhances the understanding of the decision-making context.

Enhancing the understanding and knowledge of a risk-related problem is essential for risk management. The available knowledge (justified beliefs) forms the foundation on which risks are assessed. Different methods exist on how to evaluate the strength of the knowledge, but there is a gap in the literature with respect to methods useful for the identification of relevant knowledge, and an arbitrary approach does not appear to be optimal. Paper II suggests a framework, using a systems approach, to identify and assess the background knowledge, as a means to reduce the risk of missing relevant knowledge and obtain more complete background knowledge, on which risk can be assessed. If we are unable to capture all the relevant knowledge, such as hidden assumptions, the result is incomplete background knowledge, which 
hampers risk management and the balance between value creation and protection.

The available background knowledge needs to be considered in a risk assessment, to inform the decision-makers on, for example, what assumptions the analysts made and what the risk assessment represents. The uncertainties and knowledge need adequate treatment and reflection, in order to produce informative decision support. Paper III contributes to this end and illustrates how the knowledge dimension can be integrated with a risk-based approach, supporting decisions about permanent plug and abandonment of offshore oil and gas wells. The objective of the original approach is to evaluate leakage risk from offshore wells on the basis of consequences and probability, in order to justify more costeffective solutions than the prescriptive ones. Creating cost-effective solutions, however, does not justify less focus on risk and uncertainties, and Paper III suggests an improved approach, which strengthens the decision support on the leakage risk by highlighting the uncertainties, assesses the risk of deviation from the assumptions and reflects the knowledge base.

The adoption of safety measures, such as barriers in an offshore well, is an essential activity of risk management. At the same time, it is well known that safety measures do not always give the intended effect, as new safety measures are sometimes offset by other system components. This is problematic for the balance between value creation and avoiding losses, as any company has limited resources for safety expenditure. This implies a need for proper consideration of economic concerns. However, economic evaluations are usually made with sole reference to expected values, in which no or limited weight is given to the cautionary principle. The use of expected values is rational given the portfolio theory, but, at the same time, expected values should be used with care in risk management, as the uncertainties and cautionary principle need stronger weight than what the frame of expected values supports. Papers IV and $\mathrm{V}$ discuss and illustrate why traditional economic tools need stronger 
weight on the cautionary principle when applied in a risk context. Paper IV discusses foundational issues of the use of socioeconomic profitability as a prerequisite for investments in security measures, while Paper V discusses the application of the return of investments in safety (ROSI) measure in the chemical industry. Without considerations of uncertainty and background knowledge, the economic tools might produce misguided decision support, hampering the balance of different concerns.

There is an increasing awareness of the importance of the knowledge dimension in the risk science field, in relation to managing risk. The knowledge dimension is split into general knowledge and specific knowledge. The former covers all knowledge available for related activities, whereas the latter covers specific knowledge of activities. For example, to improve patient safety in the emergency medical services, we need to know what can go wrong and why (i.e. general knowledge), but, at the same time, we need to make sure that necessary measures, such as a training programme, are implemented and functioning as intended in the emergency medical services (i.e. specific knowledge), especially when the risk management is subject to scarce resources. Papers VI and VII contribute to the latter, by producing new knowledge about the frequency of training in non-technical skills in the Norwegian emergency medical services. The studies indicate that training has had a positive effect, as the frequency of training in non-technical skills among the personnel in the helicopter emergency service has increased over recent years, and that there is a potential for learning and knowledge sharing between the two emergency medical services. This new specific knowledge provides input to evaluations and future practices of the training programmes, and to increase the general knowledge, which can assist the prehospital services in obtaining an appropriate balance between value creation and protection. 


\section{Contents}

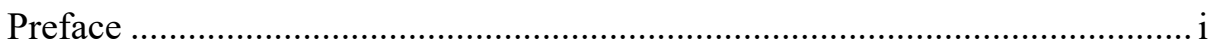

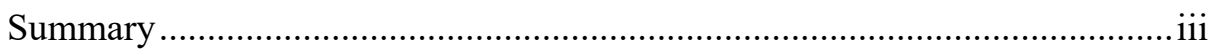

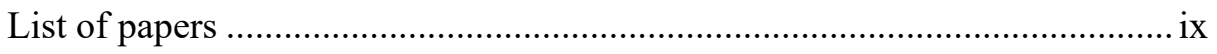

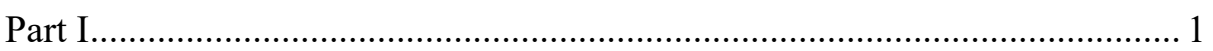

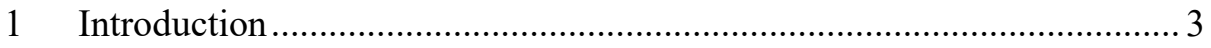

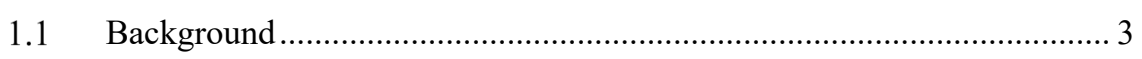

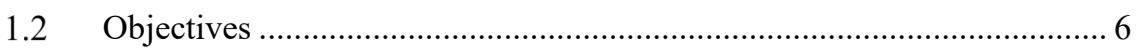

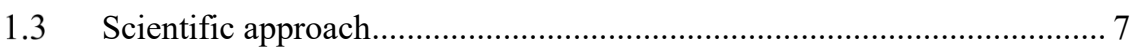

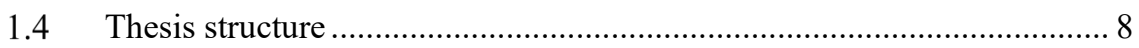

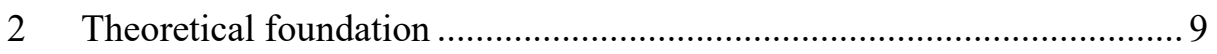

2.1 The concept of risk and its description.............................................. 9

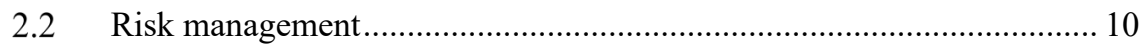

2.3 Economic principles, theories and methods ........................................... 12

2.3.1 Expected utility theory ...................................................................12

2.3.2 Cost-benefit and cost-effectiveness analysis ......................................13

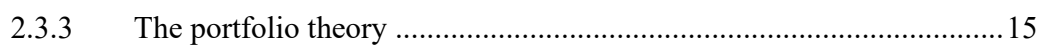

2.3.4 The use of expected values in risk management....................................16

2.4 Safety management principles .......................................................... 18

2.4.1 Cautionary and precautionary principles ...............................................19

2.4.2 Risk acceptance criteria...................................................................20

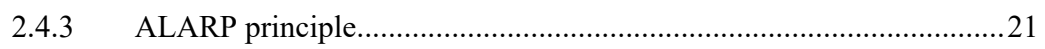

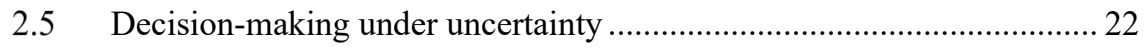

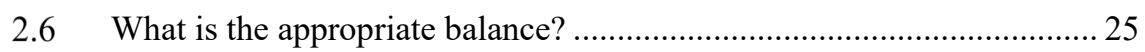

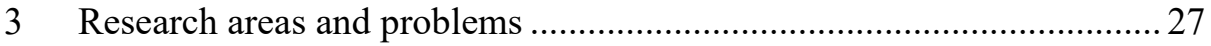

3.1 Systems thinking: the underlying thinking in risk management ............. 28

3.2 Improvement and development of approaches for risk management...... 32

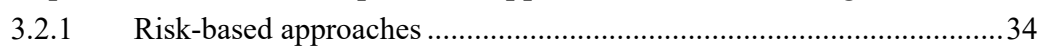

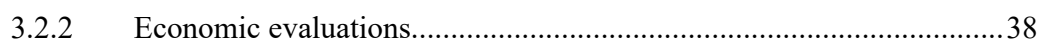

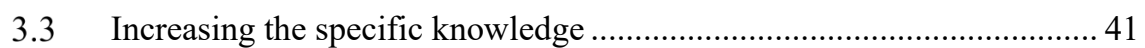

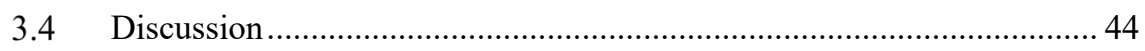

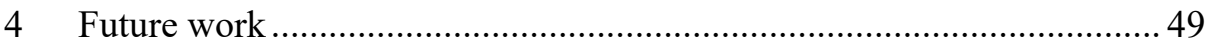

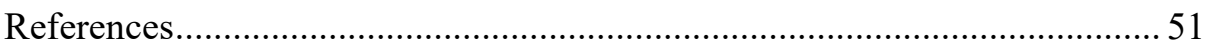

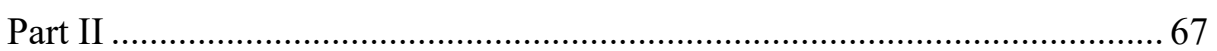




\section{List of papers}

I. Langdalen, H., Abrahamsen, E.B. and Selvik, J.T. On the importance of systems thinking when using the ALARP principle for risk management. Submitted for possible publication in Reliability Engineering \& System Safety.

II. Langdalen, H., Abrahamsen, E.B. and Abrahamsen, H.B. (2020). A new framework to identify hidden assumptions in the background knowledge of a risk assessment. Reliability Engineering \& System Safety, vol. 200. Doi: 10.1016/j.ress.2020.106909.

III. Langdalen, H., Abrahamsen, E.B., Selvik, J.T. and Lohne, H.P. (2019). Riskinformed decision-making with an improved approach to evaluate plug and abandonment designs. International Journal of Business Continuity and Risk Management, vol. 9 (3), 226-250. Doi: 10.1504/IJBCRM.2019.100415.

IV. Langdalen, H., Abrahamsen, E.B., Selvik, J.T. and Jore, S.H. (2018). A discussion on socio-economic profitability as a prerequisite for investments in security measures. The Business Review, Cambridge, vol. 26 (2), 1-8.

V. Abrahamsen, E.B., Selvik, J.T., Langdalen, H., Milazzo, M.F., Dahl, R.E., Abrahamsen, H.B. and Bansal, S. On the use of the 'return of investments in safety' (ROSI) measure for decision-making in the chemical industry. Submitted for possible publication in Reliability Engineering \& System Safety.

VI. Langdalen, H., Abrahamsen, E.B., Sollid, S.J.M., Sørskår, L.I.K. and Abrahamsen, H.B. (2018). A comparative study on the frequency of simulationbased training and assessment of non-technical skills in the Norwegian ground ambulance services and helicopter emergency medical services. BMC Health Services Research, vol. 18 (509), 1-11. Doi: 10.1186/s12913-018-3325-1.

VII. Rasmussen, K., Langdalen, H., Sollid, S.J.M., Abrahamsen, E.B., Sørskår, L.I.K., Bondevik, G.T. and Abrahamsen, H.B. (2019). Training and assessment of non-technical skills in Norwegian helicopter emergency services: a crosssectional and longitudinal study. Scandinavian Journal of Trauma, Resuscitation and Emergency Medicine, vol. 27, 1-10. Doi: 10.1186/s13049018-0538-1. 
Part I 


\section{Introduction}

\subsection{Background}

Risk management involves all activities and measures carried out to manage the risk (Aven, 2014; SRA, 2015), balancing the conflicts inherent in exploring opportunities, creating values and development, on the one side, and avoiding losses, accidents and disasters on the other (Aven, 2014; Engemann and Abrahamsen, 2020; PSAN, 2018; SRA, 2015). The process of balancing different concerns involves making decisions under uncertainty. Many situations we face, however, involve the potential for immense losses and high uncertainty, making it difficult to predict the outcome of our decisions (Aven and Vinnem, 2007; Engemann and Abrahamsen, 2020). To obtain an appropriate balance of value creation and protection, proper decision support is required (Aven, 2018; Hokstad and Steiro, 2006).

Different disciplines tend to emphasise different perspectives on how to provide an adequate basis for managing risk (Abrahamsen and Abrahamsen, 2015; Engemann and Abrahamsen, 2020; Ayyub, 2003; Möller and Hansson, 2008; Sørskår and Abrahamsen, 2017). On the one hand, an economic perspective relying on economic principles and evaluations usually leads to decisions made in reference to expected values, in order to optimise some criteria (e.g., Levy and Sarnat, 1994; Varian, 1999). This perspective mechanically highlights value creation. The use of expected values is rational, according to the portfolio theory (Levy and Sarnat, 1994; Varian, 1999). At the same time, it is argued that expected values as a basis for decision-making under uncertainty should be used with care in risk management. The main arguments are that the expected values do not give sufficient weight to the uncertainties and do not reflect the background knowledge (justified beliefs), on which they are based (see, e.g., Abrahamsen et al., 2004; Ale et al., 2015; Aven and Flage, 2009; Hoegberg, 1998; Watkiss et al., 2015). 
On the other hand, safety experts constitute a discipline that usually puts strong weight on the uncertainties (e.g., Abrahamsen and Abrahamsen, 2015; Abrahamsen et al., 2018a; Aven, 2019; Baard, 2016; Fischhoff et al., 1981; HSE, 2001; Klinke and Renn, 2002; Möller and Hansson, 2008; Paté-Cornell, 2002), for example by the means of the cautionary principle, expressing that, in the face of an activity subject to serious consequences or uncertainty, caution should be the ruling principle (Aven, 2019; Aven and Abrahamsen, 2007). This perspective gives strong weight to protection. In fact, little or no consideration of costbenefit calculations is required to justify an appropriate balance between value creation and protection with an extreme safety perspective (e.g., Abrahamsen and Abrahamsen, 2015), as caution is the ruling paradigm. As a consequence, it is hard to argue that an extreme safety perspective can be considered a general perspective to balance different concerns, as too much emphasis on caution might lead to inefficient use of resources (Abrahamsen and Abrahamsen, 2015; Abrahamsen et al., 2018a, 2018b; Lind, 2002; Vesely, 1999; Viscusi et al., 2019) and reduce innovation and development (e.g., Aven, 2019; Bhardwaj et al., 2019; Grote, 2015).

A problem occurs when the perspectives provide contradicting decision support (Abrahamsen et al., 2016, 2020a; Bedford and Cook, 2001; Engemann and Abrahamsen, 2020; Erkan et al., 2016; Sørskår and Abrahamsen, 2017). An example could be that, while high risk implies a need for protection and cannot be ignored (Hokstad and Steiro, 2006), it is important to consider that the resources available for risk management activities are usually scarce (Abrahamsen et al., 2013, 2018b). Adopting one of the perspectives while ignoring the other cannot in general be considered a good basis for obtaining an appropriate balance (Abrahamsen et al., 2016, 2018a; Kaplan and Garrick, 1981).

As already indicated, there is no one correct perspective or approach on how to balance value creation and protection in risk management (Abrahamsen et al., 2018a; Aven and Körte, 2003; Klinke and Renn, 2001; Kristensen et al., 2005). In fact, risk as a phenomenon precludes 
standardised solutions for obtaining an appropriate balance (Renn, 2008). The practical implication is that an appropriate balance between value creation and protection cannot be based on a single static decisionmaking principle (e.g., Abrahamsen et al., 2017a; ISO, 2018).

In some risk management situations, it is appropriate to make decisions with reference to a cost-benefit analysis, while, in others, no reference to expected costs and benefits should be required (Abrahamsen and Abrahamsen, 2015; Abrahamsen et al., 2020b). It is the decision-making context that should be the decisive factor for determining how to balance different concerns, which necessitates a thorough understanding of it (e.g., Abrahamsen et al., 2018b, 2020b; Amendola, 2002; Aven and Körte, 2003; Aven and Kristensen, 2019; Baard, 2016; Engemann and Abrahamsen, 2020; Grote, 2012; van der Sluijs et al., 2008). The tools of risk and decision analyses provide such decision support (see PatéCornell and Dillon, 2006), which should be applied and appropriate with respect to the context of interest. That is, they should be capable of assessing and communicating all the relevant information (e.g. complexity, uncertainty, knowledge, costs) to the decision-maker (Abrahamsen and Abrahamsen, 2015; Abrahamsen et al., 2018a; Aven, 2018; ISO, 2018; Sørskår and Abrahamsen, 2017).

This is not straightforward, but, to obtain an appropriate balance between value creation and development, it should be acknowledged that we need both economic and safety perspectives (e.g., Abrahamsen and Abrahamsen, 2015; Abrahamsen et al., 2017a; Aven, 2019; Lind, 2002). Usually the appropriate balance is found in between the two extremes (Sørskår and Abrahamsen, 2017). At the same time, the decision support is not perfect and, hence, cannot mechanically prescribe what to do (e.g., Apostolakis, 1990; Aven, 2014, 2019; Paté-Cornell, 1996). Decisionmaking in risk management needs to be risk-informed, with the decision support being subject to a greater or lesser extent to informal managerial review and judgments (e.g., Apostolakis, 2004; Aven and Körte, 2003). It then follows that increasing the general knowledge about what can go 
wrong and why, as well as the knowledge of a specific activity, is key to ensuring informative decision support (Aven, 2014; Aven and Kristensen, 2019).

Managing risk is difficult. There are usually different values at stake and goals to be reached, for which the different strategies, approaches and principles might point to different alternatives, emphasising certain factors and conditions, which could be contradictory. The produced decision support could also be misleading, as it could be based on more or less strong knowledge (Aven, 2013), and uncertainties could be hidden within it, such as assumptions that turn out to be wrong (PatèCornell, 2002). The consequences of an activity could be serious and will always be subject to more or less uncertainty. On these premises, the decision-maker needs to judge all the relevant attributes and make tradeoffs, in order to reach an appropriate balance between value creation and protection. This calls for proper decision support, capturing the knowledge and characteristics of the risk-related situation. The key is to enhance the knowledge, with respect to the specific situation of interest (Aven and Kristensen, 2019), but also of the risk science field in terms of improving and developing suitable risk management approaches, concepts, principles and strategies (Aven, 2018). It is to those ends that the thesis aims to contribute.

\subsection{Objectives}

Based on recent developments and ideas in the risk science field (see, e.g., Aven, 2018), the overall aim of the thesis is to contribute to new knowledge in risk management, by exploring the following research areas:

1. How to obtain an appropriate balance between value creation and protection.

2. Increase the specific knowledge on training in the Norwegian emergency medical services. 


\subsection{Scientific approach}

The research has an interdisciplinary approach, in which the scientific contributions have different scientific characterisations. In general, basic types of research are distinguished by the following (Kothari, 2004): descriptive vs analytical, applied vs fundamental, quantitative vs qualitative, and conceptual vs empirical. The nature of the research areas demands the application of different types of research (see, e.g., Aven, 2018). The research of the present work as one entity is at best characterised as a conglomerate of the different types. Parts of the work are descriptive, as they describe the state in the real world as it is (e.g. Papers VI and VII), while others are analytical in the sense that they use established theories and methods to search for new knowledge and critical evaluations (e.g. Papers I to V). The work is both applied (e.g. Papers III, VI and VII), as it aims to contribute to specific issues facing a society or industry, and fundamental, as it is generic and contributes to a broad spectrum of applications (e.g. Papers I, II, IV and V). The work includes both qualitative (e.g. Paper IV) and quantitative research (e.g. Paper VI). Parts of the work are empirical (e.g. Papers VI and VII), starting from a hypothesis, which by the means of data analyses results in conclusions. At the same time, the work is conceptual, as it focuses on abstract ideas, concepts and theories (e.g. Papers I and II).

The work follows the criteria for scientific quality highlighted by the Norwegian Research Council (2000). The research presented in this thesis is, to the best of the author's ability, conducted according to the criteria of originality, solidity and relevance (NRC, 2000). Originality refers to the degree of something "new", such as further development or new application of the theories and methods used in the scientific field. Solidity is expressed in the form of sound support for statements and conclusions, which are based on recognised scientific methods and principles, good source references, consistency between assertions, and critical reflections regarding the data, methods and results of the research. Relevance refers to the usefulness and applications of the 
research, with respect to both scientific and societal benefits, for example that the work is applicable for different industries.

The thesis follows the so-called "European PhD-Model" (Day and Gastel, 2006) and comprises two parts. The main part consists of the main scientific work, and the secondary part frames the scientific work in a broader context. The papers making up the main scientific work, presented in Part II, were developed by the means of literature studies, supervisory guidance, data analysis, discussions with co-authors and colleagues, preparation for and feedback from conferences, rational and creative thinking, peer reviews from international journals, selfreflection, and, finally, by a lot of hard work and hours carrying out research.

\subsection{Thesis structure}

The thesis is divided into two parts. Part I comprises the foundation and motivation of the work. Part II comprises the main scientific contributions, in the form of seven scientific papers. Of the seven papers, five are published in international scientific journals, and two are submitted for possible publication in international scientific journals.

The thesis is organised as follows. Section 2 presents the theoretical foundation related to the objective of the thesis. Section 3 summarises and discusses the scientific contributions in respect to the research areas and the overall objective. Then, Section 4 presents some potential directions for future work. Finally, Part II of the thesis presents the seven scientific papers. 


\section{Theoretical foundation}

This section summarises some of the theoretical foundations of risk management, related to concepts, principles and methods used to support the balance between value creation and protection. The purpose of the chapter is to provide a clear understanding of the background to the research presented in Section 3.

\subsection{The concept of risk and its description}

In this thesis, risk is understood as the (mental) concept that relates to the consequences of an activity. Risk comprises two dimensions: (1) the consequences of the activity, with respect to something that humans value and (2) uncertainties (Aven, 2018; SRA, 2018b). We refer to this as an uncertainty-based risk definition. The arguments supporting the uncertainty-based risk definition, rather than the more traditional probability-based definitions, are thoroughly discussed in the literature and will not be repeated here (see, e.g., Aven, 2011a; Aven and Renn, 2009; Aven and Zio, 2011; Rosa, 1998; SRA, 2015; Watson, 1994).

As we consider risk to have two dimensions - consequences and uncertainties - there is a logical distinction between how we define the risk concept and how risk is described. The risk description is obtained by specifying a set of (observable) quantities of interest (e.g. loss of lives, profit) that represents the (unknown) consequences and by using a measure to describe the uncertainties (Aven, 2018). Probability is the most common measure of uncertainty, but others exist (see, e.g., Flage et al., 2014).

In the risk analysis, the specified consequences are predicted, and the uncertainties assessed (Flage et al., 2014). The judgments about the specified consequences and uncertainties are always more or less conditional on the analyst's knowledge (justified belief) (Aven and Zio, 2018a), usually formulated as assumptions, based on data, models, 
expert opinions and so on (Flage and Aven, 2009). This knowledge can be more or less strong (Aven, 2013), and uncertainties can be hidden within it, such as assumptions that turn out to be wrong (Patè-Cornell, 2002). Therefore, a central part of the risk description is the knowledge dimension and its strength (Flage and Aven, 2009). See also Aven and Zio (2018b).

\subsection{Risk management}

To explore opportunities and create values and development, risk taking is needed. It is widely accepted that risk cannot be eliminated; thus, it must be managed (Aven and Vinnem, 2007). There are several definitions of risk management (e.g., Aven and Vinnem, 2007; COSO, 2017; Hopkin, 2013; Pritchard, 2015; PSAN, 2018; IPCC, 2012; ISO, 2018; Renn, 2008), and, in this thesis, risk management is defined as all activities and measures carried out to manage the risk (SRA, 2018a). The purpose is to support the balancing of the conflicts inherent in exploring opportunities, creating values and development, on the one hand, and avoiding losses and accidents on the other (Engemann and Abrahamsen, 2020; PSAN, 2018; SRA, 2015).

While risk management covers all the co-ordinated activities and measures carried out to control and direct an organisation with respect to risk (Aven and Vinnem, 2007; ISO, 2018), the risk management process is the systematic and structured use of policies, procedures and practices for the tasks of establishing the context and assessing, treating, communicating, consulting, monitoring and reviewing risk (ISO, 2018). The main steps of a risk management process are establishment of the context, risk assessment and risk treatment. Establishing a context includes problem definition, information gathering, organisation of work, specification of scope and objectives (Aven, 2015). The risk assessment is the main part of a risk management process, aiming to establish an informative risk picture for the various decision alternatives (Aven and Vinnem, 2007). The step includes identifying risks, analysing 
causes and consequences, establishing a risk picture and evaluating risk. The output from the risk assessment serves as input to decision-making as regards the risk treatment.

Various strategies can form the basis for supporting risk management. Amongst them, risk-informed (analysis-based), cautionary/ precautionary and discursive strategies are the most common (Renn, 2008; SRA, 2015; Stirling, 1999); see also ISO (2018). Strategy in this context refers to the underlying thinking and the principles that follow, with respect to how a decision is to be made and how the decisionmaking process should be carried out (Aven, 2011b). In simple terms, the risk-informed (analysis-based) strategy refers to treatment (avoidance, reduction, transfer, and retention) of risk on the basis of risk assessments and decision analyses (Renn, 2008). The cautionary/precautionary strategy is also referred to as a strategy for robustness and resilience (SRA, 2015), which emphasises attributes such as containment, best available technology (BAT), safety factors, flexibility and increasing knowledge (Aven, 2014). The discursive strategy includes stakeholder involvements, discussions, deliberations, building confidence through reduction of uncertainties and ambiguity, and clarifications of facts (Aven and Renn, 2010). In practice, a mixture of the three will often be the most appropriate (Renn, 2008). See also Aven and Kristensen (2019).

A central part of risk management is to provide the decision-maker with an adequate basis for managing the risk. Several tools and principles are available, such as cost-benefit analysis and the cautionary principle. The question then is what approaches and principles should be applied to provide the basis for balancing the different concerns of value creation and protection. Different disciplines tend to emphasise different perspectives to answer the question. Of special interest in this thesis are the perspectives that are attributable to traditional economic theories, on the one hand (the economic perspective), and fundamental principles of 
safety management on the other (the safety perspective). Some of them are presented in the following.

\subsection{Economic principles, theories and methods}

\subsubsection{Expected utility theory}

In theory, the answer to the question above can be found in the expected utility theory, which is the ruling paradigm for decision-making under uncertainty among economists and decision-analysts (e.g., Bedford and Cook, 2001; Bernardo and Smith, 1994; Keeney and Raiffa, 1993; Levy and Sarnat, 1994; Lindley, 1985; von Neumann and Morgenstern, 1944; Watson and Buede, 1987). The theory is attractive, as it provides a logical framework for making decisions. If a person is coherent in her preferences amongst consequences and in her assessment about uncertainties, the theory proves that the only sensible way to make a decision is to optimise her expected utility (Lindley, 1985). For a person to be coherent about consequences means to adhere to a set of axioms, such as the transitive axiom: if $\mathrm{X}$ is preferred to $\mathrm{Y}$, which is in turn preferred to $Z$, then $X$ is preferred to $Z$ (von Neumann and Morgenstern, 1944). When it comes to uncertainties, coherence means that the person follows the rules of probability (Lindley, 1985). Despite being theoretically attractive given its logical basis, the expected utility theory is difficult to apply in practice.

Assigning utility values to all possible outcomes and determining all the possible priorities between several different attributes is difficult to carry out (Lindley, 1985). Adequate specification of a utility function usually implies the use of a lottery approach (see, e.g., Lindley, 1985), which in practice is not straightforward, particularly when there are many relevant attributes that measure the performance of an alternative (Aven and Vinnem, 2007). Alternative approaches have been suggested, to simplify the assignment of utility values, for example by defining parametric 
utility functions (e.g., Bedford and Cook, 2001; Varian, 1999) or the use of weighted averages of individual utility functions (e.g., Bedford and Cook, 2001; Clemen and Reilly, 2001), but, at the same time, they introduce simplifications which are hard to justify (Aven and Abrahamsen, 2007). The expected utility theory does not reflect how people behave in real life - it is a normative theory (see, e.g., Wakker et al., 1994). This has led to the development of alternative frameworks such as the rank-dependent utility theory (e.g., Tversky and Kahneman, 1992). However, the alternatives are just as difficult to use as the classical approach (Aven and Körte, 2003).

Besides being practically challenging, the applicability of the expected utility theory also suffers from being developed for single decisionmakers (Keeney and Raiffa, 1993; Lindley, 1985), making it inappropriate for many risk management situations such as those characterised by high ambiguity (see, e.g., Aven and Renn, 2019). There is no coherent method for making a decision when there are two or more decision-makers with different preferences (Lindley, 1985; Watson and Buede, 1987), which is usually the case (Aven and Abrahamsen, 2007). Even if there were an approach which was practical and capable of treating multiple preferences, it is difficult to see that decision-makers would be willing to specify their utilities, as it could hamper flexibility of adaptation (Aven and Vinnem, 2007). In summary, the expected utility theory is attractive from a logical basis, but, in practice, to guide the balancing of different concerns, other tools that are easier to use are usually preferred, such as the cost-benefit analysis.

\subsubsection{Cost-benefit and cost-effectiveness analysis}

A cost-benefit analysis is a tool to compare the benefits and costs of a project. The idea is to measure the benefits and costs of a project using a common scale, which is usually the country's currency. The implication is that all attributes need to be transformed into monetary values, traditionally reflecting how much society is willing to pay to obtain a 
specific benefit (Adler, 2011; Farrow and Viscusi, 2011; Varian, 1999). The monetary value of market goods is relatively easy to identify, as it is reflected by the market price. Non-market goods, on the other hand, are more difficult to determine (Abrahamsen et al., 2011; Baker et al., 2008 Viscusi, 1993). Alternative pricing methods, such as contingent valuation and hedonic pricing techniques, can be applied to support the task (Hanley and Spash, 1993). See also Robinson and Hammitt (2011) and Robinson et al. (2019).

After the transformation of all attributes into one comparable unit, the overall performance of the project is usually summarised by the expected net present value, E[NPV]. To calculate the NPV of a project, all the relevant cash flows need to be specified, and the time-value of money needs to be considered (Levy and Sarnat, 1994). The NPV is calculated by the following expression:

$$
\mathrm{NPV}=\sum_{\mathrm{t}=0}^{\mathrm{T}} \frac{\mathrm{X}_{\mathrm{t}}}{\left(1+\mathrm{r}_{\mathrm{t}}\right)^{\mathrm{t}}}
$$

where $\mathrm{X}_{\mathrm{t}}$ is the future cash flow at a given time $t$ in the project's lifetime from 0 to $T$ (often in years), and $r_{t}$ is the discount rate at year $t$. The cash flows emanating from a project may materialise at different points in time, which is considered in the NPV by discounting the cashflows by an appropriate rate of return (Levy and Sarnat, 1994). Since the future cash flows are usually unknown at the time of the analysis, they are normally represented by their statistically expected values, $E\left[X_{t}\right]$, while the discount rate is adjusted on the basis of the Capital Asset Pricing Model (CAPM), reflecting the compensation expected for taking the risk (Varian, 1999).

All the relevant attributes should be included in the cost-benefit analysis, making the decision easily deductible from the result of the analysis. The underlying idea is that there is a "correct" value for all the attributes, reflecting what the society (decision-maker) is willing to pay to obtain a 
specific benefit (Aven, 2015). If a cost-benefit analysis is used as the basis for making decisions, the welfare will be optimised (Varian, 1999). This is the rationale for the approach (Aven and Vinnem, 2007). The main critique of the cost-benefit analysis is that non-market goods cannot be justifiably transformed into monetary values, as it would be immoral and illogical to monetise the intangible (Anderson, 1993; Kelman, 1981). See also Ale et al. (2015) and Aven and Körte (2003).

An alternative is the cost-effectiveness analysis, which is often applied in safety management when dealing with non-market goods, as the costeffectiveness analysis does not explicitly put monetary values on the benefits (Petitti, 2000). For example, when evaluating a risk-reducing measure in a case with potential for loss of lives, the cost-effectiveness analysis uses other indices than the value of a statistical life, such as the expected cost per expected saved life (Abrahamsen et al., 2004). Other related tools that are worth mentioning are the return of investments, measuring the expected return relative to the invested resources; multiattribute analysis, which measures the consequences of the alternatives separately for various attributes; and the more pragmatic cost-benefit approach, in which there is no search for objective correct values, and non-market goods are left out of the equation (see, e.g., Aven, 2014; Petitti, 2000).

\subsubsection{The portfolio theory}

The rationality of basing a decision on the $\mathrm{E}[\mathrm{NPV}]$ relates to the portfolio theory (see, e.g., Levy and Sarnat, 1994; Ross et al., 2011). The portfolio theory is a fundamental theory in economics, stating that the expected return of a portfolio of projects is simply the weighted average of the expected returns of the individual projects (Ross et al., 2011). The implication is that, if the number of projects in a portfolio is sufficiently large, the only risk (uncertainty) of interest is the systematic risk (uncertainty), as the unsystematic risk (uncertainty) can be justifiably ignored (Ross et al., 2011). The systematic risk (uncertainty) relates to 
general market movements, such as a new regulation, whereas the unsystematic risk (uncertainty) is the project-specific risk (uncertainty) such as an accident (Abrahamsen et al., 2004). By using textbook statistics, it can be proven that, as long as the projects in a portfolio are not perfectly correlated (i.e. correlation factor $\rho<1$ ), the effect of diversification applies (Ross et al., 2011). If the number of projects in a portfolio is sufficiently large, the actual value of a portfolio is then approximately given by its statistically expected value and systematic risk. Therefore, the major concern is not the project-specific risks and returns but, rather, how these risks and returns affect the portfolio as a whole (Abrahamsen et al., 2004). The E[NPV] can be a poor prediction of the real NPV, but this is acknowledged to be controlled by sensitivity analysis (Abrahamsen et al., 2004).

\subsubsection{The use of expected values in risk management}

The methods above rely on the use of expected values and can be considered to constitute an extreme economic perspective on decisionmaking under uncertainty (Abrahamsen and Abrahamsen, 2015). The implication of using the extreme economic perspective in risk management is a mechanical emphasis on value creation rather than protection, as decisions are usually made with sole reference to expected values. The uncertainties are not given weight beyond what is supported by the frame of expected values (Abrahamsen and Abrahamsen, 2015; Abrahamsen et al., 2018a). The use of expected values is justified from the law of large numbers (Clemen and Reilly, 2001), stating that, when the number of random quantities is sufficiently large, the average is approximately equal to the statistically expected value. From the previous section, we see that the portfolio theory plays a similar role in economic theory. However, the portfolio theory and expected values have some limitations in the context of risk management, questioning the appropriateness of the balance they support. 
In general, it is argued that expected values as a basis for decisionmaking under uncertainty should be used with care in risk management (see, e.g., Abrahamsen et al., 2004; Ale et al., 2015; Aven and Flage, 2009; Hoegberg, 1998; Hokstad and Steiro, 2006; Sandøy et al., 2005; Watkiss et al., 2015). In addition to the issue of monetising non-market goods, the main arguments are that expected values do not give enough weight to the uncertainties and that the background knowledge, on which the expected values are based, is not taken into consideration. An example could be a project, which is a part of a greater portfolio, where there is potential for big losses. For such a situation, can we in practice ignore the unsystematic risk? According to the portfolio theory, we can, but that implies an attitude towards risk and uncertainty that contrasts with the cautionary principle. We should also acknowledge that the expected values could be poor predictions of the real outcomes and that the consequences could be significant also from a portfolio perspective, implying that uncertainties need stronger weight than can be supported by the frame of expected values (Abrahamsen et al., 2004). To compensate for the weaknesses of expected values, several alternative expected value-based criteria have been proposed, to adjust for uncertainties (e.g., Jonkman et al., 2003; Lambert and Farrington, 2006; Walls, 2004). However, it is reasonable to question the extent to which they contribute to valuable decision support (see Aven and Flage, 2009).

We should also highlight the role of corporate procedures in risk management, which we refer to as a collective way of thinking within an organisation. It might be natural to think that the background knowledge, on which a single project is evaluated, is not important, as some projects will be based on strong knowledge, others on weak, leading to a "zerosum" influence of the background knowledge on the portfolio's value. However, the corporate procedures cannot be perfectly diversified and have the potential to shift the value of a portfolio in one way or another - the decision-maker might not even be aware of this effect. See e.g. Abrahamsen et al. (2004) and Paper IV. 
Despite the weakness of expected values in the context of risk management, the above arguments do not mean that the use of expected values and the approaches that follow cannot be appropriate for supporting the balance of value creation and protection (Abrahamsen et al., 2017a). For example, in a situation with a large number of quantities, low uncertainties, low expected consequences and strong knowledge, there are few good arguments for not making decisions with reference to the E[NPV] (Abrahamsen et al., 2017a). The message is that expected values cannot in general be considered an appropriate decision-making principle in risk management.

\subsection{Safety management principles}

Expected values relate to a behaviour towards risk and uncertainty that is considered to be risk neutral (Varian, 1999). Among safety experts, risk aversion is often used as an argument justifying weight on uncertainties and protection (Abrahamsen et al., 2006). In economic theory, however, risk aversion is defined as when the decision-maker prefers to have the expected value of his wealth rather than to face a gamble (Varian, 1999). It reflects that the decision-maker dislikes the negative consequences so much that he weights them more heavily than is supported by the expected values (Levy and Sarnat, 1994). In such, risk aversion is not in contrast to expected values but, rather, related to them (Abrahamsen et al., 2006). But, as Aven and Vinnem (2007) ask: "Should a decision be guided by the mean value of a large population or centre of gravity of an uncertainty distribution?" No, it should not, and this is not what risk aversion means. Risk aversion is simply describing the decision-maker's behaviour under uncertainty (Aven and Vinnem, 2007), reflecting his attitude towards risk and uncertainties (Abrahamsen et al., 2006). The key aspects guiding safety management and decisionmaking should be the values that are at stake and the associated uncertainties and not a reference to risk aversion (Abrahamsen et al., 2006). In the following, other fundamental principles for guiding 
decisions in risk management are presented, which can be considered as examples of an extreme safety perspective.

\subsubsection{Cautionary and precautionary principles}

The cautionary principle is a basic principle of safety management (Aven, 2019; Abrahamsen and Abrahamsen, 2015), expressing that, in the face of an activity subject to serious consequences or uncertainty, cautionary measures, such as implementing risk-reducing measures or not carrying out the activity, should be taken (Aven, 2019). All safety regulations are to some extent based on an underlying belief that we need to be cautious when working with risk and uncertainties (Aven and Vinnem, 2007). An example could be that it is a regulatory requirement that, on an offshore drilling rig, all personnel shall be able to be evacuated by the means of lifeboats, even if the lifeboats at one lifeboat station are lost or inaccessible. It does not matter if we calculate the $\mathrm{E}[\mathrm{NPV}]$ of the additional lifeboats to be -5 million NOK. An accident requiring evacuation by lifeboats may occur. The requirement is based on cautionary thinking, which weights the decision in favour of protection.

The precautionary principle is a special case of the cautionary principle (Aven, 2019), expressing that if "the consequences of an activity could be serious and subject to scientific uncertainties, then precautionary measures should be taken, or the activity should not be carried out" (SRA, 2018b); see also Löfstedt (2003). The difference between the two is given by the term "scientific uncertainty", which (in simple terms) relates to the understanding of the phenomenon of interest. The term is thoroughly discussed in the literature (see e.g., Aven, 2011c; Cox, 2011; Löfstedt, 2003; North, 2011) and not the major concern in the thesis.

Although, in this thesis, we consider the cautionary principle as a basic principle of safety management, providing guidance on how to handle risk, not all scholars accept the cautionary principle as a principle related 
to decision-making. With reference to the precautionary principle, Peterson (2006, 2007), for example, argues that it is incoherent and not based on a decision rule, making the principle "normatively empty". The point made also applies to the cautionary principle (Aven, 2019). The cautionary and precautionary principles are not decision rules per se, as they do not prescribe what the decision-makers must do. This is neither the intention of the principles nor desirable. In risk management, we are concerned about what the consequences of our actions will be, but there is uncertainty about them, and the results of the risk analysis describing the consequences and uncertainties can be erroneous or based on false assumptions (e.g., Paté-Cornell, 2002). There is a need to be cautious, and the cautionary principle guides how we should think about the riskrelated situation of interest (Aven, 2019). If there is a potential for serious consequences, forgoing certain alternatives to avoid unexpected consequences is justified from the idea of being cautious. In such, the cautionary principle puts strong weight on protection, with little or no considerations for cost-benefit calculations. As a consequence, it is hard to argue that the cautionary principle can be considered a general perspective for decision-making under uncertainty, as too much emphasis on caution might lead to inefficient use of resources (Abrahamsen and Abrahamsen, 2015; Abrahamsen et al., 2018a; Vesely, 1999; Viscusi et al., 2019) and reduce innovation and development (e.g., Aven, 2019; Bhardwaj et al., 2019; Grote, 2015).

\subsubsection{Risk acceptance criteria}

The SRA Glossary (2018b) defines risk acceptance as "an attitude expressing that the risk is judged acceptable by a particular individual or group". A risk acceptance criterion is then a basis (reference value) on which the risk is assessed to be acceptable or not (Rausand, 2011). This is applied in all safety regulations as some minimum safety levels to control risk in relation to certain attributes, for example safety for human lives (Aven, 2014). In risk management, it is useful to have some criteria, 
with reference to which decisions can be made (see, e.g., Abrahamsen, 2011; Aven and Vinnem, 2005) - this is based on cautionary thinking. Although risk acceptance criteria are not decision-making principles per se, they mechanically prescribe some minimum weight on the protection side of the balance. However, it is recommended that risk acceptance criteria be used with care, as they can promote the wrong focus of meeting specific criteria rather than making the best possible decisions (Aven, 2014; Aven and Vinnem, 2005). It is also essential that all risk acceptance criteria are specified by the authorities, as criteria defined by the decision-makers will not necessarily include the considerations of possible negative externalities to society (Abrahamsen and Aven, 2012).

\subsubsection{ALARP principle}

While a risk acceptance criterion is useful as a reference value against which risk is assessed as acceptable or unacceptable, it is not a strong tool to assist decision-makers in making the best decisions. A more fruitful alternative is the ALARP principle. The principle is widely discussed and applied in various contexts (e.g. Abrahamsen et al., 2018a; Ale et al., 2015; Baybutt, 2014; Jones-Lee and Aven, 2011; Kletz, 2005; Melchers, 2001; Pape, 1997; Schofield, 1998). According to the principle, risk should be reduced to a level that is As Low As Reasonably Practicable, meaning that risk-reducing measures should be implemented, provided that costs are not grossly disproportionate to the obtained benefits (HSE, 2001). In line with cautionary thinking, the ALARP principle weights decisions in favour of health and safety concerns, as its underlying presumption is that risk-reducing measures should be implemented. To avoid the sacrifice (time, trouble, money), it must be demonstrated that it is grossly disproportionate to the obtained benefits (HSE, 2001).

In verifying and demonstrating ALARP, procedures mainly based on engineering judgments and codes are used (Jones-Lee and Aven, 2011), but often supported by formal cost-benefit analyses (Ale et al., 2015; 
French et al., 2005). The cost-benefit approach is based on expected values, which, with reference to Section 2.3.4, should be used with care, as they do not give sufficient weight to the uncertainties; see also Aven and Abrahamsen (2007). The expected values relate to an attitude towards risk that results in an ALARP principle that emphasises value creation rather than protection. This is not in line with its underlying presumption of erring on the side of caution.

To better consider the uncertainties, a layered approach has been proposed for implementing the ALARP principle (Aven, 2011b). The layered approach consists of three steps, the first of which is a crude analysis of the costs. If the costs are low, gross disproportion has not been demonstrated and the measure should be implemented. Otherwise, more detailed analysis is required. The second step is usually a costbenefit analysis, the result of which being positive leads to implementation of the measure. Gross disproportion is not demonstrated if the expected benefit is greater than the expected costs (Abrahamsen et al., 2018a). The third step materialises if neither of the two first steps have resulted in implementation of the measure. Then, a checklist is used to assess other factors and issues, such as whether the measure increases manageability or if it is based on best available technology; for further details, please see Aven (2011b) and Abrahamsen et al. (2018a).

\subsection{Decision-making under uncertainty}

The principles and approaches we have described in Sections 2.3 and 2.4 are tools to support the decision-making, which is a central part of risk management (ISO, 2018). Many of the situations we face, however, involve high risks and large uncertainties, making it challenging to predict the outcomes of our decisions (Aven and Vinnem, 2007) and, hence, to determine how to obtain an appropriate balance. To increase the likelihood of achieving more good decisions than bad ones, it is attractive to establish a formal decision-making process (Aven and Körte, 2003). Following the work by Aven and Körte (2003), we contrast 
two different approaches for reaching good decisions in risk management:

1. Decision-making is an exercise in modelling alternatives, uncertainties and values, where the correct choice is the one that maximises/minimises some criteria.

2. Decision-making is a process that uses formal risk and decision analyses to provide decision support, which is followed by an informal managerial review and judgment step, to reach a decision.

The expected utility theory (Section 2.3.1) is an example of alternative 1 , which is closely linked to the school of economic decision-making theory (e.g., von Neumann and Morgenstern, 1944) and the Bayesian decision theory (e.g., Lindley, 1985; Keeney and Raiffa, 1993).

In this thesis, alternative 2 forms the basis for decision-making under uncertainty. This approach promotes risk-informed decisions, emphasising that risk-related decisions cannot follow mechanically from the results of the analyses (Apostolakis, 2004); decision-making under uncertainty should be risk-informed rather than risk-based (Apostolakis, 2004; Vesely, 1999). In general, no risk management principle should prescribe what to do: there is always a gap between the decision support and the implementation of the decision (Aven and Körte, 2003; Hertz and Thomas, 1983). This does not mean that the more prescriptive approaches are useless for all situations (see, e.g., Hopkins, 2011), but, in general, there will always be a need for some degree of managerial review and judgment (Aven and Körte, 2003). The tools we use provide valuable and informative decision support, but none of them is perfect in situations involving uncertainties (Aven, 2014). The weaknesses and limitations of the approaches need consideration.

In contrast to the strong normative frameworks on decision-making, alternative 2 is a more "moderate" view on decision-making (Fischhoff et al., 1981), which prevails in some of the literature on decision theory (e.g., French and Rios Insua, 2000; Watson and Buede, 1987). Figure 1 
illustrates a decision-making model of the "moderate" view, which forms the basis for decision-making under uncertainty in this thesis. The model is simple, and we need to emphasise that the arrows indicating the information flows and processes in Figure 1 are in practice more flexible and dynamic than the figure indicates.

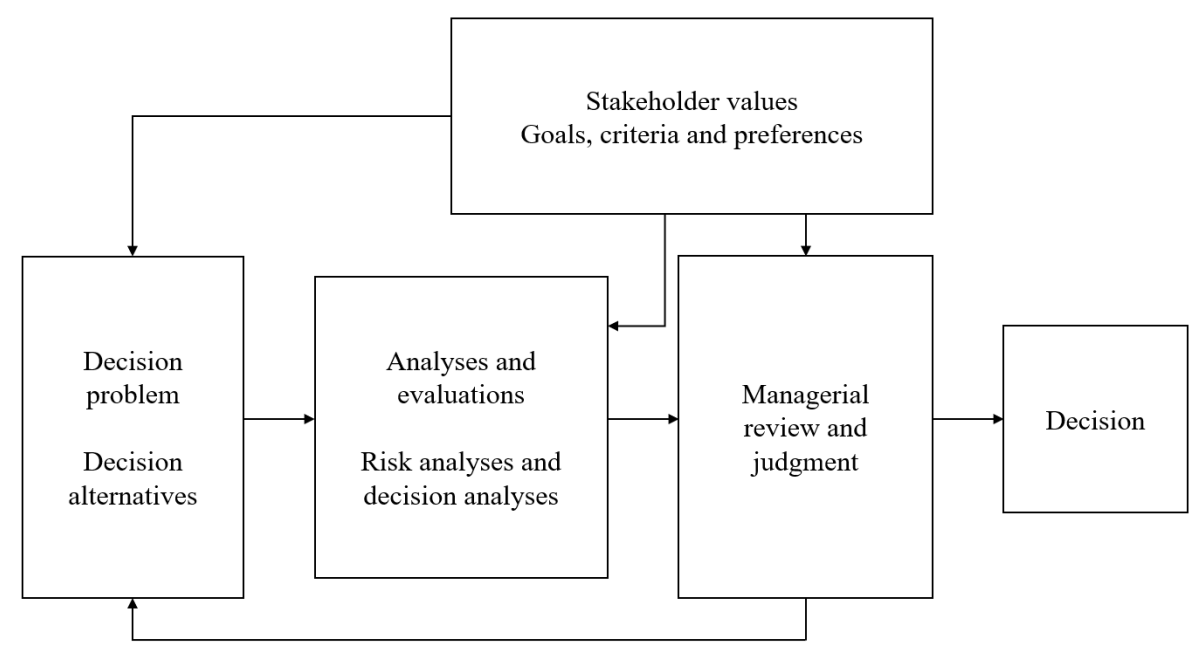

Figure 1. A model for decision-making under uncertainty (Aven, 2015; Aven and Körte, 2003).

The decision-making process in Figure 1 involves establishing the decision-making context (e.g. the decision to be made, the alternatives, the boundary conditions, the strategies to reach a decision), with respect to stakeholder values, goals, criteria and preferences (e.g. how to weight the uncertainties, how to weight pros and cons, how to express the performance of the alternatives), analyses and evaluations (e.g. risk analyses, decision analyses), and managerial review and judgment (Aven and Körte, 2003; Aven and Vinnem, 2007).

In the managerial review and judgment step, the decision-makers should take into account the limitations and constraints in the analyses and analysts, the background knowledge on which the decision support is based, the assumptions and suppositions made, as well as factors not 
included in the analyses, such as what alternatives have been evaluated, what performance measures have been assessed, difficulties in determining benefits of the alternatives, and the fact that the analyses are based on models (Aven and Körte, 2003; Aven, 2015). External factors, such as how the decision might influence a company's reputation or how stakeholder values could influence the weight on the cautionary principle, are also relevant considerations in a decision-making process (Aven and Vinnem, 2007). The managerial review and judgment step is then followed by a decision.

\subsection{What is the appropriate balance?}

As we have seen, different perspectives, principles and approaches exist that support different weights on the uncertainties. So, which is the best alternative to obtain an appropriate balance between value creation and protection? As already stated, there is no one correct perspective or approach on how to balance value creation and development in risk management (Abrahamsen et al., 2018a; Aven and Körte, 2003; Klinke and Renn, 2001).

An example illustrating this fact is the appropriateness of the ALARP principle as a general decision-making principle in safety management (see Section 2.4.3). For this to hold true, it has been shown that the gross disproportion criterion needs dynamic interpretation (Abrahamsen and Abrahamsen, 2015; Abrahamsen et al., 2017a, 2018a). One way is to interpret the ALARP principle to mean that strong weight should always be given to the uncertainties, but this is not generally appropriate (Abrahamsen and Abrahamsen, 2015). Another way is to interpret the principle to mean that the weight given to uncertainties is decided with respect to the decision-making context. In some cases, it is appropriate to demonstrate ALARP with reference to cost-benefit analysis; in others, ALARP and gross disproportion can be verified with no reference to expected costs and benefits (Abrahamsen and Abrahamsen, 2015; Abrahamsen et al., 2017a). For the ALARP principle to be considered as 
a general decision-making principle, " $[. .$.$] it must be interpreted in a way$ that allows it to range from one extreme to another, i.e., a dynamic way, as it is not considered appropriate to adopt a static decision-making principle that covers all possible decision-making contexts" (Abrahamsen et al., 2017a).

To obtain an appropriate balance between value creation and protection, we need to take advantage of both economic and safety perspectives. The appropriate balance is usually in between the two extremes (Aven, 2019; Sørskår and Abrahamsen, 2017). Given the limitations of the available tools, however, managerial review and judgment play a central role in obtaining an appropriate balance (Aven and Körte, 2003). The decision support provided to the decision-makers should take into account the decision-making context and highlight the knowledge dimension, uncertainties, consequences, economic and other relevant concerns. This is not always straightforward. To support the decision-makers, there is a need to (1) continuously improve and develop the approaches and principles and (2) strengthen our knowledge about specific situations of interest. 


\section{Research areas and problems}

This section presents, and frames in a larger context, the research areas addressed, and the contributions made by the papers presented in Part II of the thesis. The overall objective of the thesis is to contribute to new knowledge in risk management, by exploring the following research areas:

1. How to obtain an appropriate balance between value creation and protection.

2. Increase the specific knowledge on training in the Norwegian emergency medical services.

The first research area in this thesis contributes to the overall objective, by exploring approaches, principles and underlying ways of thinking related to how we can obtain the appropriate balance between value creation and protection in risk management. The second research area complements the first by a more practical approach, contributing to specific knowledge of a real-life activity.

The main scientific contribution of the thesis consists of seven papers, of which Papers I to V address the first research area and Papers VI and VII the second. The papers are listed on page ix. Despite the two-folded research focus, all seven papers relate to aspects relevant for risk management and the balance of value creation and protection. This can be illustrated by the means of the decision-making model (Figure 1).

Each of the papers can be identified as being primarily concerned with one of the steps in the decision-making model, illustrated in Figure 2. However, their contributions to a greater or lesser extent also consider other steps of the model. This is natural, as the steps are tightly coupled and the information- and workflows are dynamic and flexible. 


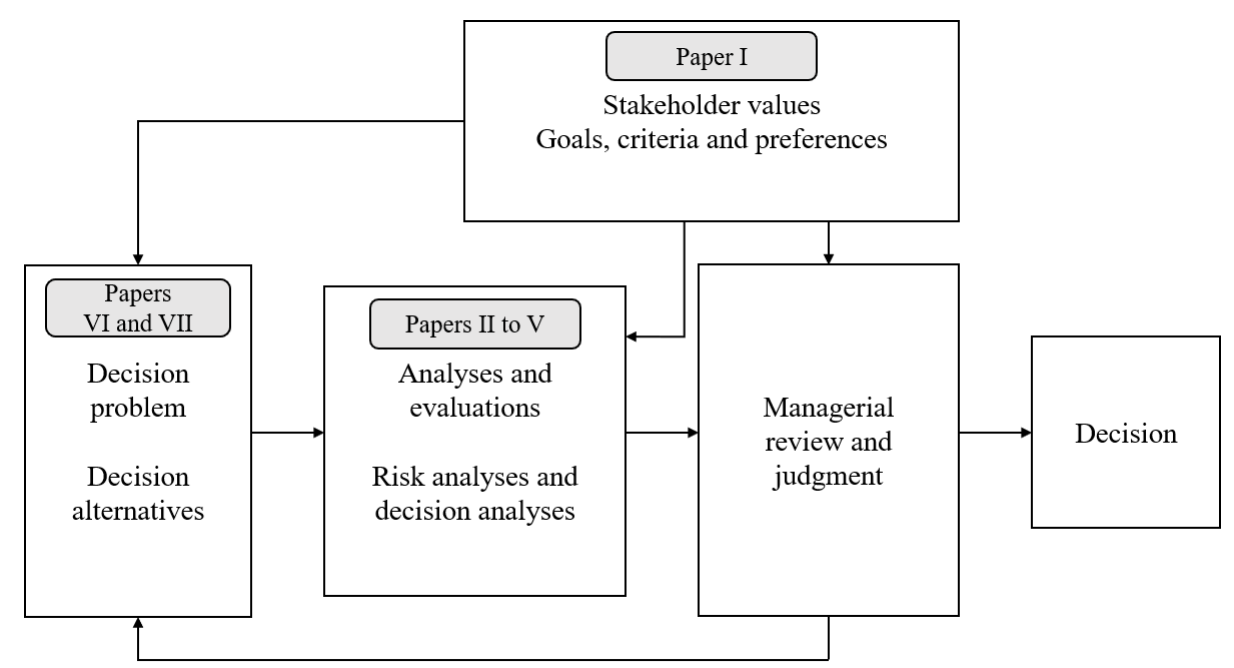

Figure 2. A sketch of the link between the papers and the model of decisionmaking under uncertainty. Based on: Aven (2015).

In summary, to obtain an appropriate balance between value creation and protection, the resulting research addresses the need for systems thinking in the risk management strategy, further improvements of the approaches and principles that follow, and the specific knowledge of a real-life activity. In the remainder of the chapter, we describe and discuss the topics addressed by and the contributions of the seven papers with respect to the research areas, but also in a broader context.

\subsection{Systems thinking: the underlying thinking in risk management}

In risk management, we often find defined goals, criteria and preferences, which reflect important concerns of the decision-maker or other stakeholders (Aven and Körte, 2003; Aven and Vinnem, 2007; Baard, 2016; Duijm et al., 2008; Hoegberg, 1998). These boundary conditions influence how we balance value creation and protection, by guiding the selection of the high-level risk management strategies and decision principles (Aven and Körte, 2003; Aven and Vinnem, 2007). 
This is considered in Figure 2 by the "stakeholder values and goals" step, which is expanded in Figure 3 to better reflect the roles of the decisionmaker and other stakeholders in selecting the risk management strategy (see Section 2.2).

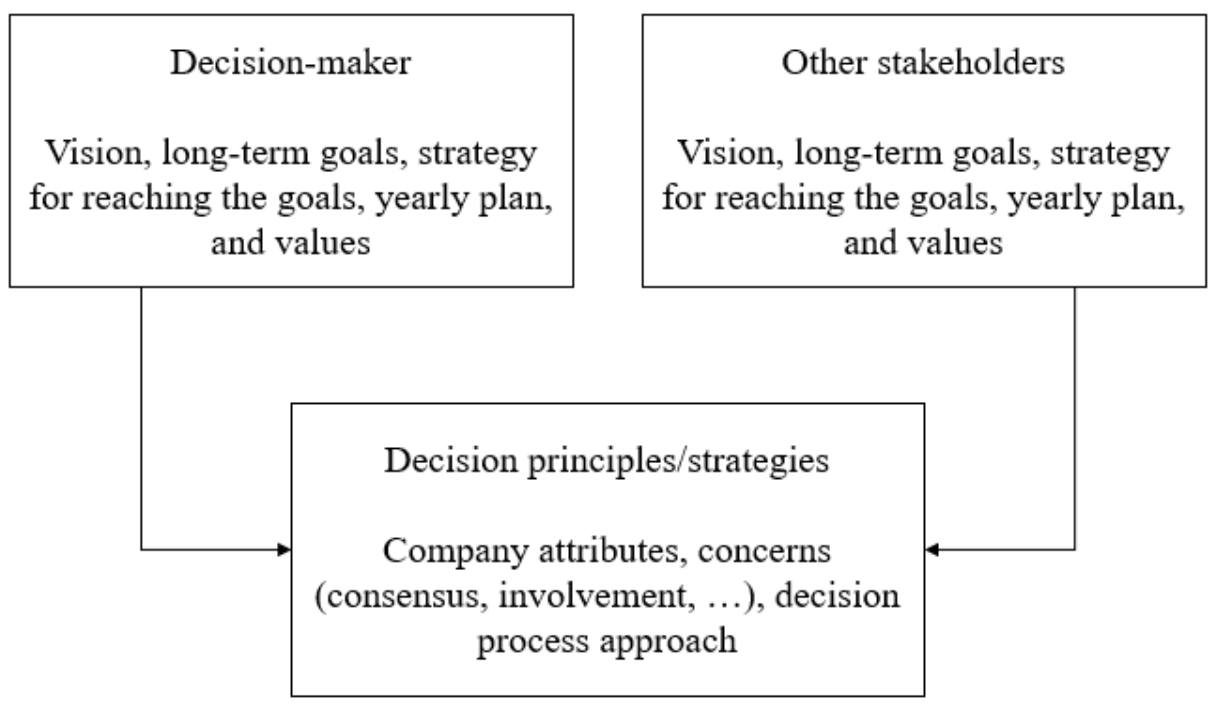

Figure 3. The steps of selecting high-level risk management strategy and decision principles within the decision-making model in Figure 2. Based on: Aven and Vinnem (2007).

According to Aven (2011b), the strategy of a risk management refers to "the underlying way of thinking, and the principles and approaches that follow, with respect to how a decision is to be made and how the decision-making process should be carried out". An example could be that the management decides that the guiding strategy within the company is cautionary/precautionary and that the ALARP principle shall be implemented for all issues concerning personnel safety (see Aven and Vinnem, 2007). A number of frameworks have been suggested to assist decision-makers select the appropriate strategy by considering different aspects of the decision context (e.g., Abrahamsen et al., 2017b; Aven and Kristensen, 2019; Klinke and Renn, 2002; Kristensen et al., 2005; Renn, 2008; Wiencke et al., 2006), including whether a system perspective is 
required (e.g., Ford et al., 2008) and if the system is "holistic", meaning that the system properties can only be described by the whole and not in terms of single parts (e.g., Kastenberg et al., 2004). The latter is closely linked to the concept of complexity; see, e.g., Jensen and Aven (2018).

Here, systems thinking is understood as "a conceptual framework for seeing the whole and interconnections" (Aven, 2014), rather than isolated parts of the system (Flood and Carson, 1988; Senge, 1990). This contrasts with the underlying thinking that is observed in most of the literature on how to verify ALARP and gross disproportion. This observation is the motivation of Paper I.

\section{Paper I: On the importance of systems thinking when using the ALARP principle for risk management}

The ALARP principle states that risk-reducing measures should be implemented unless the costs are grossly disproportionate to the obtained benefits (HSE, 2001; Jones-Lee and Aven, 2011). Reference is made to Sections 2.4.3 and 2.6 for details. When verifying ALARP and gross disproportion, the majority of the literature interprets this to mean that it is sufficient to focus on the direct costs and benefits of the risk-reducing measures in isolation (e.g., Abrahamsen and Selvik, 2013; Agrawal et al., 2017; Nesticò et al., 2018; Ruud and Mikkelsen, 2008; Whittingham, 2008). With reference to the discussion in Section 2, highlighting the importance of the decision-making context and dynamic decision principles when managing risk, Paper I questions the appropriateness of the decision support produced by an ALARP process if no consideration is given to the system and its associated interactions.

Firstly, considering a risk-reducing measure in isolation might lead to an inappropriate weight on the relevant uncertainties and the cautionary principle (e.g., Abrahamsen et al., 2017a; Hurst et al., 2018). For the ALARP principle to be considered a general decision-making principle, it has been shown that it needs a dynamic interpretation, ranging from an 
extreme economic perspective (Section 2.3) to an extreme safety perspective (Section 2.4), which is appropriate for the specific decision context of interest (Abrahamsen and Abrahamsen, 2015). The system in which a safety measure is being implemented, and its associated interactions, is a part of this context.

Given that different decision-making contexts require different decisionmaking principles (Aven and Körte; Aven et al., 2007; Klinke and Renn, 2001), it then follows that systems thinking will most likely support a different weight on the cautionary principle than if a single measure is considered in isolation. An example could be an ALARP process related to a single project. If this project is considered in isolation, high projectspecific uncertainty can result in strong weight on the cautionary principle, as it cannot be justified to base the decision on the E[NPV]; please refer to Sections 2.3.3 and 2.3.4. On the other hand, if the project is a part of a portfolio of projects, then, following the portfolio theory, gross disproportion could be verified in reference to cost-benefit calculations, as the E[NPV] is then considered a sufficiently accurate approximation of the real NPV; reference is made to Paper I.

The practical implications of systems thinking on the use of the ALARP principle in risk management is that it will increase the likelihood of supporting an appropriate weighting of the cautionary principle with respect to the decision-making context (e.g., Abrahamsen et al., 2017a; Hurst et al., 2018). As discussed in Section 2.4.1, too much weight on the cautionary principle is not necessarily desirable, as it might lead to inefficient use of resources (Abrahamsen et al., 2018b).

The second issue addressed in Paper I relates to the costs and benefits, on which ALARP and gross disproportion are verified. With no attention paid to the system, it is likely that the relevant effects of a risk-reducing measure are not identified in the analysis. This is illustrated in Paper I, and an example could be limited resources, which, being ignored, might lead to fewer resources for other safety initiatives and, therefore, a 
possibly lower than intended effect on safety (see Abrahamsen et al., 2018b). By not considering the interactions within a system (see, e.g., Carayon et al., 2006; Leveson, 2011), the verification of gross disproportion is likely to be based on an incomplete foundation that ignores important factors related to the measure and situation of interest (e.g., Sørskår et al., 2019).

The fact is that adopting safety measures in a system does not always give the intended effect, as it can be offset by or affect other system components such as other safety measures (Abrahamsen et al., 2013, 2018b; Bryant et al., 2018; Kletz, 2005; Menon et al., 2013); see also Assum et al. (1999), Sagberg et al. (1997) and Vrolix (2006). By ignoring the system, another practical implication of the ALARP principle could be support of risk-reducing measures that involve grossly disproportionate sacrifices compared to the benefits.

The main contribution of Paper I is to highlight the role and importance of thinking about the system as a whole, when using the ALARP principle in risk management. This is relevant for risk assessment and management in general, as the key is to enhance the understanding of the risk-related situation of interest (see Section 2.6).

\subsection{Improvement and development of approaches for risk management}

An underlying theme of this thesis is that, in order to obtain an appropriate balance between value creation and protection, the tools and approaches we use in risk management need to be dynamic and appropriate for the specific decision-making context (see Section 2.6). However, the tools are just tools, with their own weaknesses and limitations. Reference is made to Sections 2.3 to 2.6. The decision support might be misleading, which again might hamper the balance of value creation and protection. The managerial review and judgment step is one measure to reduce the risk of misguided decisions, but it is not 
always sufficient. There is a need to further improve and develop the approaches, aiming at increasing our understanding of them and their ability to treat and reflect all the relevant attributes, such as the uncertainties.

Ideally, all uncertainties should be accurately quantified, but the fact is that not all uncertainties can be transferred into or expressed by quantitative values (Flage, 2010). One alternative, then, is to use a semiquantitative approach, where probability is used as a measure of uncertainty, interpreted as the degree of belief (Lindley, 1985), which is supported by a qualitative measure of the strength of the background knowledge (Aven, 2013, 2017; Aven and Zio, 2018a; Flage and Aven, 2009). The background knowledge is the analyst's justified beliefs (Flage and Aven, 2009), usually formulated as assumptions, based on data, models, and so on. This knowledge can be more or less strong (Aven, 2013), and uncertainties can be hidden within. The knowledge and its strength inform the decision-makers about what the risk and economic analyses consider and represent, what the outcome expresses, the knowledge that guided the analyst's assessments, and the issues that have not yet been taken into consideration (Aven and Zio, 2018b).

In practice, the integration of knowledge, strength of knowledge and risk and decision analyses is not straightforward. More research has been called for in this regard, to properly inform the decision-makers about the risk-related situation of interest (Aven and Flage, 2018).

To a greater or lesser extent, Papers II to V all contribute to this end, with respect to the "analyses and evaluations" step in the decision-making model, Figure 2. Papers II and III contribute to the risk-based approaches, aiming to ensure an appropriate weight on protection, whereas Papers IV and V contribute to the economic evaluations, aiming to ensure an appropriate weight on value creation. In summary, Papers II to $\mathrm{V}$ emphasise the importance of assessing and reflecting the uncertainties and, especially, the knowledge dimension, on which the 
risk and decision analyses are based. This is a key to obtaining an appropriate balance of value creation and protection. In the following, the contributions of the papers are presented.

\subsubsection{Risk-based approaches}

\section{Paper II: A new framework to identify hidden assumptions in the background knowledge of a risk assessment}

There is increasing interest in and attention on the importance of the knowledge dimension in relation to managing risk (see, e.g., Amundrud et al., 2017; Aven, 2014; Aven and Kristensen, 2019; Aven and Zio, 2018a; Bani-Mustafa et al., 2020; Flage, 2019; Flage and Askeland, 2020; PSAN, 2018). Over recent years, various methods have been developed for considering and reflecting the strength of the background knowledge (e.g., Askeland et al., 2017; Aven, 2013; Bani-Mustafa et al., 2020; Flage and Aven, 2009; Goerlandt and Reniers, 2016; van der Sluijs et al., 2005).

A prerequisite for all these methods to be fully informative is that the content of the background knowledge is of high quality, meaning that it includes all the relevant and available knowledge such as assumptions. If critical assumptions are not included, such as limited resources or behavioural adaptation (e.g., Abrahamsen et al., 2018b; Vrolix, 2006), the outcome of the risk assessment might be misleading, hampering the balance of value creation and protection. To identify all the relevant assumptions, however, is not a trivial task, especially when the situation of interest is complex (Aven and Ylönen, 2018; Sørskår et al., 2019). There is a gap in the literature with respect to approaches useful for supporting this task, which Paper II aims to fill.

The main contribution of Paper II is a framework for identifying and assessing the background knowledge, as a means to reduce the risk of missing relevant knowledge and to obtain more complete background 
knowledge, on which risk can be assessed. The framework suggests using a systems approach for the task of identifying the relevant knowledge elements, which then can be assessed in terms of their criticality for the risk assessment and real-life situation of interest. The Systems Engineering Initiative for Patient Safety (SEIPS) model is applied in Paper II to identify the relevant knowledge elements. The SEIPS model is illustrated in Figure 4. Despite being developed for the healthcare domain (Carayon et al., 2006, 2014), and being one of many potential systems models (e.g., Bellamy et al., 2007; Hollnagel et al., 2006; Leveson, 2011; Marca and McGowan, 1988; Rasmussen, 1997), the SEIPS model is generally applicable for the task of identifying knowledge elements, as it takes a systems approach, captures both social and technological features and addresses the external environment. Please refer to Paper II for stronger argumentations.

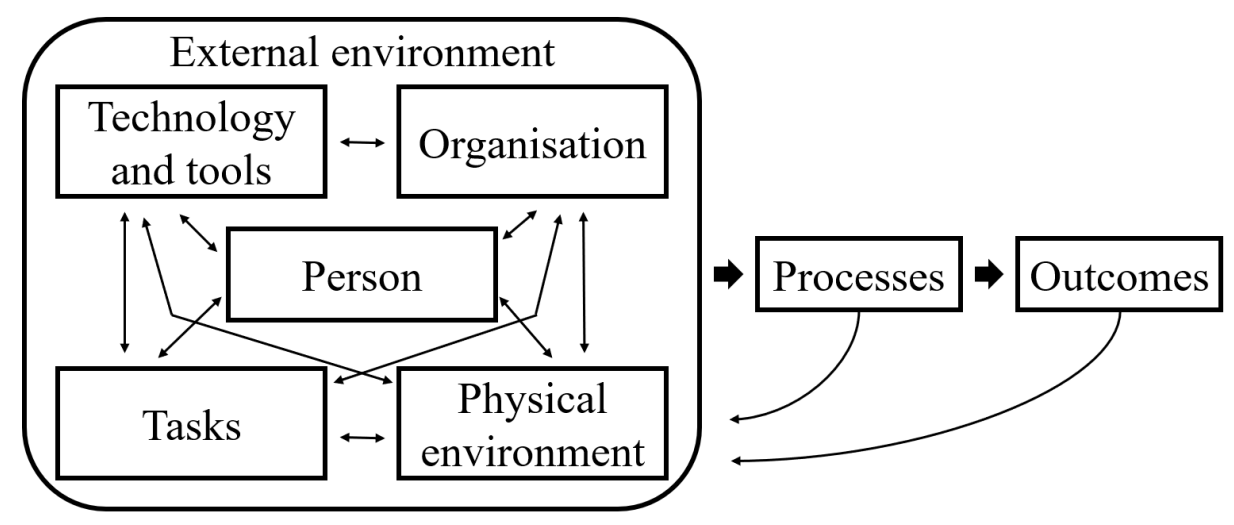

Figure 4. The SEIPS model. Based on: Carayon et al. (2014).

The framework consists of three main steps. The first is to apply the SEIPS model to identify relevant knowledge elements. In Paper II, it is recommended that this be carried out by starting with the single components, before progressing to the interactions within the system of interest (see e.g., Holden et al., 2013). The second step is an assessment of the identified knowledge elements with respect to their criticality. It is suggested that this be carried out by an assessment of the strength of 
knowledge, impact on the risk assessment, and uncertainty analysis of the knowledge elements' impact. The final step is treatment of the critical knowledge elements. In Paper II, an example is included to illustrate how the suggested framework can produce more complete background knowledge, on which risk is assessed, reduce the risk of missing relevant knowledge and, thus, increase confidence in the produced risk assessment, its results and recommendations.

In a broader context, the suggested framework in Paper II has the potential to increase the understanding of the risk-related situation of interest. As such, the underlying thinking of Paper II is much like the one presented for Paper I: the key to obtaining an appropriate balance between value creation and protection is to enhance the understanding and knowledge of the situation of interest. To obtain perfect knowledge is not possible, but it does not negate the goal of searching for it (Leveson, 2015). Identifying all the relevant knowledge is one issue related to the background knowledge, another is to adequately assess its strength and communicate it to the decision-makers. Paper III contributes to the latter.

\section{Paper III: Risk-informed decision-making with an improved approach to evaluate plug and abandonment designs}

A common approach to evaluate the strength of knowledge is the crude categorisation of Flage and Aven (2009), which evaluates the background knowledge with respect to how reasonable the assumptions are, how reliable the data is, the degree of consensus among experts, understanding (modelling) about the phenomenon of interest, and whether this knowledge has been scrutinised, for example in terms of unknown knowns (Aven, 2017). However, with a significant number of assumptions, it might be challenging to evaluate and informatively reflect the strength of knowledge from a crude categorisation as the one proposed by Flage and Aven (2009). 
An alternative method is the concept of assumption deviation risk, developed by Aven (2013). The concept aims to assess the consequences of assumptions deviating from their fixed values, the associated uncertainties and the strength of knowledge, on which the deviation risk assessment is based. As such, the assumption deviation risk assessment is a means to identify critical assumptions, potential surprises and the overall foundation, on which risk is assessed (Aven, 2013).

In Paper III, the concept of assumption deviation risk is integrated with a risk-based approach, which relates to a specific risk-related issue of permanent plugging and abandonment of oil and gas wells. On the Norwegian continental shelf, all plug and abandonment (P\&A) operations are governed by the NORSOK Standard D-010. With respect to permanent $\mathrm{P} \& \mathrm{~A}$, the standard prescribes how a design should be, for example in terms of the thickness of barrier elements. This "one-sizefits-all" approach is criticised for not being cost-effective (Arild et al., 2017,2018 ), which is of great economic concern for the operators and government given the significant number of wells which need to be permanently plugged and abandoned in the coming decades.

As an alternative to the prescriptive approach, a risk-based approach has been developed to calculate the leakage risk related to non-prescriptive P\&A designs (Arild et al., 2017, 218). The intention is to incorporate the well-specific characteristics, such as reservoir flow potential, to assess the leakage risk and support P\&A designs that are "fit-for-purpose". The leakage risk is described by the probability of barrier failure and the associated leakage rate (i.e. consequences). Moving away from the regulations governed by the NORSOK Standard D-010 implies a need to treat and reflect all the relevant uncertainties. Given the large number of uncertain parameter values and assumptions made in the risk-based approach, Paper III questions whether the risk-based approach produces an adequate description of leakage risk when only focusing on the probabilities, which are not perfect measures of uncertainties and do not 
reflect the background knowledge. Reference is made to the introduction of Section 3.2.

The main contribution of Paper III is an improved approach for assessing the leakage risk; by highlighting the uncertainties rather than the probabilities, it assesses the risk of deviation from the assumptions and reflects the knowledge base. The improved approach enables the analysts to reflect the underlying knowledge base, which increases the confidence of making decisions on the acceptability of non-prescriptive plugging designs. An example is included in Paper III to illustrate the additional decision support obtained by the improved approach.

\subsubsection{Economic evaluations}

This section presents the two papers contributing to economic evaluations in risk management. The main theme of both papers is the use of expected values to guide decision-making in risk management, in line with Sections 2.3.2 to 2.3.4.

\section{Paper IV: A discussion on socioeconomic profitability as a prerequisite for investments in security measures}

The motivation behind Paper IV was a statement about the use of socioeconomic profitability as a fundamental prerequisite for investments in security measures associated with an update of the Norwegian National Security Law, in 2018. It is stated that the Law should be: "[...] a cost-effective regulation that ensures balance between acceptable residual risk and cost for the security level. Economic profitability should be the basic prerequisite, i.e. current security measures should have a socioeconomic benefit that as a whole exceeds the costs" (NOU, 2016). From a traditional economic perspective, profitability is normally interpreted as the expected benefits minus expected costs, which implies making a decision with reference to the E[NPV]. Reference is made to Sections 2.3.2 and 2.3.3. 
However, is a cost-benefit approach appropriate to guide decisionmaking in a context usually characterised by high uncertainty, ambiguity and complexity (e.g., Jore, 2019)? In addition, do cost-benefit analyses properly deal with the dynamic risk picture, in which the perpetrator is adaptable and might change target according to the adopted risk management strategy (e.g., Dillon et al., 2009)? Paper IV addresses such questions.

Although a reference to costs and benefits is important prior to investments (see Section 2.3), Paper IV discusses five challenges, which make it hard to use socioeconomic profitability as a fundamental prerequisite for investments in security measures if profitability is given the traditional economic interpretation:

1. Restricted focus on production values (i.e. market goods), requiring all attributes to be transformed into monetary values. This is problematic when working with life, health, symbolic values, etc.

2. Expected values can be poor predictions of the reality, meaning that we cannot ignore the unsystematic uncertainty, and the background knowledge is not taken into consideration.

3. Assigning probabilities on security events is challenging, which affects the confidence of the statistically expected costs and benefits.

4. Corporate procedures influence the portfolio's value and how it is evaluated. See Section 2.3.4.

5. Security risk normally involves high ambiguity, which should not be substituted by a mathematical equation.

By and large, the challenges are similar to those discussed in Section 2.3.4 with respect to the use of expected values in safety management. For a detailed discussion, please see Paper IV. In conclusion, Paper IV supports a broader interpretation of socioeconomic profitability than can be supported by the frame of expected benefits minus expected costs. Social discourse, communication with stakeholders, cautionary/precautionary principles, and so on, have a role to play when 
investing in security. The main contribution of Paper IV is a discussion on the use of socioeconomic profitability as a fundamental prerequisite for investments in security measures, pointing at foundational issues which need to be considered in order to obtain an appropriate balance between value creation and protection.

\section{Paper V: On the use of the 'return of investments in safety' (ROSI) measure for decision-making in the chemical industry}

In Paper V, the context is the chemical and process industries, which are characterised by a high potential to damage people, as well as environmental contaminations (Palazzi et al., 2015; Papazoglou et al., 2003). The experience in the industry points to a strong need for objective criteria and methods to optimise investments, emphasising the benefits of investing in safety measures by the safeguarding of health and the environment, and the constraints of limited resources (e.g., Abrahamsen et al., 2018b; Tappura et al., 2015; Yoon et al., 2000). In such cases, the return of investments in safety (ROSI) is considered to be a strong tool (Phillips et al., 2014; Talarico and Reniers, 2016). The ROSI quantifies the expected return of the investments in safety with respect to the invested resources (Sonnenreich et al., 2006). Mathematically, this is expressed as:

$$
\mathrm{ROSI}=\frac{\mathrm{E}[\mathrm{X}]-\mathrm{E}[\mathrm{C}]}{\mathrm{E}[\mathrm{C}]}
$$

where the benefits $(\mathrm{X})$ and costs $(\mathrm{C})$ are represented by their expected values. For justification of expected values, reference is made to Sections 2.3.2 and 2.3.3. The purpose of the ROSI measure is to provide decision support on the balance of safety measure costs and potential savings from future adverse events. Paper V discusses the use of this measure, as it is founded on expected values and the balance they supports.

The main contribution of Paper $\mathrm{V}$ is a discussion on the ROSI metric as an appropriate tool for guiding the prioritisation of safety measures. The 
arguments are given in points 1, 2 and 4 in the list above in relation to Paper IV. To avoid repetition, reference is made to Paper V. To overcome the identified issues, Paper V suggests an extension to the ROSI framework, in which the background knowledge and uncertainties are assessed. In addition, the framework suggests assessing the expected return of investments, relative to the expected costs, given an accidental event occurring. Paper V concludes that the ROSI measure should be used with caution in risk management, as limited weight is given to uncertainties and the significance of an accident. Events that have low probabilities of producing high returns might be wrongly prioritised, as the expected values do not capture the potential return if the event occurs. An example is included in the paper, to illustrate the extended framework.

\subsection{Increasing the specific knowledge}

While Papers I to V primarily contribute to risk management by the development and improvement of approaches, principles and methods in relation to how to obtain an appropriate balance between value creation and protection, Papers VI and VII have a more practical approach, contributing to new specific knowledge of an activity in the real world: training in the Norwegian prehospital services. This type of knowledge indirectly affects the balance between value creation and protection, as it contributes to the background knowledge on which risk can be assessed and managed (Aven, 2014) but also to the establishment of context in terms of revealing decision problems and opportunities (Aven and Vinnem, 2007). With reference to the decision-making model in Figure 2, Papers VI and VII are primarily concerned with the "decision problem and alternatives" step.

With the aim of obtaining an appropriate balance between value creation and protection, there is value in strengthening our knowledge about an activity of interest (Aven, 2014; Rowley, 2007), as by focusing on knowledge we can make stronger statements (Aven and Ylönen, 2019). 
See also Hansson (2002). This includes the strengthening of the general knowledge, covering the available knowledge about related activities, including conditions and factors that influence what can go wrong and why (Aven and Kristensen, 2019), but also the strengthening of the specific knowledge covering the knowledge about a specific activity, including how to control the conditions and factors that threaten successful realisation of objectives or that might lead to failures (Aven and Kristensen, 2019). Papers VI and VII contribute to the latter, by data analyses and inference, producing new specific knowledge on nontechnical skills (NTS) in the Norwegian emergency medical service (EMS), which is a high-risk domain subject to scarce resources (Aehlert, 2011; Grote, 2015). The basis was a safety-climate survey responded to by the personnel in the Norwegian EMSs conducted in 2016 (see Sørskår, 2018). The two papers are presented in the following.

\section{Paper VI: A comparative study on the frequency of simulation- based training and assessment of non-technical skills in the Norwegian ground ambulance services and helicopter emergency medical services}

The Norwegian EMS, constituted by the helicopter (HEMS) and ground (GEMS) emergency medical service, is dedicated to providing medical care outside hospitals in the case of emergency or acute illness (NOU, 2015). The general knowledge about HEMS and GEMS points to a work environment with intense time pressure, high values at stake, complexity, interdisciplinary tasks, and so on (St. Pierre et al., 2011), making the prehospital service a high-risk domain prone to human errors (Atack and Maher, 2010; Gordon et al., 2012; Manser, 2009). Reducing the risks of human errors is therefore paramount in the HEMS and GEMS, to ensure patient and operational safety (Myers et al., 2016), which, according to the literature, can be done by enhancing the so-called NTS (O'Connor et al., 2008). This relates to the specific knowledge. 
NTS are commonly understood as "the cognitive, social and personal resource skills that complement technical skills, and contribute to safe and effective task performance" (Flin et al., 2008). In the Norwegian HEMS, there has been an increasing focus on NTS over recent years, but training in an assessment of them are resource-demanding initiatives. Mapping the level of training in NTS provides information that could guide future decision-making in the prehospital services, for example on the training programme's cost-effectiveness, development of skills among personnel and possible future practices.

In Paper VI, the aim was to document and compare the frequency of simulation-based training in and assessment of NTS between the Norwegian HEMS and GEMS, conditional on workplace and occupation. The results of the study indicate that the frequency of training in the HEMS was statistically significantly greater than in the GEMS during 2015. There is statistically significantly less training among health trust personnel than among employees in the flight operations. The physicians working in HEMS, however, differ from the other health trust employees, by undergoing more training and assessment. The data analyses indicate that the HEMS has become superior to GEMS, in terms of frequency of training in and assessment of NTS. It is tempting to assert that the identified difference is a result of focus and resources in the HEMS, which, if true, implies that there is a potential for the GEMS to learn from the HEMS and to increase awareness on NTS in the GEMS. An interesting observation, which calls for further study, was the tendency for lesser focus on the assessment of the NTS compared to training. If the simulation-based training is conducted wrongly or personnel have a false belief about their own NTS, this can be a threat to patient and operational safety. 
Paper VII: Training and assessment of non-technical skills in the Norwegian helicopter emergency services: a cross-sectional and longitudinal study

Paper VII also studied the frequency of training in and assessment of NTS, but exclusively among HEMS personnel (physicians, pilots, HEMS crew members). The background for the study was a previous study by Abrahamsen et al. (2015) on the level (frequency) of simulation-based training in and assessment of NTS in 2012. The result of Abrahamsen et al. (2015) indicated that physicians underwent less training and assessment of NTS than pilots and HEMS crew member, and that all personnel working in the HEMS had little training in coping with fatigue. In the period from 2012 to 2016, focus on NTS had increased in the HEMS, and Paper VII aimed to document the development.

The outcome of the study pointed to a statistically significant increase in the frequency of training in and assessment of NTS for all professional groups in the Norwegian HEMS, especially among the physicians. Like the observation of Paper VI, assessment of the NTS was performed less frequently than simulation-based training. In conclusion, the study indicates that the culture among flight operator employees has been transferred to the HEMS' physicians. One possible reason is the invested resources and increased focus on training in NTS in the HEMS.

\subsection{Discussion}

The previous section summarised the scientific contributions of the thesis. In this section, the resulting research is briefly discussed in a broader context with respect to how to obtain an appropriate balance between different concerns.

In a broader context, the contributions of the scientific papers aim to improve future decision-making in risk management. When we implement a decision in practice, such as starting a new activity, we do 
not know the future consequences of the activity, but if the risks are judged acceptable in relation to the expected benefits, we are willing to pursue the opportunity (Aven, 2014). Risk management deals with such situations, aiming to obtain a balance between realising the benefits (e.g. creating values, development, exploring opportunities), while minimising losses (Aven and Vinnem, 2007). The basis for managing risk is the risk assessments and decision analyses, which aim to produce informative decision support about the situation of interest. This implies that the approaches and methods we use to produce decision support have to be capable of addressing and reflecting the relevant factors (e.g., consequences, uncertainty, economic concerns) of the balance between value creation and protection.

The word "appropriate" is open to different value judgments and interpretations of how much weight we should place on the uncertainties when balancing value creation and protection (see Section 1.1). The many situations we face are characterised by various features, such as complexity, vulnerability and ambiguity (see, e.g., Abrahamsen et al., 2017b; Aven and Renn, 2019; Selvik and Abrahamsen, 2020), making it meaningless to prescribe a definition of what weight on the uncertainties represents the appropriate balance. In one case characterised by low uncertainty and strong knowledge, decision-making on the basis of the $\mathrm{E}[\mathrm{NPV}]$ might be judged as resulting in an appropriate balance between value creation and protection. In another case, where there is the potential for big losses and high uncertainty, sole reference to the $\mathrm{E}[\mathrm{NPV}]$ might not result in an appropriate balance; stronger weight is needed on the cautionary principle to obtain an appropriate balance (e.g., Aven, 2019). However, the judgment of what constitutes an appropriate balance between the different concerns will always be case-specific and subject to the decision-maker's attitude towards risks and uncertainties.

Despite the many potential factors and features we face, it is reasonable to argue that an appropriate balance between value creation and protection will always relate to the risk - the consequences of an activity 
and the associated uncertainties - and the available resources (e.g. money, time, capacity). In a fixed frame, it might be the objective to reduce the risk, for example related to an accident at a chemical plant (e.g., Paper V), but how to best do this will always be subject to the available resources, which are normally scarce or limited (Abrahamsen et al., 2013; Vesely, 1999). Resources that are not invested in certain risk management activities or measures can be used to create values or development elsewhere in a company or society, for example by preventing other accidents or reducing other risks (e.g., Abrahamsen et al., 2018b). As such, without considerations of the economic concerns, risk management might impose a danger to the safety. This needs to be taken into consideration, as the aim is to obtain an appropriate balance between value creation and protection, which, from a broader perspective, implies allocating the available resources where we obtain the "most" safety (see, e.g., Paper I).

For the decision-makers to determine where we obtain the most safety from the available resources, proper decision support is essential, which captures and reflects all the relevant factors of the situation of interest (Aven and Körte, 2003; Engemann and Abrahamsen, 2020). As introduced in Section 1.1, different perspectives tend to emphasise different approaches and principles, to provide proper decision support on how to "best" manage risk. No single perspective can be appropriate for all situations, and we need to acknowledge the contributions of all perspectives, in order to obtain the appropriate balance between value creation and protection (Abrahamsen and Abrahamsen, 2015). Despite their differences, the resulting research of the thesis indicates that, to obtain proper decision support, all approaches and principles need adequate consideration of the uncertainties, knowledge dimension and the system as a whole.

The importance of uncertainty is intuitive, as it is a main component of risk - we do not know the consequences of an activity (see, e.g., Aven, 2014). In order to adequately manage risks, uncertainties (both epistemic 
and aleatory) need consideration, as they guide how much weight we should place on value creation and protection. (Uncertainty alone is not of major concern, as it needs to be viewed in light of the values at stake; see, e.g., Aven and Renn, 2019.) The knowledge, interpreted as the justified beliefs, is another central dimension of the decision support, informing the decision-makers on what foundation it is based, what it represents, how much confidence can be placed on the recommendations, and so on (see, e.g., Aven and Kristensen, 2019; Aven and Zio, 2018b). The importance of these two dimensions has been stressed in all the papers and acknowledge in the literature, as they will always have a role to play when managing risk and, thus, influence the balance between value creation and protection that is judged to be appropriate. To identify all the relevant uncertainties and knowledge, however, is not straightforward (e.g., Papers I and II).

To reduce the risk of missing relevant information and "wrong" allocation of resources, hampering the balance between value creation and protection, the resulting research points to the importance of thinking about the system as a whole. Systems thinking might assist the analysts in identifying the relevant attributes and factors of the situation of interest, increasing the understanding of how a particular decision might influence or be influenced by the system; a thorough understanding of the decision context is a necessity to balance value creation and protection (Engemann and Abrahamsen, 2020). Systems thinking is not new in the domain of safety and risk (e.g., Dekker et al., 2011; Deming, 2000; Hollnagel et al., 2006; Kastenberg et al., 2004; Leveson, 2011; Rasmussen, 1997). In simple terms, the main argument for using systems thinking follows that traditional chain-of-events methods, such as event trees, have strong limitations in revealing the relevant insight into complex systems (Aven, 2014; Dekker et al., 2011). However, in this thesis, systems thinking is also considered useful, regardless of the complexity, as most situations of interest can be (broadly) interpreted as a system (Aven and Ylönen, 2018), in which the interactions and 
interconnections might have a role to play in how to best manage the risks. Thinking about the whole might also be useful for revealing black swan events, as well as checking for robustness in the system of interest (Aven, 2014). In addition, systems thinking might be advantageous to ensure efficient allocation of the available resources, as it can enhance the attention on other projects and investments within an organisation.

Risk management is challenging. It involves difficult value judgments and trade-offs about the future, which implies a need for proper decision support. To improve future decision-making, the resulting research of this $\mathrm{PhD}$ project supports a stronger focus on systems thinking in risk management, which can enhance the understanding of the situation of interest by revealing the relevant uncertainties and knowledge, which always need consideration, in order to obtain an appropriate balance between value creation and protection. 


\section{Future work}

The scientific contributions presented in this thesis identify some potential future work, which will be detailed in the following. The section addresses some general directions, as well as suggesting more specific proposals for further work, inspired by the work of the $\mathrm{PhD}$ project.

- Systems thinking appears to have a role to play in risk management and assessment; further studies are recommended to increase the knowledge on how to integrate it in the risk management strategy and in the other decision principles such as the ALARP principle.

- The framework presented in Paper II builds on the SEIPS model by Carayon et al. (2006), but is it the best alternative for the task of identifying the relevant background knowledge? Although a brief literature study was performed before selecting the SEIPS model in Paper II, it would be informative to study different system models in depth, with respect to identification of knowledge elements.

- The framework presented in Paper II will benefit from being applied in a real case, as it has just been illustrated on the basis of an example in Eidesen et al. (2009), which the authors of Paper II used to illustrate the additional value in thinking about the system.

- An unaddressed issue of the framework of Paper II is how it should be applied when including the time dimension and, especially, when decisions need to be made rapidly.

- An unanswered topic in the thesis relates to Paper III and how to perform multiple assumption deviation risks. This type of study is strongly recommended, not just for the improved risk-based approach presented in Paper III, but for the concept of assumption deviation risk in general. 
- To further improve the leakage risk assessment of P\&A designs, more research is needed to increase the understanding of the probability distributions, for example with respect to the uncertain parameters and assumptions on the well and reservoir characteristics.

- When writing the discussion on socioeconomic profitability and security measures, a potential area for future study was identified: what is the real benefit of security measures? From an extreme perspective, it is possible to argue that investments in security measures have zero effect, as the perpetrator shifts focus to new targets.

- An identified topic for future research, based on Paper V and a contribution not included in the thesis (Langdalen et al., 2020), is the order of prioritisation that guides when in time each safety measure should be adopted, to obtain an appropriate balance between value creation and protection.

- Paper VI identified a potential for knowledge sharing between the different disciplines in the Norwegian prehospital services. It is recommended that this information be used to develop training programmes tailored to the ground ambulance services and crossdisciplinary work. The latter would be highly beneficial when serious accidents and disasters occur, in which safety and efficiency rely on the level of teamwork and shared understanding between the different disciplines.

- To further strengthen the specific knowledge in the Norwegian prehospital services about the NTS, studies need to be conducted that reveal something about the quality of the NTS among the personnel.

- In Papers VI and VII, a lack of assessment of the NTS was identified. The results support greater focus on how to ensure appropriate assessment of the NTS in the Norwegian EMSs. 


\section{References}

Abrahamsen, E.B. (2011). On the rationality of using risk acceptance criterion based on the expected utility theory. International Journal of Business Continuity and Risk Management, vol. 2 (1), 70-78. Doi: 10.1504/IJBCRM.2011.040016.

Abrahamsen, E.B. and Aven, T. (2012). Why risk acceptance criterion need to be defined by the authorities and not the industry? Reliability Engineering \& System Safety, vol. 105, 47-50. Doi: 10.1016/j.ress.2011.11.004.

Abrahamsen, E.B. and Selvik, J.T. (2013). A framework for selection of inspection intervals for well barriers. Safety, Reliability and Risk Analysis: Beyond the Horizon: ESREL 2013, 631-636. London, UK: CRC Press.

Abrahamsen, E.B., Abrahamsen, H.B. and Selvik, J.T. (2017a). A note on the layered approach for implementing ALARP and the grossly disproportionate criterion. International Journal of Business Continuity and Risk Management, vol. 7 (3), 204-210. Doi: 10.1504/IJBCRM.2017.088807.

Abrahamsen, E.B., Asche, F. and Aven, T. (2011). To what extent should all the attributes be transformed to one comparable unit when evaluating safety measures. The Business Review, Cambridge, vol. 19 (1), 70-76.

Abrahamsen, E.B., Asche, F. and Milazzo, M.F. (2013). An evaluation of the effects on safety of using safety standards in major hazard industries. Safety Science, vol. 59, 173-178. Doi: 10.1016/j.ssci.2013.05.011.

Abrahamsen, E.B., Aven, T. and Sandøy, M. (2006). A note on the concept of risk aversion in safety management. Proceedings of the Institution of Mechanical Engineers, Part O: Journal of Risk and Reliability, vol. 220 (1), 69-71. Doi: 10.1243/1748006XJRR16.

Abrahamsen, E.B., Selvik, J.T. and Abrahamsen, H.B. (2020a). Using costeffectiveness acceptability curves as a basis for prioritizing investments in safety measures in the offshore oil and gas industry. International Journal of Performability Engineering, vol. 16 (2), 163-170. Doi: 10.23940/ijpe.20.02.p1.163170.

Abrahamsen, E.B., Selvik, J.T. and Berg, H. (2016). Prioritising of safety measures in land use planning: on how to merge a risk-based approach with a cost-benefit analysis approach. International Journal of Business Continuity and Risk Management, vol. 6 (3), 182-196. Doi: 10.1504/IJBCRM.2016.079007.

Abrahamsen, E.B., Abrahamsen, H.B., Milazzo, M.F. and Selvik, J.T. (2018a). Using the ALARP principle for safety management in the energy production sector of chemical industry. Reliability Engineering \& System Safety, vol. 169, 160-165. Doi: $10.1016 /$ j.ress.2017.08.014. 
Abrahamsen, E.B., Aven, T., Vinnem, J.E. and Wiencke, H. (2004). Safety management and the use of expected values. Risk, Decision and Policy, vol. 9 (4), 347-357. Doi: 10.1080/14664530490896645.

Abrahamsen, E.B., Selvik, J.T., Lohne, H.P. and Arild, Ø. (2020b). Plug and abandonment decision-making: quality at the right price. International Journal of Performability Engineering, vol. 16 (1), 1-9. Doi: 10.23940/ijpe.20.01.p1.19.

Abrahamsen, E.B., Pettersen, K.A., Aven, T., Kaufmann, M. and Rosqvist, T. (2017b). A framework for selection of strategy for management of security measures. Journal of Risk Research, vol. 20 (3), 404-417. Doi: 10.1080/13669877.2015.1057205.

Abrahamsen, E.B., Moharamzadeh, A., Abrahamsen, H.B., Asche, F., Heide, B. and Milazzo, M.F. (2018b). Are too many safety measures crowding each other out? Reliability Engineering \& System Safety, vol. 174, 108-113. Doi: 10.1016/j.ress.2018.02.011.

Abrahamsen, H.B. and Abrahamsen, E.B. (2015). On the appropriateness of using the ALARP principle in safety management. Safety and Reliability of Complex Engineered Systems: ESREL 2017, 773-777. London, UK: CRC Press.

Abrahamsen, H.B., Sollid, S.J.M., Öhlund, L., Røislien, J. and Bondevik, G. (2015). Simulation-based training and assessment of non-technical skills in the Norwegian helicopter emergency medical services: a cross-sectional survey. Emergency Medicine Journal, vol. 32, 647-653. Doi:10.1136/emermed-2014203962.

Adler, M.D. (2011). Well-Being and Fair Distribution: Beyond Cost-Benefit Analysis. New York: Oxford University Press.

Aehlert, B. (2011). Paramedic Practice Today: Above and Beyond. Vol. 1. Burlington, MA: Jones \& Bartlett Learning.

Agrawal, H., Shuayli, M.A. and Salmani, M. (2017). Reducing operational flaring through ALARP based decision making. International Petroleum Exhibition \& Conference, Abu Dhabi, UAE, November 13-17, 2017. Society for Petroleum Engineers.

Ale, B.J.M., Hartford, D.N.D. and Slater, D. (2015). ALARP and CBA all in the same game. Safety Science, vol. 76, 90-100. Doi: 10.1016/j.ssci.2015.02.012.

Amendola, A. (2002). Recent paradigms for risk informed decision making. Safety Science, vol. 40 (1-4), 17-30. Doi: 10.1016/S0925-7535(01)00039-X.

Amundrud, Ø., Aven, T. and Flage, R. (2017). How the definition of security risk can be made compatible with safety definitions. Proceedings of the Institution of Mechanical Engineers. Part O, Journal of Risk and Reliability, vol. 231 (3), 286294. Doi: 10.1177/1748006X17699145.

Anderson, E. (1993). Value in Ethics and Economics. Cambridge, MA: Harvard University Press. 
Apostolakis, G.E. (1990). The concept of probability in safety assessment of technological systems. Science, vol. 250 (4986), 1359-1364. Doi: $10.1126 /$ science. 2255906 .

Apostolakis, G.E. (2004). How useful is quantitative risk assessment? Risk Analysis, vol. 24 (3), 515-520. Doi: 10.1111/j.0272-4332.2004.00455.x.

Arild, Ø., Lohne, H.P., Majoumerd, M.M., Ford, E.P. and Moeinikia, F. (2017). Establishment of a quantitative risk-based approach for evaluation of containment performance in the context of permanently plugged and abandoned petroleum wells. Offshore Technology Conference 2017, OTC-27711-MS, Offshore Technology Conference, Houston, TX.

Arild, Ø., Lohne, H.P., Nielsen, M., Moeinikia, F., Selvik, J.T., Abrahamsen, E.B., Ford, E.P. et al. (2018). Permanent P\&A design: what is good enough? SPE Annual Technical Conference and Exhibition 2018, SPE-191414-MS, Society of Petroleum Engineers, Dallas, TX.

Arnold, R.D. and Wade, J. (2015). A definition of systems thinking: a systems approach. Procedia Computer Science, vol. 44, 669-678. Doi: 10.1016/j.procs.2015.03.050.

Askeland, T., Flage, R. and Aven, T. (2017). Moving beyond probabilities: strength of knowledge characterisations applied to security. Reliability Engineering \& System Safety, vol. 159, 196-205. Doi: 10.1016/j.ress.2016.10.035.

Assum, T., Bjørnskau, T., Fosser, S. and Sagberg, F. (1999). Risk compensation: the case of road lighting. Accident Analysis and Prevention, vol. 31 (5), 545-553. Doi: 10.1016/S0001-4575(99)00011-1.

Atack, L. and Maher, J. (2010). Emergency medical and health provider's perception of key issues in prehospital patient safety. Prehospital Emergency Care, vol. 14 (1), 95-102. Doi: 10.3109/10903120903349887.

Aven, T. (2010). On how to define, understand and describe risk. Reliability Engineering \& System Safety, vol. 95, 623-631. Doi: 10.1016/j.ress.2010.01.011.

Aven, T. (2011a). A risk concept applicable for both probabilistic and non-probabilistic perspectives. Safety Science, vol. 49, 1080-1086. Doi: 10.1016/j.ssci.2011.04.017.

Aven, T. (2011b). Quantitative Risk Assessment: The Scientific Platform. Cambridge: Cambridge University Press.

Aven, T. (2011c). On different types of uncertainties in the context of the precautionary principle. Risk Analysis, vol. 31 (10), 1515-1525. Doi: 10.1111/j.15396924.2011.01612.x.

Aven, T. (2013). Practical implications of the new emerging risk perspectives. Reliability Engineering \& System Safety, vol. 115, 136-145. Doi: 10.1016/j.ress.2013.02.020. 
Aven, T. (2014). Risk, Surprises and Black Swans: Fundamental Ideas and Concepts in Risk Assessment and Risk Management. New York: Routledge.

Aven, T. (2015). Risk Analysis. $2^{\text {nd }}$ ed. Chichester, UK: John Wiley \& Sons.

Aven, T. (2017). Improving risk characterisations in practical situations by highlighting knowledge aspects, with applications to risk matrices. Reliability Engineering \& System Safety, vol. 167, 42-48. Doi: 10.1016/j.ress.2017.05.006.

Aven, T. (2018). An emerging new risk analysis science: foundations and implications. Risk Analysis, vol. 38 (5). Doi: 10.1111/risa.12899.

Aven, T. (2019). The cautionary principle in risk management: foundation and practical use. Reliability Engineering \& System Safety, vol. 191. Doi: 10.1016/j.ress.2019.106585.

Aven, T. and Abrahamsen, E.B. (2007). On the use of cost-benefit analysis in the ALARP process. International Journal of Performability Engineering, vol. 3 (3), 345-353.

Aven, T. and Flage, R. (2009). Use of decision criteria based on expected values to support decision-making in a production assurance and safety setting. Reliability Engineering \& System Safety, vol. 94, 1491-1498. Doi: 10.1016/j.ress.2009.02.007.

Aven, T. and Flage, R. (2018). Risk assessment with broad uncertainty and knowledge characterisation: an illustrating case, in Aven, T. and Zio, E. (Eds.) Knowledge in Risk Assessment and Management, 3-26. Chichester, UK: John Wiley \& Sons.

Aven, T. and Kristensen, V. (2019). How the distinction between general knowledge and specific knowledge improve the foundation and practice of risk assessment and risk-informed decision-making. Reliability Engineering \& System Safety, vol. 191. Doi: 10.1016/j.ress.2019.106553.

Aven, T. and Körte, J. (2003). On the use of risk and decision analysis to support decision-making. Reliability Engineering \& System Safety, vol. 76, 90-100. Doi: 10.1016/S0951-8320(02)00203-X.

Aven, T. and Renn, O. (2009). On risk defined as an event where the outcome is uncertain. Journal of Risk Research, vol. 12 (1), 1-11. Doi: 10.1080/13669870802488883.

Aven, T. and Renn, O. (2010). Risk Management and Risk Governance. Berlin, Germany: Springer Verlag.

Aven, T. and Renn, O. (2019). Some foundational issues related to risk governance and different types of risks. Journal of Risk Research. Doi: 10.1080/13669877.2019.1569099.

Aven, T. and Vinnem, J.E. (2005). On the use of risk acceptance criteria in the offshore oil and gas industry. Reliability Engineering \& System Safety, vol. 90 (1), 15-24. Doi: 10.1016/j.ress.2004.10.009. 
Aven, T. and Vinnem, J.E. (2007). Risk Management: with Applications from the Offshore Petroleum Industry. New York: Springer Verlag.

Aven, T. and Ylönen, M. (2018). A risk interpretation of sociotechnical safety perspectives. Reliability Engineering \& System Safety, vol. 175, 13-18. Doi: 10.1016/j.ress.2018.03.004.

Aven, T. and Ylönen, M. (2019). The strong power of standards in the safety and risk fields: a threat to proper development of these fields? Reliability Engineering \& System Safety, vol. 189, 279-286. Doi: 10.1016/j.ress.2019.04.035.

Aven, T. and Zio, E. (2011). Some considerations on the treatment of uncertainties in risk assessment for practical decision-making. Reliability Engineering \& System Safety, vol. 96, 64-74. Doi: 10.1016/j.ress.2010.06.001.

Aven, T. and Zio, E. (2018a). Knowledge in Risk Assessment and Management. Chichester, UK: John Wiley \& Sons.

Aven, T. and Zio, E. (2018b). Quality of risk assessment: definition and verification, in Aven, T. and Zio, E. (Eds.) Knowledge in Risk Assessment and Management, 297312. Chichester, UK: John Wiley \& Sons.

Aven, T., Vinnem, J.E. and Wiencke, H.S. (2007). A decision framework for risk management, with application to the offshore oil and gas industry. Reliability Engineering \& System Safety, vol. 92 (4), 433-448. Doi: 10.1016/j.ress.2005.12.009.

Ayyub, B.M. (2003). Risk Analysis in Engineering and Economics. Boca Raton, FL: Chapman \& Hall.

Baard, P. (2016). Risk-reducing goals: ideals and abilities when managing complex environmental risks. Journal of Risk Research, vol. 19 (2), 164-180. Doi: 10.1080/13669877.2014.961513.

Baker, R., Chilton, S., Jones-Lee, M. and Metcalf, H. (2008). Valuing lives equally: defensible premise or unwarranted compromise? Journal of Risk and Uncertainty, vol. 36, 125-138. Doi: 10.1007/s11166-008-9034-0.

Bani-Mustafa, T., Zeng, Z., Zio, E. and Vasseur, D. (2020). A practical approach for evaluating the strength of knowledge supporting risk assessment models. Safety Science, vol. 124. Doi: 10.1016/j.ssci.2019.104596.

Baybutt, P. (2014). The ALARP principle in process safety. Process Safety Progress, vol. 33 (1), 36-40. Doi: 10.1002/prs.11599.

Bedford, T. and Cook, R. (2001). Probabilistic Risk Analysis: Foundations and Methods. Cambridge, UK: Cambridge University Press.

Bellamy, L.J., Ale, B.J.M., Geyer, T.A.W., Gossens, L.H.J., Hale, A.R., Oh, J., Mud, M., Bloemhof, A., Papazoglou, I.A. and Whiston, J.Y. (2007). Storybuilder - A tool for the analysis of accident reports. Reliability Engineering \& System Safety, vol. 92, 735-744. Doi: 10.1016/j.ress.2006.02.010.

Bernardo, J.M. and Smith, A.F.M. (1994). Bayesian Theory. Chichester, UK: Wiley. 
Bhardwaj, S., Bhattacharya, S., Tang, L. and Howell, K.E. (2019). Technology introduction on ships: the tension between safety and economic rationality. Safety Science, vol. 115, 329-338. Doi: 10.1016/j.ssci.2019.02.025.

Bryant, P.A., Croft, J. and Cole, P. (2018). Integration of risks from multiple hazards into a holistic ALARA/ALARP demonstration. Journal of Radiological Protection, vol. 38, 81-91. Doi: 10.1088/1361-6498/aa8e53.

Carayon, P., Hundt, A.S., Karsh, B.T., Gurses, A.P., Alvarado, C.J., Smith, M. and Brennan, P.F. (2006). Work system design for patient safety. the SEIPS model. Quality and Safety in Health Care, vol. 15 (1), i50-i58. Doi: 10.1136/qshc.2005.015843.

Carayon, P., Wetterneck, T.B., Rivera-Rodriguez, A.J., Hundt, A.S., Hoonakker, P., Holden, R. and Gurses, A.P. (2014). Human factors systems approach to healthcare quality and patient safety. Applied Ergonomics, vol. 45(1), 14-25. Doi: 10.1016/j.apergo.2013.04.023.

Clemen, R.T. and Reilly, T. (2001). Making Hard Decisions with DecisionTools. $2^{\text {nd }}$ ed. Pacific Grove, CA: Duxbury Thomson Learning.

COSO (Committee of Sponsoring Organizations of the Treadway Commission) (2017). Enterprise Risk Management: Integrating with Strategy and Performance. New York: AICPA.

Cox, T. (2011). Clarifying types of uncertainty: when are models accurate, and uncertainties small? Risk Analysis, vol. 31 (10), 1530-1533. Doi: 10.1111/j.15396924.2011.01706.x.

Day, R.A. and Gastel, B. (2006). How to Write and Publish a Scientific Paper. Cambridge: Cambridge University Press.

Dekker, S., Cilliers, P. and Hofmeyr, J.H. (2011). The complexity of failure: implications of complexity theory for safety investigations. Safety Science, vol. 49 (6), 939-945. Doi: 10.1016/j.ssci.2011.01.008.

Deming, W.E. (2000). The New Economics. $2^{\text {nd }}$ ed. Cambridge, MA: MIT CAES.

Dillon, R.L., Liebe, R.M. and Bestafka, T. (2009). Risk-based decision-making for terrorism applications. Risk Analysis, vol. 29 (3), 321-335. Doi: 10.1111/j.15396924.2008.01196.x.

Duijm, N.J., Fiévez, C., Gerbec, M., Hauptmanns, U. and Konstandinidou, M. (2008). Management of health, safety and environment in process industry. Safety Science, vol. 46 (6), 908-920. Doi: 10.1016/j.ssci.2007.11.003.

Eidesen, K., Sollid, S.J. and Aven, T. (2009). Risk assessment in critical care medicine: a tool to assess patient safety. Journal of Risk Research, vol. 12 (3-4), 281-294. Doi: $10.1080 / 13669870802456914$.

Engemann, K.J. and Abrahamsen, E.B. (2020). Advances in safety risk management, in Engemann, K.J. and Abrahamsen, E.B. (Eds.) Safety Risk Management: 
Integrating Economic and Safety Perspectives, V-XI. Berlin, Germany: Walter de Gruyter. Doi: 10.1515/9783110638189-202.

Erkan, B., Ertan, G., Yeo, J. and Comfort, L.K. (2016). Risk, profit, or safety: sociotechnical systems under stress. Safety Science, vol. 88, 199-210. Doi: 10.1016/j.ssci.2016.02.002.

Farrow, S. and Viscusi, W.K. (2011). Towards principles and standards for the benefitcost analysis of safety. Journal of Benefit-Cost Analysis, vol. 2 (3), 1-25. Doi: 10.2202/2152-2812.1033.

Fischhoff, B., Lichtenstein, S., Slovic, P., Derby, S. and Keeney, R. (1981). Acceptable Risk. New York: Cambridge University Press.

Flage, R. (2010). Contributions to the Treatment of Uncertainty in Risk Assessment and Management. PhD Thesis, University of Stavanger, Faculty of Science and Technology, Stavanger, Norway.

Flage, R. (2019). Implementing an uncertainty-based risk conceptualisation in the context of environmental risk assessment, with emphasis on the bias of uncertain assumptions. Civil Engineering and Environmental Systems, vol. 36 (2-4), 149171. Doi: 10.1080/10286608.2019.1702029.

Flage, R. and Askeland, T. (2020). Assumptions in quantitative risk assessments: when explicit and when tacit? Reliability Engineering \& System Safety, vol. 197. Doi: 10.1016/j.ress.2020.106799.

Flage, R. and Aven, T. (2009). Expressing and communicating uncertainty in relation to quantitative risk analysis. Reliability \& Risk Analysis: Theory \& Applications, vol. 2 (13), 9-18.

Flage, R., Aven, T., Zio, E. and Baraldi, P. (2014). Concerns, challenges, and directions of development for the issue of representing uncertainty in risk assessment. Risk Analysis, vol. 34 (7), 1196-1207. Doi: 10.1111/risa.12247.

Flin, R.H., O'Connor, P. and Crichton, M. (2008) Safety at the Sharp End: A Guide to Nontechnical Skills. Farnham, UK: Ashgate Publishing.

Flood, R.L. and Carson, E.R. (1988). Dealing with Complexity: An Introduction to the Theory and Application of System Science. New York: Plenum Press.

Ford, E., Aven, T., Røed, W. and Wiencke, H.S. (2008). An approach for evaluating methods for risk and vulnerability assessments. Journal of Risk and Reliability, vol. 220, 315-326. Doi: 10.1243/1748006XJRR120.

French, S. and Rios Insua, D. (2000). Statistical Decision Theory. London: Arnold.

French, S., Bedford, T. and Atherton, E. (2005). Supporting ALARP decision making by cost-benefit analysis and multiattribute utility theory. Journal of Risk Research, vol. 8 (3), 207-223. Doi: 10.1080/1366987042000192408.

Goerlandt, F. and Reniers, G. (2016). On the assessment of uncertainty in risk diagrams. Safety Science, vol. 84, 67-77. Doi: j.ssci.2015.12.001. 
Gordon, M., Darbyshire, D. and Baker, P. (2012). Non-technical skills training to enhance patient safety: a systematic review. Medical Education, vol. 46, 10421054. Doi: $10.1111 /$ j.1365-2923.2012.04343.x.

Grote, G. (2012). Safety management in high-risk domains: all the same? Safety Science, vol. 50 (10), 1938-1992. Doi: 10.1016/j.ssci.2011.07.017.

Grote, G. (2015). Promoting safety by increasing uncertainty: implications for risk management. Safety Science, vol. 71, 71-79. Doi: 10.1016/j.ssci.2014.02.010

Hanley, N. and Spash, C.L. (1993). Cost-Benefit and the Environment. Aldershot, UK: Edward Elgar Publishing.

Hansson, S.O. (2002). Uncertainties in the knowledge society. International Social Science Journal, vol. 54 (171), 39-46. Doi: 10.1111/1468-2451.00357.

Hertz, D.B. and Thomas, H. (1983). Risk Analysis and its Application. Chichester, UK: Wiley.

Hoegberg, L. (1998). Risk perception, safety goals and regulatory decision-making. Reliability Engineering \& System Safety, vol. 59 (1), 135-139. Doi: 10.1016/S0951-8320(97)00134-8.

Hokstad, P. and Steiro, T. (2006). Overall strategy for risk evaluation and priority setting of risk regulations. Reliability Engineering \& System Safety, vol. 91 (1), 100-111. Doi: 10.1016/j.ress.2004.11.014.

Holden, R.J., Carayon, P., Gurses, A.P., Hoonakker, P., Hundt, A.S., Ozok, A.A. and Rivera-Rodriguez, A.J. (2013). SEIPS 2.0: a human factors framework for studying and improving the work of healthcare professionals and patients. Ergonomics, vol. 56 (11), 1669-1686. Doi: 10.1080/00140139.2013.838643.

Hollnagel, E., Woods, D.D. and Leveson, N.C. (2006). Resilience Engineering: Concepts and Precepts. Aldershot, UK: Ashgate.

Hopkin, P. (2013). Risk Management. London: Kogan Page Ltd.

Hopkins, A. (2011). Risk-management and rule-compliance: decision-making in hazardous industries. Safety Science, vol. 49 (2), 110-120. Doi: 10.1016/j.ssci.2010.07.014.

HSE [Health and Safety Executive]. (2001). Reducing Risks, Protecting People: HSE's Decision-making Process. Norwich, UK: HSE Books.

Hurst, J., McIntyre, J., Tamauchi, Y., Kinuhata, H. and Kodama, T. (2018). A summary of the 'ALARP' principle and associated thinking. Journal of Nuclear Science and Technology, vol. 56 (2), 241-253. Doi: 10.1080/00223131.2018.1551814.

IPCC (Intergovernmental Panel on Climate Change). (2012). Managing the Risks of Extreme Events and Disasters to Advance Climate Change Adaptation: A Special Report of Working Groups I and II of the Intergovernmental Panel on Climate Change. Field, C.B., Barros, V., Stocker, T.F., Qin, D., Dokken, D.J., Ebi, K.L., et al. (Eds.). Cambridge: Cambridge University Press. 
ISO (International Organization for Standardization). (2018). ISO 31000: Risk Management: Principles and Guidelines. Switzerland: ISO.

Jensen, A. and Aven, T. (2018). A new definition of complexity in a risk analysis setting. Reliability Engineering \& System Safety, vol. 171, 169-173. Doi: 10.1016/j.ress.2017.11.018.

Jones-Lee, M. and Aven, T. (2011). ALARP - what does it really mean? Reliability Engineering \& System Safety, vol. 96, 877-882. Doi: 10.1016/j.ress.2011.02.006.

Jonkman, S.N., van Gelder, P.H.A.J.M. and Vrijling, J.K. (2003). An overview of quantitative risk measures for loss of life and economic damage. Journal of Hazardous Materials, vol. 99 (1), 1-30. Doi: 10.1016/S0304-3894(02)00283-2.

Jore, S.H. (2019). The conceptual and scientific demarcation of security in contrast to safety. European Journal of Security Research, vol. 4, 157-174. Doi: 10.1007/s41125-017-0021-9.

Kaplan, S. and Garrick, B.J. (1981). On the quantitative definition of risk. Risk Analysis, vol. 1 (1), 11-27. Doi: 10.1111/j.1539-6924.1981.tb01350.x.

Kastenberg, W., Hauser-Kastenberg, G. and Norris, D. (2004). On developing a risk analysis framework for post-industrial age technologies, in Spitzer, C., Schmocker, U. and Dang, V.N. (Eds.) PSAM7, 2378-2383. London: Springer.

Keeney, R. and Raiffa, H. (1993). Decisions with Multiple Objectives: Preferences and Value Tradeoffs. Cambridge: Cambridge University Press.

Kelman, S. (1981). Cost-benefit analysis: an ethical critique. Regulation, vol. 5 (1), 3340.

Kletz, T.A. (2005). Looking beyond ALARP: overcoming its limitations. Process Safety and Environmental Protection, vol. 83 (2), 81-84. Doi: $10.1205 /$ psep.04227.

Klinke, A. and Renn, O. (2001). Precautionary principle and discursive strategies: classifying and managing risks. Journal of Risk Research, vol. 4 (2), 159-173. Doi: 10.1080/136698701750128105.

Klinke, A. and Renn, O. (2002). A new approach to risk evaluation and management: risk-based, precautionary-based, and discourse-based strategies. Risk Analysis, vol. 22 (6), 1071-1094. Doi: 10.1111/1539-6924.00274.

Kothari, C.R. (2004). Research Methodology: Methods and Techniques. $2^{\text {nd }}$ ed. New Delhi, India: New Age International (P) Ltd., Publishers.

Kristensen, V., Aven, T. and Ford, D. (2005). A new perspective on Renn and Klinke's approach to risk evaluation and management. Reliability Engineering \& System Safety, vol. 91 (4), 421-432. Doi: 10.1016/j.ress.2005.02.006.

Lambert, J.H. and Farrington, M.W. (2006). Cost-benefit functions for the allocation of security sensors of air containment. Reliability Engineering \& System Safety, vol. 92 (7), 930-946. Doi: 10.1016/j.ress.2006.06.002. 
Langdalen, H., Abrahamsen, E.B., Selvik, J.T. and Berg, H. (2020). An extended approach for prioritising physical safety measures to handle flood and landslide risks, in Engemann, K.J. and Abrahamsen, E.B. (Eds.), Safety Risk Management: Integrating Economic and Safety Perspectives, 155-172. Berlin, Germany: Walter de Gruyter. Doi: 10.1515/9783110638189-010.

Leveson, N. (2011). Engineering a Safer World: Systems Thinking Applied to Safety. Cambridge, MA: MIT Press.

Leveson, N. (2015). A systems approach to risk management through leading safety indicators. Reliability Engineering \& System Safety, vol. 136, 17-34. Doi: 10.1016/j.ress.2014.10.008.

Levy, H. and Sarnat, M. (1994). Capital Investment \& Financial Decisions. $5^{\text {th }}$ ed. New York, NY: Prentice Hall.

Lind, N. (2002). Social and economic criteria of acceptable risk. Reliability Engineering \& System Safety, vol. 78 (1), 21-25. Doi: 10.1016/S09518320(02)00051-0.

Lindley, D.V. (1985). Making Decisions. $2^{\text {nd }}$ ed. London, UK: John Wiley \& Sons.

Löfstedt, R.E. (2003). The precautionary principle: risk, regulation and politics. Process Safety and Environmental Protection, vol. 81 (1), 36-43. Doi: $10.1205 / 095758203762851976$.

Manser, T. (2009). Teamwork and patient safety in dynamic domains of healthcare: a review of the literature. Acta Anaesthesiologica Scandinavica, vol. 53 (2), 143151. Doi: $10.1111 / \mathrm{j} .1399-6576.2008 .01717 . x$.

Marca, D.A. and McGowan, C.L. (1988). SADT: Structured Analysis and Design Technique. New York: McGraw-Hill Book Co. Inc.

McNab, D., McKay, J., Shorrock, S., Luty, S. and Bowie, P. (2019). Development and application of 'systems thinking' principles for quality improvement. BMJ Open Quality, vol. 9 (1), 1-10. Doi:10.1136/ bmjoq-2019-000714.

Melchers, R.E. (2001). On the ALARP approach to risk management. Reliability Engineering \& System Safety, vol. 71, 201-208. Doi: 10.1016/S09518320(00)00096-X.

Menon, C., Bloomfield, R.E. and Clement, T. (2013). Interpreting ALARP. Proceedings of the $8^{\text {th }}$ IET International System Safety Conference. IET.

Möller, N. and Hansson, S.O. (2008). Principles of engineering safety: risk and uncertainty reduction. Reliability Engineering \& System Safety, vol. 93 (6), $798-$ 805. Doi: 10.1016/j.ress.2007.03.031.

Myers, J.A., Powell, D.M.C., Psirides, A., Hathaway, K., Aldington, S. and Haney, M.F. (2016). Nontechnical skills evaluation in the critical care air ambulance environment: introduction of an adapted rating instrument: an observational study. Scandinavian Journal of Trauma, Resuscitation and Emergency Medicine, vol. 24. Doi: 10.1186/s13049-016-0216-5. 
Nesticò, A., He, S., De Mare, G., Benintendi, R. and Maselli, G. (2018). The ALARP principle in cost-benefit analysis for the acceptability of investment risk. Sustainability, vol. 10 (12), 1-22. Doi: 10.3390/su10124668.

North, W.D. (2011). Uncertainties, precaution, and science: focus on the state of knowledge and how it may change. Risk Analysis, vol. 31 (10), 1526-1529. Doi: 10.1111/j.1539-6924.2011.01707.x.

Norwegian Research Council. (2000). Kvalitet i norsk forskning: En oversikt over begreper, metoder og virkemilder.

NOU (Official Norwegian reports). (2015). Først og fremst. Et helhetlig system for håndtering av akutte sykdommer og skader utenfor sykehus [Primarily. A comprehensive system for dealing with acute diseases and injuries outside hospitals]. NOU Norges Offentlige Utredninger No. 17, 2015. Norwegian Government Security and Service Organization. Retrieved from https://www.regjeringen.no/no/ dokumenter/nou-2015-17. Accessed 27.03.2020.

NOU (Official Norwegian Reports). (2016). Samhandling for sikkerhet: beskyttelse av grunnleggende samfunnsfunksjoner i en omskiftelig tid [only in Norwegian]. NOU Norges Offentlige Utredninger No. 16, 2016, Oslo, Norway. Retrieved from https://www.regjeringen.no/no/dokumenter/nou-2016-19/id2515424/. Accessed 19.03.2020.

O’Connor, P., Campbell, J., Newon, J., Melton, J., Salas, E. and Wilson, K.A. (2008). Crew resource management training effectiveness: a meta-analysis and some critical needs. The International Journal of Aviation Psychology, vol. 18 (4), 353368. Doi: 10.1080/10508410802347044.

Palazzi, E., Currò, F. and Fabiano, B. (2015). A critical approach to safety equipment and emergency time evaluation based on actual information from the Bhopal gas tragedy. Process Safety and Environmental Protection, vol. 97 37-48. Doi: 10.1016/j.psep.2015.06.009.

Papazoglou, I.A., Bellamy, L.J., Hale, A.R., Aneziris, O.N., Ale, B.J.M., Post, J.G. and Oh, J.I.H. (2003). I-Risk: development of an integrated technical and management risk methodology for chemical installations. Journal of Loss Prevention in the Process Industries, vol. 16 (6), 575-591. Doi: 10.1016/j.jlp.2003.08.008.

Pape, R.P. (1997). Developments in the tolerability of risk (TOR) and the application of ALARP. Nuclear Energy, vol. 36 (6), 457-463.

Patè-Cornell, E. (1996). Uncertainties in risk analysis: six levels of treatment. Reliability Engineering \& System Safety, vol. 54 (2-3), 95-111. Doi: 10.1016/S0951-8320(96)00067-1.

Patè-Cornell, E. (2002). Finding and fixing systems weaknesses: probabilistic methods and applications in engineering risk analysis. Risk Analysis, vol. 22 (2), 319-334. Doi: 10.1111/0272-4332.00025. 
Paté-Cornell, E. and Dillon, R.L. (2006). The respective roles of risk and decision analyses in decision support. Decision Analysis, vol. 3 (4), 220-232. Doi: 10.1287/deca.1060.0077.

Peterson, M. (2006). The precautionary principle is incoherent. Risk Analysis, vol. 26 (3), 595-601. Doi: 10.1111/j.1539-6924.2006.00781.x.

Peterson, M. (2007). The precautionary principle should not be used as a basis for decision-making. Talking point on the precautionary principle. EMBO Reports, vol. 8 (4), 305-308. Doi: 10.1038/sj.embor.7400947.

Petitti, D.B. (2000). Meta-Analysis, Decision Analysis, and Cost-Effectiveness Analysis. Oxford: Oxford University Press.

Phillips, J.J., Phillips, P.P. and Pulliam, A. (2014). Measuring ROI in Environment, Health, and Safety. Wiley Online Library. Doi: 10.1002/9781118899281.

Pritchard, C.L. (2015). Risk Management: Concepts and Guidance. $5^{\text {th }}$ ed. New York, NY: Taylor \& Francis Group.

PSAN (Petroleum Safety Authority Norway). (2018). Integrated and Unified Risk Management in the Petroleum Industry. Retrieved from https://www.ptil.no/contentassets/8d93722526cb4c57a5068e680be90a7b/risikos tyring-2018-engelsk.pdf. Accessed 21.02.2020.

Rasmussen, J. (1997). Risk management in a dynamic society: a modelling problem. Safety Science, vol. 27 (2/3), 183-213. Doi: 10.1016/S0925-7535(97)00052-0.

Rausand, M. (2011). Risk Assessment: Theory, Methods, and Applications. Hoboken, NJ: Wiley.

Renn, O. (2008). Risk Governance: Coping with Uncertainty in a Complex World. London, UK: Earthscan.

Robinson, L.A. and Hammitt, J.K. (2011). Behavioral economics and the conduct of benefit-cost analysis: towards principles and standards. Journal of Benefit-Cost Analysis, vol. 2 (2), 1-51. Doi: 10.2202/2152-2812.1059.

Robinson, L.A., Hammitt, J.K. and O'Keeffe, L. (2019). Valuing mortality risk reductions in global benefit-cost analysis. Journal of Benefit-Cost Analysis, vol. 10 (S1), 15 - 50. Doi: 10.1017/bca.2018.26.

Rosa, E.A. (1998). Metatheoretical foundations for post-normal risk. Journal of Risk Research, vol. 1 (1), 15-44. Doi: doi.org/10.1080/136698798377303.

Ross, S.A., Westerfield, R.W., Jaffe, J.F. and Jordan, B.D. (2011). Core Principles and Applications of Corporate Finance: Global Edition. $3^{\text {rd }}$ ed. New York: McGrawHill /Irwin.

Rowley, J. (2007). The wisdom hierarchy: representation of the DIKW hierarchy. Journal of Information Science, vol. 33 (2), 163-180. Doi: $10.1177 / 0165551506070706$. 
Ruud, S. and Mikkelsen, Å. (2008). Risk-based rules for crane safety systems. Reliability Engineering \& System Safety, vol. 93, 1369-1376. Doi: 10.1016/j.ress.2007.08.004.

Sagberg, F., Fosser, S., and Sætermo, I.F. (1997). An investigation of behavioural adaptation to airbags and antilock brakes among taxi drivers. Accident Analysis and Prevention, vol. 29 (3), 293-302. Doi: 10.1016/S0001-4575(96)00083-8.

Sandøy, M., Aven, T. and Ford, D. (2005). On integrating risk perspectives in project management. Risk Management, vol. 7, 7-21. Doi: 10.1057/palgrave.rm.8240224.

Schofield, S. (1998). Offshore QRA and the ALARP principle. Reliability Engineering \& System Safety, vol. 61 (1-2), 31-37. Doi: 10.1016/S0951-8320(97)00062-8.

Selvik, J.T. and Abrahamsen, E.B. (2020). How to achieve dynamic decision principles for maintenance planning of safety critical equipment in the oil and gas industry, in Engemann, K.J. and Abrahamsen, E.B. (Eds.) Safety Risk Management: Integrating Economic and Safety Perspectives, 125-140. Berlin, Germany: Walter de Gruyter. Doi: 10.1515/9783110638189-008.

Senge, P.M. (1990). The Fifth Discipline: The Art and Practice of the Learning Organization. New York: Doubleday.

Society for Risk Analysis (SRA). (2015). Risk Analysis Foundations. Retrieved from www.sra.org/sites/default/files/pdf/FoundationsMay7-2015-sent-x.pdf. Accessed 18.02.2020.

Society for Risk Analysis (SRA). (2018a). Society for Risk Analysis: Fundamental Principles. Retrieved from https://www.sra.org/sites/default/files/pdf/SRA\%20Fundamental\%20Principles \%20-\%20R2.pdf. Accessed 24.02.20.

Society for Risk Analysis (SRA). (2018b). Society for Risk Analysis Glossary. Retrieved from www.sra.org/sites/default/files/pdf/SRA\%20Glossary\%20\%20FINAL.pdf. Accessed 18.02.2020.

Sonnenreich, W., Albanese, J. and Stout, B. (2006). Return on security investment (ROSI): a practical quantitative model. Journal of Research and Practice in Information Technology, vol. 38 (1).

St Pierre, M., Hofinger, G., Buerschaper, C. and Simon, R. (2011). Crisis Management in Acute Care Settings: Human Factors, Team Psychology, and Patient Safety in a High Stakes Environment. $2^{\text {nd }}$ ed. Berlin: Springer.

Stirling, A. (1999). Risk at a turning point? Journal of Environmental Medicine, vol. 1 (3), 119-126. Doi: 10.1002/1099-1301(199907/09)1:3<119::AIDJEM20>3.0.CO;2-K.

Sørskår, L.I.K. (2018). Contributions to Effective Risk Management: On the Use of Safety Principles, Economic Tools and Safety Climate Instruments. PhD Thesis, University of Stavanger, Faculty of Science and Technology, Stavanger, Norway. 
Sørskår, L.I.K. and Abrahamsen, E.B. (2017). On how to manage uncertainty when considering regulatory HSE interventions. EURO Journal on Decision Processes, vol. 5, 97-116. Doi: 10.1007/s40070-017-0073-0.

Sørskår, L.I.K., Abrahamsen, E.B. and Abrahamsen, H.B. (2019). On the use of economic evaluation of new technology in helicopter emergency medical services. International Journal of Business Continuity and Risk Management, vol. 9 (1), 1-23. Doi: 10.1504/IJBCRM.2019.10016930.

Talarico, L. and Reniers, G. (2016). Risk-informed decision making of safety investments by using the disproportion factor. Process Safety and Environmental Protection, vol. 100, 117-130. Doi: 10.1016/j.psep.2016.01.003.

Tappura, S., Sievänen, M., Heikkilä, J., Jussila, A. and Nenonen N. (2015). A management accounting perspective on safety. Safety Science, vol. 71 (part B), 151-159. 10.1016/j.ssci.2014.01.011.

Tversky, A. and Kahneman, D. (1992). Advances in prospect theory: cumulative representation of uncertainty. Journal of Risk and Uncertainty, vol. 5, 297-323. Doi: 10.1007/BF00122574.

Van der Sluijs, J.P., Craye, M., Funtowicz, S., Kloprogge, P., Ravetz, J. and Risbey, J. (2005). Combining quantitative and qualitative measures of uncertainty in modelbased environmental assessment: the NUSAP system. Risk Analysis, vol. 25 (2), 481-492. Doi: 10.1111/j.1539-6924.2005.00604.x.

van der Sluijs, J.P., Petersen, A.C., Janssen, P.H.M., Risbey, J.S. and Ravetz, J.R. (2008). Exploring the quality of evidence for complex and contested policy decisions. Environmental Research Letters, vol. 3 (2). Doi: 10.1088/17489326/3/2/024008.

Varian, H.R. (1999). Intermediate Microeconomics: A Modern Approach. $5^{\text {th }}$ ed. New York: W. W. Norton and Company.

Vesely, W.E. (1999). Principles of resource-effectiveness and regulatory-effectiveness for risk-informed applications: reducing burdens by improving effectiveness. Reliability Engineering \& System Safety, vol. 63 (3), 283-292. Doi: 10.1016/S0951-8320(98)00044-1.

Viscusi, W.K. (1993). The value of risk to life and health. Journal of Economic Literature, vol. 31 (4), 1912-1946.

Viscusi, W.K., Huber, J. and Bell, J. (2019). Responsible precautions for uncertain environmental risks. Journal of Benefit-Cost Analysis, vol. 10 (2), 296-315. Doi: 10.1017/bca.2019.14.

von Neumann, J. and Morgenstern, O. (1944). Theory of Games and Economic Behavior. Princeton: Princeton University Press.

Vrolix, K. (2006). Behavioural Adaptation, Risk Compensation, Risk Homeostasis and Moral Hazards in Traffic Safety; Literature Review. RA-2006-95. Steunpunt Verkeersveiligheid, September 2006. 
Wakker, P., Erev, I. and Weber, E.U. (1994). Comonotonic independence: the critical test between classical and rank-dependent utility theories. Journal of Risk and Uncertainty, vol. 9, 195-230. Doi: 10.1007/BF01064200.

Walls, M.R. (2004). Combining decision analysis and portfolio management to improve project selection in the exploration and production firm. Journal of Petroleum Science and Engineering, vol. 44, 55-65. Doi: 10.1016/j.petrol.2004.02.005.

Watkiss, P., Hunt, A., Blyth, W. and Dyszynski, J. (2015). The use of new economic decision support tools for adaptation assessment: a review of methods and applications, towards guidance on applicability. Climate Change, vol. 132 (3), 401-416. Doi: 10.1007/s10584-014-1250-9.

Watson, S.R. (1994). The meaning of probability in probabilistic safety analysis. Reliability Engineering and System Safety, vol. 45 (3), 261-269. Doi: 10.1016/0951-8320(94)90142-2.

Watson, S.R. and Buede, D.M. (1987). Decision Synthesis: The Principles and Practice of Decision Analysis. Cambridge, NY: Cambridge University Press.

Whittingham, R.B. (2008). Preventing Corporate Accidents: An Ethical Approach. Oxford, UK: Elsevier Ltd.

Wiencke, H.S., Aven, T. and Hagen, J. (2006). A framework for selection of methodology for risk and vulnerability assessments of infrastructures depending on information and technology. Safety and Reliability for Managing Risk: Proceedings of the 15th European Safety and Reliability Conference (ESREL 2006), 2297-2304. London, UK: CRC Press.

Yoon, H., Lee, H. and Moon, L. (2000). Quantitative business decision-making for the investment of preventing safety accidents in chemical plants. Computers \& Chemical Engineering, vol. 24 (2-7), 1037-1041. Doi: 10.1016/S00981354(00)00531-7. 
Part II 



\section{Paper I}

On the importance of systems thinking when using the ALARP principle for risk management

Authors: Henrik Langdalen, Eirik B. Abrahamsen and Jon T. Selvik

Submitted for possible publication in Reliability Engineering \& System Safety

This paper is not included in Brage for copyright reasons. 



\section{Paper II}

A new framework to identify hidden assumptions in the background knowledge of a risk assessment

Authors: Henrik Langdalen, Eirik B. Abrahamsen and Håkon B. Abrahamsen

Published in Reliability Engineering \& System Safety, vol. 200, 2020. Doi: 10.1016/j.ress.2020.106909

Earlier version of the paper: "A systems approach to identify hidden assumptions in the background knowledge. In: Proceedings of the $29^{\text {th }}$ European Safety and Reliability Conference, ESREL 2019, 1447-1456. Research Publishing Services." 



\title{
A New Framework To Idenitfy And Assess Hidden Assumptions In The Background Knowledge Of A Risk Assessment
}

\author{
Henrik Langdalen $^{\mathrm{a}, *}$, Eirik Bjorheim Abrahamsen ${ }^{\mathrm{a}}$, Håkon Bjorheim Abrahamsen ${ }^{\mathrm{a}, \mathrm{b}}$ \\ ${ }^{a}$ University of Stavanger, Department of Safety, Economics and Planning, P.O. Box 8600 Forus, 4036 Stavanger, Norway \\ ${ }^{\mathrm{b}}$ Stavanger University Hospital, Department of Anaesthesiology and Intensive Care, Stavanger, Norway
}

\section{A R T I C L E I N F O}

\section{Keywords:}

Risk assessment

Background knowledge

Quality

Assumptions

Systems approach

SEIPS

\begin{abstract}
A B S T R A C T
A risk assessment has a more or less subjective nature, as the analyst needs to make assumptions, analyse data, use models, and so on, to produce risk-related knowledge of the phenomena of interest. This background knowledge that forms the foundation of a risk assessment can be more or less strong, implying that it needs to be taken into consideration when describing and communicating risks. To meet this challenge, different methods have been developed to evaluate and inform the decision-maker about the strength of the background knowledge. For all these methods to be fully informative, the content of the background knowledge needs to be of good quality, covering, for example, all the relevant assumptions. To identify all the relevant assumptions, however, is not a trivial task, and the risk of missing assumptions increases with the complexity of the situation of interest. Hidden assumptions, which are not considered or identified, may induce false confidence in the risk assessment, its results and recommendations. This paper suggests a framework, using a systems approach, to identify and assess the background knowledge, as a means to reduce the risk of missing critical knowledge and obtain a more complete background knowledge, on which risk can be assessed.
\end{abstract}

\section{Introduction}

If we are to study risk of real-life systems and activities, such as offshore installations or emergency medical services, the assessments will inevitably be more or less conditional on our knowledge (justified beliefs), which is often formulated as assumptions [14], founded on data, models, information, and so on [39]. The fact is that a risk assessment is subjective by nature $[16,47]$, which implies that the background knowledge, $\mathrm{K}$, on which a risk assessment is based, needs to be taken into consideration when describing and communicating risk $[8,46]$. By simply addressing the conditional risk description, all the relevant uncertainties are not properly reflected [16], as the knowledge can be more or less strong [5] and uncertainties can be hidden within it, such as assumptions that turn out to be wrong [71]. To meet these challenges and inform the decision-maker of the foundation of the risk assessment, different approaches have been developed over recent decades to consider and reflect the strength of the background knowledge (e.g., [5,8,39,46,56,90]).

A prerequisite for all these methods to be fully informative is that the content of the background knowledge is of high quality, covering, for example, all the relevant assumptions. To identify all the relevant and critical assumptions, however, is not always straightforward, especially if the situation of interest is complex $[53,87]$. Take the case of evaluating the background knowledge associated with a risk assessment. Following common practice, the analyst identifies, inter alia, a list of assumptions and evaluates the extent to which they are reasonable. The more reasonable the assumptions are, the stronger is the judged strength of knowledge [39]. But what if this knowledge only includes a fraction of the relevant assumptions? The consequence is incomplete background knowledge, which hampers risk management and decision-making and potentially leads to false confidence in the produced risk description and level of safety [17]. The issue is that the analyst might be unaware that crucial assumptions are missing.

In other words, it is not always sufficient just to have a sound methodology to evaluate the strength of the knowledge. In many situations, there is also a need to assist the analyst in identifying the critical and relevant assumptions, to obtain more complete background knowledge. Here, assumptions are understood as fixed conditions/inputs that underlie the risk assessment but which are acknowledged to have the potential to deviate [20]. The hidden assumptions are then understood as the ones not identified (i.e. missed) by the analyst. Consequently, they are not included in the analysis and therefore not presented to the decision-makers. Multiple reasons can be seen as factors for not having identified the hidden assumptions. Amongst them,

\footnotetext{
* Corresponding author.

E-mail addresses: henrik.langdalen@uis.no (H. Langdalen), eirik.b.abrahamsen@uis.no (E.B. Abrahamsen), hakon.b.abrahamsen@uis.no (H.B. Abrahamsen).
} 
the paper particularly addresses the assumptions that are made implicitly by the analyst, in the sense that the analyst is not aware of them, or the ones missed as a result of lack of understanding of the phenomenon of interest, for example that relevant interactions are ignored. The assumptions are subjective beliefs, expectations or considerations about some unknown aspects (in a broad sense) related to the real system of interest. The challenge is therefore not to identify assumptions per se but to identify the unknown aspects of the real world that we want to make fixed in the assessment. We refer to these unknown aspects as knowledge elements, which have a role to play in the background knowledge.

Although there are a few methods that address how to identify assumptions in certain situations (e.g., [32,59]), there is, to the extent of our knowledge, no systematic framework for identifying and assessing the knowledge elements that contribute to obtaining good-quality background knowledge in a risk assessment context. Perfect knowledge is obviously unachievable in any practical setting, but it does not negate the goal of searching for more complete knowledge [59]. Another practical problem is that it is not feasible to consider all possible knowledge elements; thus, the analyst must limit the identification and assessment of knowledge, to some extent. However, a more or less arbitrary approach to these tasks does not appear to be the optimal solution [87].

In this paper, we suggest a framework that takes a systems approach to identify and assess relevant knowledge elements for a risk assessment, which assists the risk analyst in obtaining a good-quality background knowledge, reduces the arbitrariness of how the identification is carried out and reduces the risk of missing critical knowledge elements. In the safety and risk domains, there is a significant number of system approaches that could be applied, ranging from linear thinking of accidents as chains of events (e.g., $[18,19,62,75]$ ) to consideration of the dynamic interactions (e.g., $[26,48,51,54,58,59,61,73])$. But, as our goal is to develop a framework to identify and assess knowledge elements rather than accident scenarios and hazards, the systems engineering initiative for patient safety (SEIPS) by Carayon et al. [26] seems to be promising (see, [57]). The SEIPS model is relatively easy to use and suitable for most systems and activities, as it forms a general basis for identifying and describing system components and interactions. In addition, the model provides a starting point to evaluate how critical the identified knowledge elements are with respect to the risk assessment; thus, the framework is also a means to increase the trustworthiness of the risk assessment and inform the decision-maker about the quality and uncertainty of the background knowledge [87]. Although the suggested framework can inform the decision-makers about the knowledge, which is an important dimension of risk [16], it is also a means to provide information on which the other system models can be based, such as the Workgroup Occupational Risk Model (Papazoglou and Ale, 2007) or Storybuilder [18]. The key is to ensure a good knowledge base on which risk is assessed.

The remainder of the paper is organised as follows. In Section 2, we motivate the need for a systems approach to identify and assess background knowledge. Section 3 introduces the SEIPS model, which is the starting point for the framework presented in Section 4. Section 5 illustrates the framework with an example. A discussion of the framework is given in Section 6. Finally, in Section 7, we make some concluding remarks.

\section{Motivativing the need to assist the risk analyst}

To motivate the need for a framework that can assist the risk analyst in mapping and assessing knowledge elements, parts of a risk assessment performed by Eidesen et al. [36] will be used. The case of interest is a medical procedure called tracheotomy, which is used to secure the airway of critically ill patients that require ventilator support. In simple terms, the procedure consists of making an incision on the frontal aspect of the patient's neck, where a tube is inserted, allowing the patient to breathe without the use of mouth or nose. Traditionally, surgeons have performed this type of procedure, but an increasing number are now being performed at the bedside in the intensive care unit (ICU), using a special technique called percutaneous dilatational tracheotomy (PDT). The experience from the Norwegian ICUs, at least at the time when Eidesen and her colleagues conducted their study, indicated the potential for serious complications and negative patient outcomes related to PDT [86]. This resulted in a discussion among experts about whether PDT should be the preferred technique in cases where tracheotomy is deemed necessary [36]. One way to contribute to the discussion is by a risk assessment, which was carried out in Eidesen et al. [36], aiming to produce risk-related knowledge in respect of performing a PDT procedure in the ICU.

In light of the premises outlined in Section 1, proper treatment and communication of risk and uncertainties related to the PDT procedure is conditional on the background knowledge being taken into account. The risk assessment in Eidesen et al. [36] is in compliance with this understanding, as the background knowledge was assessed in an apparently comprehensive manner. For example, 12 years of data on tracheotomy practice at the Stavanger University Hospital's ICU were collected, analysed and evaluated. In addition, a series of interviews with attending physicians or managers at 30 Norwegian ICUs had been conducted (see, [86]), which provided both general and specific knowledge. All the available information was structured and evaluated to form the background knowledge, on which the risk was assessed. The identified background knowledge in Eidesen et al. [36] is presented in Figure 1.

More specifically, the knowledge assessment indicated three components of importance: the physician, the patient and the system. For each component, several associated aspects (i.e. knowledge elements) were identified, each with its own potential to affect the real procedure and, therefore, also the risk assessment. This knowledge, $\mathrm{K}$, and its strength explicitly inform the decision-makers about the foundation of the risk assessment results and recommendations [16] and implicitly affect the decisions. But does the background knowledge, $\mathrm{K}$, in Figure 1 include and express all the relevant knowledge elements for this particular case?

The ICU is a sociotechnical system of interdisciplinary character, with high stress, high values at stake, intense time pressure, a myriad of decisions and shifting clinical situations [37,64], indicating that it is unlikely that all the relevant background knowledge is revealed by the consideration of three single components in isolation. The interactions between the system components clearly have a role to play. For example, the physician performs a PDT procedure in a certain physical environment that is likely to cause fatigue or stress [84]. If the mental or physical condition of the physician turns out to be lower than normal, which we have interpret to be the state implicitly assumed in Eidesen et al. [36], the risk assessment does not fully reflect the situation of interest. Another example of missed knowledge in this case is that the work environment could lead to contemporary disorders or interruptions, possibly affecting the procedure if they occur. The knowledge aspects depicted in Figure 1, such as a physician's level of training and the available equipment, cannot be viewed solely in isolation, as the interactions are also relevant for the real case of interest and, therefore, the associated risk assessment.

We are concerned that important information has been overlooked as a result of hidden assumptions of which the analyst is unaware or difficulties in identifying the relevant knowledge. These concerns are not particularly related to the PDT case but to (almost) all risk assessments, especially those concerning sociotechnical systems. It is, however, difficult to capture all the relevant background knowledge in a risk assessment context, and there is often a veil of arbitrariness surrounding the mapping of background knowledge, which stems from the subjective nature of this process. By acknowledging this, it is reasonable to call for a more systematic approach to identify the knowledge elements, especially those generated more or less by subjective reasoning, such as assumptions [15]. 


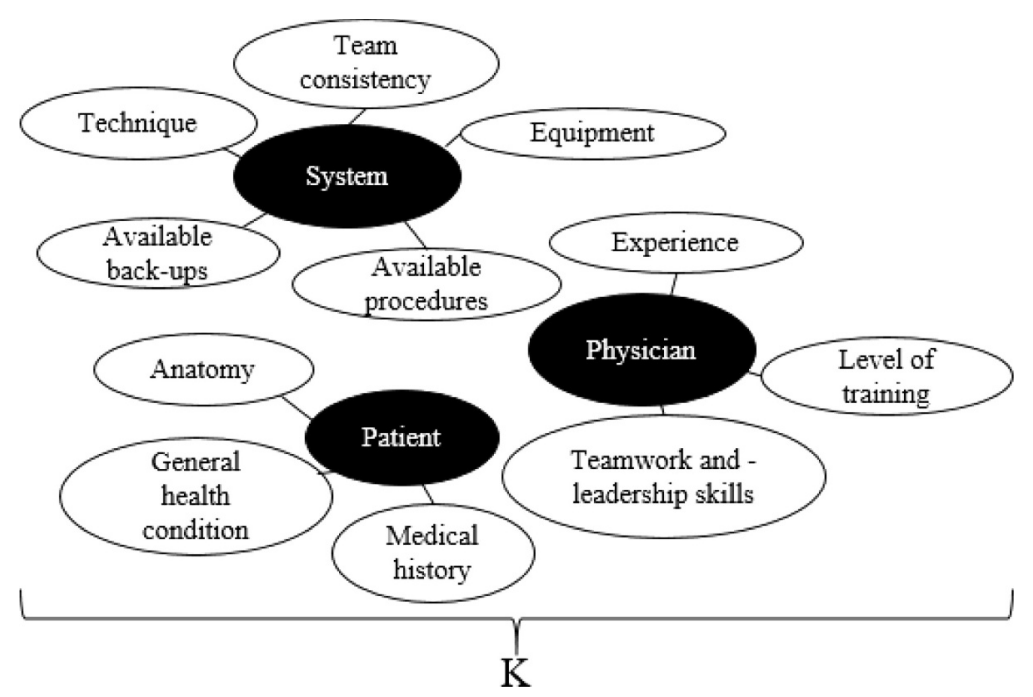

Figure 1. An overview of the knowledge on which the risk related to the PDT procedure was assessed. Based on: Eidesen et al. [36].

A general approach that guides the analyst in mapping the background knowledge appears to be useful and needed. Such an approach must take a holistic perspective on the system of interest, to capture both single components and interactions, given that many contemporary systems have sociotechnical features, which are characterised by their continuously interacting and influencing components $[31,55]$. In addition, the approach should explicitly assist the analyst, by pointing out where to look for knowledge, using simple generic components relevant for any system of interest. One issue, however, is that in theory an infinite number of knowledge elements can be embedded in a particular system, not all of which are critical for the reallife situation or risk assessment. It is therefore necessary to distinguish critical from non-critical knowledge elements, to inform the decisionmakers about knowledge elements that might require further attention. Although a systematic approach to search for assumptions in the background knowledge is no guarantee that important knowledge will be missed, it is likely to reduce the risk of it happening.

\section{The systems engineering initiative for patient safety}

On these premises, an attractive tool for identifying the relevant knowledge elements of a system of interest is the systems engineering initiative for patient safety (SEIPS). The SEIPS model, developed by Carayon et al. [26], is custom-made to describe and understand the sociotechnical features of healthcare systems [27,50]. Despite the model's healthcare orientation, its components are general and suitable for most systems. The model, which is illustrated in Figure 2, builds on Donabedian's [33] structure-process-outcome model and consists of three dynamically influencing parts.

To illustrate, the SEIPS model components can be described in the case of, say, an air traffic control system. The person, who can be an individual or a group of individuals, such as a traffic controller or an organisational unit, respectively, is at the centre of the work system, performing certain tasks, which can be considered as actions, for example communicating with the aircraft crew. The tasks are performed within a physical environment, such as a control centre, supported by different technologies and tools, for example software simulators. All the tasks are subject to the organisational conditions such as rules and procedures. In addition, the external environment provides a boundary for the other five components, through resources, standards, legislation, and so on. The work system influences the processes, which are a series of steps [26], for example to direct the runway traffic, generating the outcomes, such as safe and effective flow of runway traffic. Finally, feedback loops are present in the model, to promote learning, knowledge sharing and improvement [27].

Although the SEIPS model requires all the relevant components within a work system to be described individually, it forms a framework which emphasises the interactions between the components, in order to provide a deeper and broader understanding of how they influence each other, the processes and outcomes [27]. If any changes occur within a work system, for example that a new technology is introduced, they have possible positive or negative effects on the other work system components, processes and outcomes (see, e.g., [87]). The SEIPS model can identify such implications, which is why the SEIPS model is attractive for the purpose of identifying and structuring relevant knowledge elements, on which a risk assessment can be based.

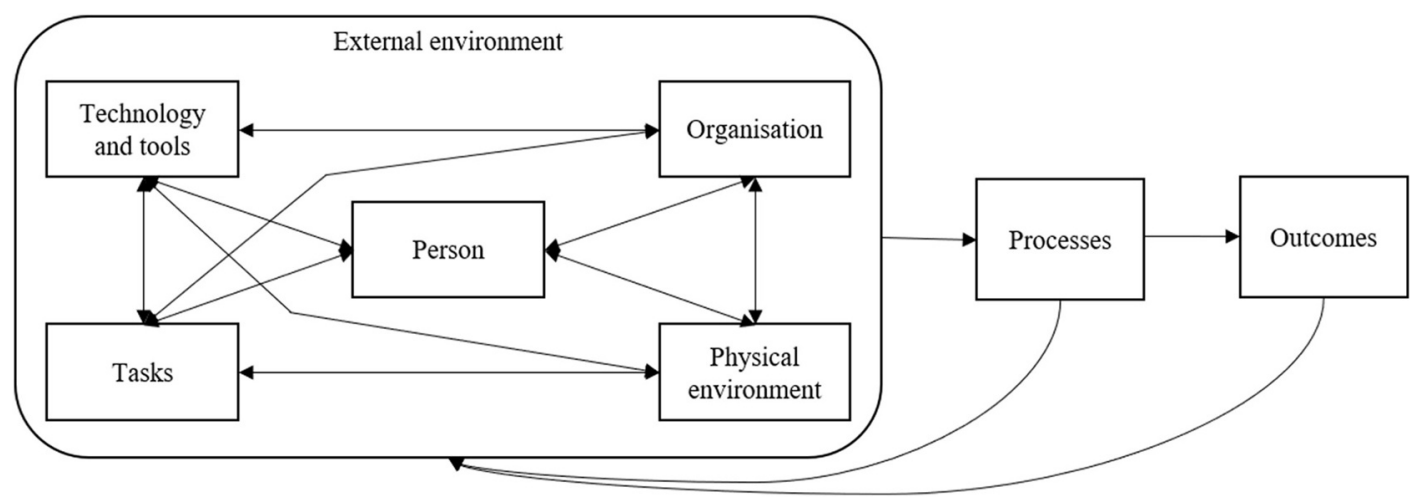

Figure 2. The SEIPS model. Based on: Carayon et al. [27]. 
Identify knowledge elements with the SEIPS model

\begin{tabular}{|c|c|c|}
\hline $\begin{array}{c}\text { Strength of } \\
\text { knowledge that } \\
\text { guided the } \\
\text { identification }\end{array}$ & $\begin{array}{c}\text { Impact of the } \\
\text { knowledge } \\
\text { element on the } \\
\text { risk assessment }\end{array}$ & $\begin{array}{c}\text { Uncertainty of } \\
\text { the knowledge } \\
\text { element's impact } \\
\text { on the risk } \\
\text { assessment }\end{array}$ \\
\hline Treatment of the critical knowledge elements
\end{tabular}

Figure 3. The workflow of the suggested framework.

The key is to remember that the work system components are networked, mutually interacting with and influencing each other. But, as the processes and outcomes are thought to be shaped by all the interactions in the work system at the same time, it is in theory possible that any number of work system components can interact with any other simultaneously [50]. The result is an unmanageable situation, in which there are too many interactions associated with a particular process of interest. To overcome this issue, Holden et al. [50] suggest applying the concept of configuration. The idea of configuration is to limit all the possible interactions which can occur in the work system to a subset of them, which includes only those relevant for the particular process of interest [50]. Building a configurative model is not straightforward, but, if performed correctly by qualified analysts with knowledge of the situation on interest, the SEIPS model can assist the analyst in scrutinising the system components and interactions, in order to identify knowledge elements that are not intuitively and easily discovered. One issue, which was highlighted by one reviewer of an earlier version of the paper, is that such simplifications can lead to missed assumptions. This is true and important to acknowledge. However, we believe that simplifications will always be more or less required when using the tools available in a risk assessment; for example, a model is a simplified representation of reality [6]. This fact is not an argument against the use of configurative models and the SEIPS, but rather a part of the motivation to develop a framework for identifying the relevant background knowledge, such that we foster increased understanding of what knowledge the risk analysis considers and what it does not take into account.

\section{The framework}

This section introduces the suggested framework, which intends to guide the analyst in identifying and assessing relevant background knowledge to support a risk assessment. The foundation of the framework stems from the SEIPS model and its ability to identify knowledge elements, which have a role to play in the background knowledge. In such matters, the framework aims to reduce the risk of missing critical assumptions (knowledge elements). Depending on the characteristics of the system in focus, the number of identified knowledge elements might be significant, resulting in an unmanageable situation, where the many identified knowledge elements provide limited practical decision support, possibly concealing those which need further treatment. It is therefore recommended to distinguish the critical knowledge elements from the non-critical.

Here, the meaning of criticality is influenced by the ones in the literature on critical infrastructure, in which it is commonly referred to as an incapacity or destruction which leads to significant consequences $[21,94]$. In light of this, we consider a critical knowledge element to be an element of the background knowledge related to the phenomena of interest, where its incapacity or destruction leads to significant consequences, for both the real case of interest and the risk assessment. To determine whether a knowledge element is critical, we evaluate its foundation (background knowledge), implication for the risk assessment and associated uncertainty. The background knowledge, on which the knowledge element is identified, is reasonable to consider in this context, as an element can be related to more or less strong knowledge. The impact of a knowledge element on the risk assessment should also be evaluated, as some elements are likely to be of greater importance for the risk assessment than others. Finally, we must take into account that the impact is uncertain, and it is informative to know whether the evaluated impact can be considered to give a good or poor prediction of the real impact. These three evaluations provide information about the uncertainties and quality of the knowledge elements, making the framework a means to increase the trustworthiness of the risk assessment. From the list of critical knowledge elements, the analyst can also study how to best treat and control them. The main parts of the framework are illustrated in Figure 3.

Before the framework can be applied, however, it is paramount that the analyst has a good understanding of the risk assessment context, which is established in a planning phase [7]. This involves, amongst other things, clarifying and specifying the decisions to be supported by the risk assessment and developing the objectives of the assessment [11]. Without a clear and unambiguous context, the analyst will struggle to understand which knowledge elements are relevant and critical for a particular case of interest. In the following, we discuss each step of the framework.

\subsection{Identification of the Knowledge Elements}

The first step in the framework is to identify relevant knowledge elements using the SEIPS model, which requires it to be customised to the risk assessment context. Only then can the analyst use its generic components as guidance for identifying those knowledge elements which are relevant to the real processes and the risk assessment. In theory, however, any number of work system components can interact with any other at the same time [50], resulting in a situation with too many (irrelevant) interactions. To overcome this issue, we apply the concept of configuration, which is similar to our idea of identifying the relevant knowledge elements. We consider the configuration to be a two-step procedure, in which we first focus on single components and then the interactions.

The single components are identified and described using the SEIPS model and its generic components as guidance, that is, to identify and describe the person, tasks, physical environment, technologies and tools, organisation, and external environment, associated with the specified processes and outcomes. Based on human factors principles (e.g., [34]), a natural starting point is the person component at the centre of the work system, followed by the other work system components, systematically. The components should be accompanied by descriptions of their characteristics (see, e.g., [26]).

Following the single component characterisations, the analyst has a basis to identify interactions among the components that are relevant for the processes. This is more challenging and time-consuming than the single component considerations, but it is also likely to be more rewarding, given that the risk of missing knowledge elements is greater among the interactions [87]. Different approaches are possible [50], but we recommend starting by pairing two and two components and their characteristics, for example the person's level of training and the tasks' complexity, then proceeding with person and physical environment, and so forth. Depending on the scope of the risk assessment, the analyst might also consider the interactions between three or more components.

The identified components and interactions (i.e. the configurative model) are the basis for identifying relevant knowledge elements, which are believed to influence the processes of interest and/or risk assessment. To illustrate, consider the case of applying the SEIPS model 
to identify knowledge elements for a risk assessment related to a medical procedure. First, the analyst directs his attention to the person component, leading to the physician performing the procedure being identified and described. Secondly, the analyst focuses on the task component, leading to an identification and description of multiple actions (e.g., communication, decision-making, teamwork). For simplicity, we limit this example to those two components. The physician is characterised, among others, by his experience and training. The levels of these two attributes have the potential to influence the process and, therefore, should be considered and explicitly listed as knowledge elements. The link between the person and tasks is obvious, but the key is to remember that this interaction is networked with the other components and must be evaluated from a systems perspective; how will the physician perform the tasks, given the presence of the other work system components? Depending on the system of interest, the physician can experience fatigue or stress, which will affect his performance. These are other examples of knowledge elements, potentially affecting the process, and, therefore, have a role to play in the background knowledge.

The SEIPS model assists the analyst in taking a systematic and holistic approach to identify knowledge elements, which is likely to reduce the risk of missing relevant knowledge $[57,87]$. We suggest that the identified knowledge elements are listed and presented along with descriptions of the elements, as well as a reflection of the source (i.e. expert judgments, assumptions, data, and models) that guided the identification.

\subsection{Assessment of the Knowledge Elements}

Despite the fact that all the identified knowledge elements are believed to have an effect on the processes of interest and the risk assessment, it is likely that some of them are more critical than others. Considerations of the criticality should be made to increase the trustworthiness of the risk assessment and to fully inform the decisionmaker about the uncertainties in the background knowledge. In addition, highlighting the critical knowledge elements means that the decision-maker obtains a basis for understanding which knowledge elements require further treatment and how to efficiently respond to the threats ([13], p.136). The three aspects of criticality will be discussed in the following.

\subsubsection{Evaluation of the Strength of Knowledge}

Knowing whether it was expert judgments, data, models, assumptions or, most likely, a combination of the four, which resulted in a particular knowledge element being identified is informative for the decision-makers $[6,46]$. More important is knowing whether the knowledge elements constitute uncertainty, in the sense that they might be based on poor or insufficient knowledge. This relates to the purpose of this step in the framework: to reveal any weak or insufficient knowledge elements, which might demand further treatment, as they impose uncertainties on the risk assessment.

The arguments for taking the strength of the knowledge, which guided the identification of knowledge elements, into account, follow those presented in Section 1. That is, the knowledge can be more or less strong, and uncertainties can be hidden within it. To evaluate the strength of knowledge (SoK) associated with the identified knowledge elements, we suggest using the qualitative categorisation by Flage and Aven [39], but other methods exist (e.g., $[46,90]$ ). The crude SoK categorisation is presented in Table 1. In a stringent form, the knowledge elements are said to be based on strong knowledge if all the aspects (whenever they are applicable) in the left column of Table 1 are met, and weak knowledge if at least one of the aspects in the right column is satisfied [6]. Cases in between strong and weak are said to be medium SoK $[6,39]$. The evaluation of SoK will be case-specific and subject to the analyst's judgments, where each of the four aspects related to weak and strong SoK can take on a weak, medium or strong score [41]. The SoK can be represented as an overall evaluation of the four aspects (see, [6]) or by separately highlighting the SoK for each of the four aspects (see, [46]).

\subsubsection{Evaluation of the Impact}

Although an assumption that is formulated on the basis of a weaker knowledge element is often considered a (strong) simplification, it can be justified if the knowledge element has a negligible impact on the risk assessment [42]. All the identified knowledge elements are assumedly affecting the risk assessment but most likely to varying degrees, in the sense that some knowledge elements are of greater importance for the risk assessment than others. The purpose of this step is to gain such understanding, emphasising that the analyst must address what effects the knowledge elements have on the risk assessment. Traditionally, sensitivity analysis is preferred in such cases, as it can be understood as the "study of the relationships between information flowing in and out of a model" [82]. However, given that many of the identified knowledge elements will have a qualitative nature without a mathematical relationship to the risk assessment, it is not straightforward to use sensitivity analysis as a standard tool [83]. Please note that sensitivity analysis is not the same as uncertainty analysis [10,82].

Whenever a knowledge element relates to an observable quantity or direct input to a mathematical model, its value and impact on risk can be expressed quantitatively. A common approach is to use predictors, for example expected values, to represent the quantities of interest [87], but such metrics have limitations [1]. An alternative is to represent the quantities by prediction intervals (credibility intervals for model parameters), reflecting that we are, say, $90 \%$ certain that the unknown quantity will be in the interval $[\mathrm{a}, \mathrm{b}]$, i.e. $\mathrm{P}(\mathrm{a} \leq \mathrm{X} \leq \mathrm{b})=0.90$ [10]. For these knowledge elements, which are direct input to mathematical models, traditional sensitivity analysis is recommended to determine the impact on the risk assessment (see, e.g., [83]).

For other knowledge elements, which are neither observable nor direct input to models, it can be meaningless, but not impossible or undesirable, as it is not economical, to assign quantitative values and use them as input in a model. If quantification is desired, however, the analyst can build a mathematical model, which links the "qualitative" knowledge elements, expressed for example by a cardinal $(0.5,1.5,2.3$ $\ldots$ ) or ordinal (low $=1$, medium $=2 \ldots$ ) scale [24], to the risk assessment. However, there are two aspects which must be considered: is such treatment of knowledge elements in line with the context of the risk assessment, and does it, in comparison to, say, a qualitative scoring of the impact, produce additional decision support. It is outside the scope of the paper to study these questions in detail, but we strongly recommend making such considerations before evaluating the impact.

Although a qualitative evaluation of the knowledge elements' impact on risk assessment does not give the comprehensive and integrated level of quantitative insight of traditional sensitivity analysis, it offers practicality and manageability, providing a sufficient impression of the knowledge elements' impact on the risk assessment [5,42]. We suggest expressing the impact qualitatively (e.g. low, medium, and high), unless traditional sensitivity analysis is believed to significantly increase the decision support or strongly desired. Consequently, it is necessary to clarify what is meant by, for example, a scoring of low, medium and high impact. A qualitative categorisation, which is frequently used in the literature (e.g., $[12,20,89])$, is the crude sensitivity classification suggested by Flage and Aven [39], which we have modified to fit our context (based on [39]):

3- High impact: Relatively small changes in the knowledge elements needed to bring about different risk assessment results and recommendations.

3- Medium impact: Relatively large changes in the knowledge elements needed to bring about different risk assessment result and recommendations.

3- Low impact: Unrealistically large changes in the knowledge elements needed to bring about a different risk picture. 
Table 1

The strength of knowledge (SoK) categorisation $[6,39]$.

\begin{tabular}{|c|c|}
\hline Strong SoK & Weak SoK \\
\hline - The assumptions made are seen as very reasonable & - The assumptions made are seen as strong simplifications \\
\hline - Large amount of reliable and valid data & - None or highly unreliable data \\
\hline - There is broad agreement among experts & - There is strong disagreement among experts \\
\hline $\begin{array}{l}\text { - The phenomena in focus are well understood; the models are known to give predictions } \\
\text { with required accuracy. }\end{array}$ & $\begin{array}{l}\text { - The phenomena in focus are poorly understood; models are non-existent or believed } \\
\text { to give poor predictions. }\end{array}$ \\
\hline
\end{tabular}

The intent of this section is not to propose a "correct" method to evaluate the impact but, rather, to highlight the importance of considering how each knowledge element can affect the risk assessment. We must emphasise that the impact evaluations and, therefore, the definitions of the qualitative categories, will be case-specific $[39,89]$. It is not our intention, or desire, that the framework should be a "blackbox", with an explicit input-output relation, but a tool for guidance and assistance on how to manage the knowledge elements. In Table 2, we have provided an example of how the analyst can summarise the impact evaluation in a clear and informative matter, by a consideration of the knowledge element, "person's level of experience"; the impact is evaluated and represented qualitatively, complemented by informative descriptions.

\subsubsection{Evaluation of the Stochastic Uncertainty}

From the previous step, each knowledge element has been evaluated in terms of its impact on the risk assessment, but the evaluated impact could be a good or poor prediction of the real (unknown) impact. To be in line with fundamental principles of risk management, such as the cautionary principle, we need to be aware of these uncertainties. Over time, system components, both social and technological, will be replaced, fail, change, be repaired, age, adapt to their surroundings, and so on [95], indicating that the associated knowledge elements' impact can vary. In other words, the evaluated impact could turn out to be wrong. This is of especial importance working with sociotechnical systems, which involve (unpredictable) human actions and components that are adaptive and dynamic by nature $[31,55]$. Conditioned on the knowledge elements' SoK and impact on risk assessment, the quality of the knowledge elements' expected impact might be a trigger for taking precautionary actions.

To reflect the evaluated impact's quality in predicting the real impact, we suggest considering the stochastic uncertainties. A qualitative measure of the stochastic uncertainty in the knowledge element's impact (i.e., low, medium or high) is considered sufficient for the scope of the paper. We therefore suggest the following criteria for evaluating the quality of the impact (based on [3]):

3- High stochastic uncertainty: The uncertainty is classified as high if the expected impact is considered to give a poor prediction of the real impact.

3- Low stochastic uncertainty: The uncertainty is classified as low if the expected impact is considered to give a good prediction of the real impact.

Medium stochastic uncertainty is then given as cases in between high and low. All these evaluations must be seen in light of the available knowledge, for example referring to the SoK from Section 4.2.1. Through these definitions, stochastic uncertainty is understood as a reflection of variation, in the sense that high (low) stochastic uncertainty is used when the population of a certain knowledge element has high (low) variation. To inform the decision-makers about the variation in the expected impact, the uncertainty can be represented next to the impact evaluation, as in Table 2.

\subsubsection{Summarising the Critical Knowledge Elements}

After the three evaluations, the results should be communicated to the decision-maker in a clear and unambiguous way, which helps to classify critical knowledge elements. Here, the challenge is to decide on which combinations of SoK, impact and uncertainty make a knowledge element critical. Is a knowledge element with, say, weak SoK, low impact and medium stochastic uncertainty more critical than another with strong SoK, high impact and medium stochastic uncertainty? We consider this to be a managerial issue, which must be seen in light of the context of the risk assessment. Following general risk management principles, however, it is intuitive that the weaker the SoK is and the greater the impact and stochastic uncertainty are, the more critical is the knowledge element for the risk assessment.

Various policies can be used to determine criticality. For example, a simplified scoring system (see, e.g., [88]) with a predetermined criterion might be sufficient, but this could also lead to a mechanistic classification of criticality, which hampers risk-informed decisionmaking. We, therefore, recommend summarising the evaluations from the previous steps, as in Table 3, in which criticality can be determined by an overall evaluation of the SoK, impact and uncertainty. In terms of being precautious, however, cases in which the SoK is evaluated to be weak might require special treatment, as the implication is that the impact and uncertainty evaluations are founded on weak knowledge. The summary informs the decision-makers on what knowledge the decision support is based, which elements that are deemed critical and how they could affect the risks. From this, the decision-makers has a basis to evaluate if the system is safe enough and to consider different types of treatment of the critical elements. This can be achieved by considering one knowledge element of the time, or by an overall impression of all the knowledge elements (e.g. a majority of critical knowledge elements might need precautionary measures such as not carrying out the activity).

\subsection{Treatment of the Critical Knowledge Elements}

A critical knowledge element is one which calls for further attention, as it brings about uncertainty and/or a possible adverse effect on the system of interest, potentially weakening the credibility of the risk

Table 2

Example of impact and uncertainty evaluation.

\begin{tabular}{|c|c|c|c|}
\hline Knowledge element & Impact & $\begin{array}{l}\text { Stochastic } \\
\text { uncertainty }\end{array}$ & Comments \\
\hline The level of experience & Medium/high & Medium & $\begin{array}{l}\text { The values of the element can be medium or high. Given the complexity of the tasks, level of experience is } \\
\text { likely to be important for the outcome. The knowledge element contributes more to uncertainty than to the } \\
\text { consequences. }\end{array}$ \\
\hline
\end{tabular}


Table 3

Example of a summary of the identified knowledge elements.

\begin{tabular}{|c|c|c|c|c|c|c|}
\hline Knowledge element & SoK & Impact & Stochastic uncertainty & Critical & Risk-reducing measure & Effects and costs \\
\hline$\# 1$ & Strong & High & Medium & Yes & Physical safety measure. & Reduces consequences. Medium costs. \\
\hline$\# 2$ & Weak & Medium & Medium & Yes & Increase the knowledge base. & No direct impact on system. Low costs. \\
\hline$\# 3$ & Medium & Low & Low & No & - & - \\
\hline
\end{tabular}

Table 4

A non-exhaustive list and description of the relevant SEIPS components for the example case. Based on: Langdalen et al. [57].

\begin{tabular}{|c|c|}
\hline System components & Descriptions and characteristics \\
\hline Person & $\begin{array}{l}\text { Physician who performs the tasks, with the following characteristics: } \\
\text { - Education, specialty (e.g., intensive, anaesthesiology, neurology), experience. } \\
\text { - Level and type of training and post-assessment of the training. } \\
\text { - Level of non-technical skills (i.e., decision-making, leadership, communication, situation awareness, teamwork, managing stress, coping with fatigue). } \\
\text { Patient, not relevant/performing any tasks in our case, but his/her characteristics are important for the outcome: Medical history, general health condition, } \\
\text { anatomy, medication, etc. }\end{array}$ \\
\hline Tasks & $\begin{array}{l}\text { Performing the tracheotomy; different steps and techniques: } \\
\text { - Communication, care coordination, decision-making, leadership, teamwork, stress, high work demand, etc. }\end{array}$ \\
\hline Technology and tools & $\begin{array}{l}\text { Perform tracheotomy with the PDT technique, requiring the following tools: } \\
\text { - Equipment (endotracheal tube, monitors, headlights/source of natural light, mechanical ventilator, bronchoscope and video screen, checklists, } \\
\text { anaesthetics, sedatives, etc.), supplies (haemostats, dilators, surgical sutures, etc.) and back-ups. }\end{array}$ \\
\hline Physical environment & $\begin{array}{l}\text { Intensive care unit, characterised by, e.g.: } \\
\text { - Noise, lighting, air quality, room hygiene, space (large enough), etc. } \\
\text { - Physical layout of the room (location of the bed, monitors, ventilator, etc.), unit (e.g., sleeping/resting facilities for on-call staff, waiting area for family) } \\
\text { and team (e.g., physician on the right side of the bed). }\end{array}$ \\
\hline Organisation & $\begin{array}{l}\text { Department/hospital level } \\
\text { - Interaction with managers, organisational support, information flow, safety culture and climate, procedures, best practice guidelines, rules, teamwork, } \\
\text { team composition, experience, etc. }\end{array}$ \\
\hline External environment & Resources, legislation, standards, new technology, duty regulations, etc. \\
\hline Processes & The PDT procedure, which is affected by all the components in the work system. \\
\hline Outcomes & Patient safety and quality of care. \\
\hline
\end{tabular}

assessment results and recommendations. The final step in the framework is to provide decision support on how to best manage the knowledge elements of potential risk-reducing measures and the implication of those measures for the system. One way to present the findings to the decision-makers is to include them in the summary of the knowledge elements, for example as in the two right-most columns of Table 3.

Which risk-reducing measures are required can be seen in light of the criticality evaluations, where the measures should, at least, aim to reduce the uncertainty and consequence of incapacity or destruction of a knowledge element, by strengthening the factors that contributed the most to its criticality. For example, the first knowledge element in Table 3 has a high impact on the risk assessment, indicating that it should be treated, for example, by implementing a physical measure to reduce the associated vulnerabilities in the system. Other risk-reducing measures could be to increase the knowledge base and understanding, as is relevant for the second knowledge element in Table 3. The critical elements are those which mostly require treatment, but we also suggest going through the non-critical elements in terms of potential surprises, unexpected or unwanted events.

An evaluation of the effects of the identified measures is recommended, since the measures might have lower than intended or unexpected negative effects on the system. Implementation of risk-reducing measures also raises concerns about costs and benefits which should be taken into consideration. It is outside the scope of this paper to say how this should be done, but alternative methods could be costbenefit analyses or the ALARP principle (see, e.g., [9]). The final task for the analyst is to ensure that all the information is presented in a clear and unambiguous way to the decision-maker for review and judgments, as it enhances the risk management and decision-making process [6]. The results can, for example, be presented by the summary in Table 3 with references to Table 2 and a list of the identified knowledge elements. See also Sørskår et al. [87] for inspiration on how to represent the findings.

\section{An example: applying the framework to support the pdt risk assessment}

In this section, we revisit the PDT case of Eidesen et al. [36], introduced in Section 2, to illustrate how the suggested framework can support the risk analyst in revealing and reducing the risk of missing critical knowledge elements. We therefore focus on the first two steps of the framework: the identification of knowledge elements (Section 4.1) and the assessment of criticality (Section 4.2). The identification step of the example is a revised version of the example presented in Langdalen et al. [57], improved by the experience of creating the initial study. Prior to operationalising the framework, however, we need to align the SEIPS model to the risk assessment context. Given that the objective of the risk assessment introduced in Section 2 is to provide risk-related knowledge of performing PDT procedures in the ICU, it is reasonable to specify the processes of interest as the PDT procedure, while limiting the outcomes to patient safety and quality of care. The SEIPS model and its components can then be used to identify knowledge elements to support the risk assessment.

\subsection{Identification of the Knowledge Elements}

The first steps of the framework are to identify and describe the components and interactions within the work system, which are relevant for the specified process and outcomes. According to the workflow described in Section 4.1, we start by identifying and describing the person component and systematically mapping all the other components. The characteristics of the components of interest are presented in Table 4. Although the framework suggests that the single component descriptions should be followed by identification and description of the relevant interactions, such as the fact that the level of experience affects the way the different tasks are performed, we have, for the sake of simplicity, not reported the list of interactions. But, based on all the characterised single components and (non-reported) interactions, we 


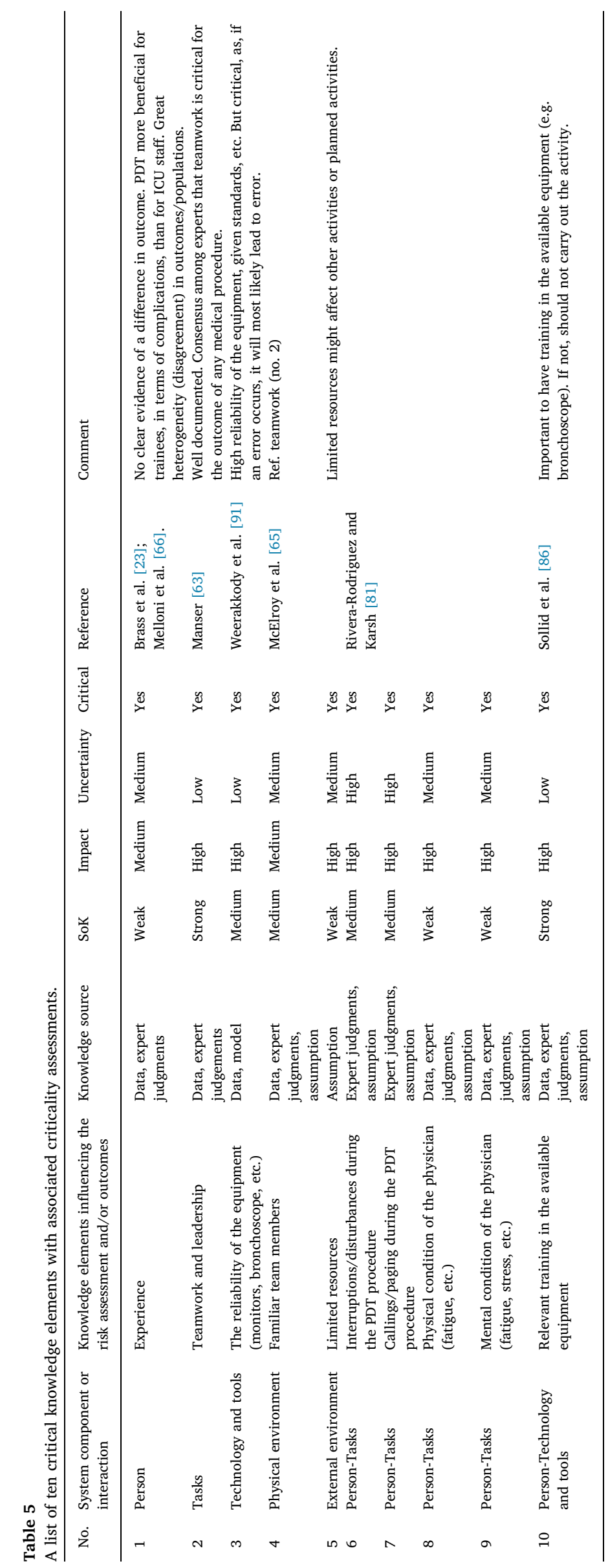


have identified numerous knowledge elements that are relevant for this particular case, which are summarised in Tables 5 and A1.

\subsection{Assessment of the Knowledge Elements}

To fully inform the decision-maker about the uncertainties and quality of the knowledge element, we proceed by evaluating the associated criticality, according to Section 4.2. For the purpose of this example, it is sufficient to qualitatively evaluate the three aspects of criticality. The knowledge that guided the identification is classified using the crude SoK classification by Flage and Aven [39], as explained in Section 4.2.1. For the impact evaluations, we follow the criteria listed in Section 4.2.2, whereas the uncertainty related to the impact is determined according to the qualitative criteria presented in Section 4.2.3. Based on the three aspects, we have made an overall judgment about each knowledge element's criticality for the risk assessment. If this had been a real-life project, we would have continued the assessment by identifying risk-reducing measures for the knowledge elements and evaluated the associated effects on the system (as discussed in Section 4.3). However, the purpose of this example is to illustrate how the suggested framework provides additional information, compared to the case of not taking a systematic and holistic approach to the knowledge identification. We therefore proceed by comparing the findings in Tables 5 and A1 with the information provided in Section 2.

\subsection{Comparing the Different Knowledge Bases}

After we have applied the SEIPS model to identify knowledge elements, it is reasonable to say that the identified knowledge in Eidesen et al. [36] was incomplete. By comparing the knowledge elements in Figure 1 and Tables 5 and A1, it is clear that the systematic and holistic approach is capable of providing a more complete and informative knowledge base. More specifically, the systems approach is able to identify interactions between the single components, identify more knowledge elements for each single component, and highlight the quality and uncertainty associated with the identified elements.

It is the ability to take the interactions into consideration that really makes the framework and SEIPS model attractive in terms of obtaining a more complete background knowledge. As an example, in Figure 1, the relevant components (physician, patient, system) are considered in isolation, such as the physician's level of training and the type of equipment that is available, but what is important for the real PDT procedure is whether the physician has training in using the available equipment (no. 10 in Table 5). The systematic and holistic approach has identified other apparently critical knowledge elements that should have been considered in the risk assessment (see Table 5). The physician's mental and physical conditions, for example, are implicitly assumed to be good in Eidesen et al. [36], implying that any physician performing a PDT procedure will neither be, nor has been during his time on-call, subject to fatigue or stress at the time of the procedure, if the risk assessment results and recommendation can be considered representative for the real case of interest. These assumptions, however, can easily be violated, given the characteristics of working in the ICU (see, [84]). As the SEIPS model assists the analyst in taking a system perspective, the risk of missing such assumptions is reduced (nos. 8 and 9, Table 5). Other critical interactions, which were ignored by the somewhat atomistic and arbitrary identification in Eidesen et al. [36], are listed in Table 5 .

Although it is the ability to identify and consider interactions that really promotes the use of the SEIPS model to map knowledge elements, the systematic and structured approach of the framework also enables the risk analyst to identify more knowledge elements related to each single component than is the case if a non-systematic approach is taken. For example, the external environment's impact on a system of interest (no. 5 in Table 5 and nos. 37 and 38 in Table A.1), is easily forgotten when working with sociotechnical systems [93]. The framework, on the other hand, will explicitly direct the analyst's focus towards the relevant system components, demanding that each component is fully understood and described; it reduces the risk of missing critical knowledge elements.

The assessment of criticality is clearly informative and ensures that the uncertainties and quality of the background knowledge are properly understood, reflected and communicated. In such matters, the framework assists the risk analyst in proper treatment of the background knowledge (e.g., [16]). The SoK, impact and uncertainty evaluations inform the decision-makers about the quality of what the risk assessment considers and represents, what the outcome expresses and the knowledge that guided the analyst. Therefore, the framework is also a means to increase the trustworthiness of the risk assessment. Finally, we must emphasise that our aim is not to criticise the work of Eidesen et al. [36] but, rather, to highlight the advantage of and need for a systematic and holistic approach to identify, structure and evaluate the background knowledge.

\section{DISCUSSION}

The fundamental idea of the paper is that, in order to map and obtain good-quality background knowledge, a systems or holistic approach, which captures both single components and system interactions, is often needed. Risk assessments will always be more or less conditional on the available background knowledge (data, information, assumptions, etc.) and it is important that this knowledge contains all the relevant elements. Making sure that the background knowledge contains all the relevant information is a challenging task. The current practice of identifying background knowledge does not appear to be the ideal solution, as it is usually a more or less arbitrary approach. The suggested framework, provides a methodological approach that contributes to this end and can be applied to assist the risk analyst in the search of relevant knowledge, on which the risk assessment can be based. This is an important issue as the quality of the background knowledge influences the risk management. The suggested framework can be used to assist the risk analysts to increase the quality of the risk analysis by improving the quality of the background knowledge and reducing the risk of missing assumptions. By presenting the results to the decision-makers, the framework can also increase the trustworthiness and understanding of the produced decision support.

We have suggested a framework which can assist the risk analyst. Firstly, the framework reduces the risk of missing critical knowledge, as it guides the analyst in the search for knowledge elements which have a role to play in the background knowledge. However, a reasonable question that needs further elaboration is why the SEIPS model, and not one of the many other system models reported in the literature, should be applied. Secondly, the framework increases the trustworthiness of the risk assessment, which is achieved by evaluating the SoK, impact and stochastic uncertainty related to the identified knowledge elements. The suggested framework, however, does not need to be applied in this depth of detail. Its application and implementation should be seen in light of the scope of the risk assessment and the uncertainty, complexity and ambiguity of the risk-related problem. We therefore also need to discuss the practical application of the suggested framework.

\subsection{Why the SEIPS model?}

The SEIPS model is, as stated in the introduction, one of many candidates with promising features for identifying knowledge elements. The reader may therefore wonder why the SEIPS model was selected over the other system models reported in the literature (e.g., $[18,19,48,51,54,58,59,61,62,69,73,75])$. First of all, we are not claiming that the SEIPS model is the only model which is applicable for mapping knowledge elements, but it is, to the extent of our knowledge and understanding, one of the most suitable models for this task with 
respect to certain aspects which we consider essential for obtaining good-quality background knowledge: (1) the model takes a systems approach and perspective, (2) the model captures both social and technological aspects, and (3) the model also captures external factors, such as economic concerns.

In many contemporary real-life systems, the complexity is high and increasing, as a result of globalisation, digitalisation and so on [34,55]. The increased complexity gives rise to previously rare and non-existent forms of risk [49,73], such as unforeseen interactions between the system components $[25,30]$. Therefore, most of the traditional approaches to systems design and safety that were considered adequate in the past are now seen as less useful [60]. It is, for example, acknowledged that, to capture the complexity of many contemporary systems, traditional root-cause analysis is unsuitable $[31,59]$. Consequently, a model which is based on linear thinking is generally not suitable to map all the relevant knowledge elements to support a risk assessment, as such models are likely to miss knowledge elements whenever interactions within a system are present (see, e.g., [87]). The SEIPS model supports this way of thinking, as it captures the interactions and interdependencies among the system components. This is what we mean when speaking of taking a systems approach, which is similar to the understanding of a systems approach within the disciplines of ergonomics and human factors (see, e.g., [34]).

We should emphasise that this does not imply that SEIPS is only applicable if the system involves non-linear and non-foreseen scenarios or that other system models that does not see non-linearity as an essential factor of complexity can be used in the framework. Tools such as Workgroup Occupational Risk Model [69] or Storybuilder [18], are examples of promising tools for identifying relevant knowledge elements. However, they are based on a different way thinking compared to the one in the suggested framework. In the suggested framework, we are concerned about the background knowledge, which is used as input data in the other tools when focusing on scenarios and accidents. The challenge with those models, is that they imply a reliance on having the input data. The SEIPS model, when applied as described in Section 4, can contribute to this end by providing relevant knowledge about the situation. Although the analysts use should use their own and other experts' experience, available literature and logic to identify scenarios [18], we believe that a more systematic approach is needed to reduce the risk of missing relevant knowledge. In addition, the framework can complement risk assessments and accident investigations when there is insufficient data about the situation of interest. For example, Bellamy et al. [18] states that determining if a centre event in a bow-tie model occurs implies a reliance on having knowledge about the barriers. It is this knowledge the suggested framework aims to identify and reveal to the decision-maker.

Which interactions we are able to identify in a system, however, is also conditional on which single components we include in the system model, as the system as an integrated whole is understood as the set of interactions between the single components [34]. A framework which is supposed to reduce the risk of missing knowledge needs to take the relevant single components into account. The number of possible system components that can be relevant for any risk assessments is almost infinite, and we need to generalise it to a manageable number. In the human factors discipline, for example, system components are commonly divided into humans and their environment, understood as other humans and so-called human-made artefacts, such as workplaces, tools, technologies, tasks, products, organisational procedures, and so on $[34,92]$. This is similar to the common understanding of sociotechnical systems, which can be defined as the influencing combination of "humans, machines, environments, work activities and organizational structures and processes impacting an organization and its performance" [25], in which the system components are related to either social or technological aspects [68]. Therefore, the system model applied to identify knowledge elements in the suggested framework should be capable of considering both social and technological components, which the SEIPS model does.

Although it is essential to focus on the individual components and interactions within a work system, to map the relevant background knowledge, the external environment (pressure, factors) could also have a role to play $[27,74,93]$. If the decision to be supported by a risk assessment is, say, formulated as a go or no-go decision about a certain process, it is essential that, for example, the economic (budget) constraints are taken into account. Resources spent on one activity might lead to fewer resources spent on other activities or planned activities [2]. Then, from a portfolio perspective, assuming that a company is involved in several projects (activities, systems), the effect of an activity might be less than intended if economic concerns are not taken into consideration. This is often forgotten when working with sociotechnical systems [93], which is why we find it important to explicitly have the external environment as an element in the system model, in order to obtain good-quality background knowledge, on which risk can be assessed. In the initial SEIPS model [26], the external environment was not separated from the physical environment. But, as a result of increased understanding [50], the external environment is now considered a separate component in the SEIPS model [27], which increases the likelihood of identifying knowledge elements related to external aspects, such as scarce resources or new technology, as well as the potential implications and effects of the external environment on the work system and its components.

The SEIPS model and the use of configurative models to identify knowledge elements have some weaknesses which we must acknowledge. As one of the reviewers of an earlier version of the paper highlighted, knowledge elements that are not considered critical toady may become critical in the future. Using configurative models implies that we are taking snapshots of the system as it is today, which might be different in the future (see e.g. [87]). The time dimension could be an addition to the three aspects of criticality that we mentioned in Section 4. One possible method that appears to be useful is the concept of assumption deviation risk (see, e.g., [5]). The three aspects of criticality (SoK, impact and stochastic uncertainty) provide relevant information to assess the deviation risk of the knowledge elements. This is potentially a topic for further development and improvement of the suggested framework.

To summarise, any model that is applied to identify relevant knowledge to support a risk assessment should take a systems approach, cover single components related to both social and technological aspects, and motivate considerations of external factors such as economic concerns. This does not imply that the SEIPS model is the only option, although it is clearly an attractive alternative. In addition, the SEIPS model does not rely on any initial assumptions about the system of interest before it is applied. It has a given structure with a few generic components, which can be used directly to assist the risk analyst in identifying the relevant knowledge elements.

\subsection{Using the Framework in Practice}

Independent of which system model is used as the search engine of the framework (e.g. SEIPS or SADT), it is, as presented in Section 4, somewhat detailed and comprehensive. Consequently, it might not 


\begin{tabular}{|l|c|}
\hline Mapping \\
Small scope \\
Low uncertainty \\
Low complexity \\
Low ambiguity
\end{tabular}$\quad \begin{gathered}\text { Identification + assessment + treatment } \\
\text { Large scope } \\
\text { High uncertainty } \\
\text { High complexity } \\
\text { High ambiguity }\end{gathered}$

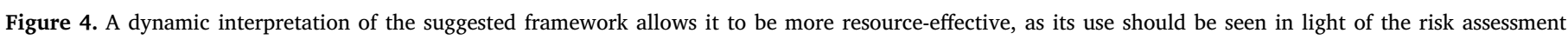
context.

always be resource-effective nor in line with the risk assessment context to apply the full framework (i.e. identification, assessment and treatment of knowledge elements). This does not mean that the framework has limited applicability, as the fundamental idea of taking a systems approach to map the background knowledge will always be relevant. The key is to understand when to perform a crude mapping of knowledge elements versus a full identification and assessment.

In the planning phase of the risk analysis process, we therefore recommend considering the scope (e.g., aim and resources) of the risk assessment and the uncertainty, complexity and ambiguity of the riskrelated phenomena of interest. Then the analyst can decide how detailed and rich in information the background knowledge should be, to fully support the risk assessment. We have presented the two boundaries of the framework's applications in Figure 4. In general, a risk assessment that is characterised by a small scope and low degrees of uncertainty, complexity and ambiguity is likely to be sufficiently supported by a crude mapping of the background knowledge, by using, for example, the first step of the suggested framework (see Section 4.1). Whenever the scope is large and the uncertainty, complexity and ambiguity are high, it is reasonable to call for a more detailed approach to handle the background knowledge.

There are various types of risk problems that require different types of risk assessment and management strategies, which the suggested framework acknowledges when being interpreted as a dynamic framework that ranges from a crude mapping to a more detailed assessment of knowledge elements (Figure 4). For the simpler risk problems, in which the phenomena of interest are well understood, the consequences are obvious, the uncertainty and ambiguity are low [80], it would not necessarily be resource-effective to perform a full assessment of the knowledge elements in terms of SoK, impact, uncertainty and risk-reducing measures. On the other hand, a risk problem that is, say, emerging (e.g., [40]) or systemic (e.g., [79]) would require a more detailed and holistic approach to risk assessment. Then, the value of the background knowledge is likely to increase with its quality of information, implying that a more detailed and comprehensive treatment of its uncertainties and quality can be justified and should be taken, for example as described in Section 4.

The key, however, is to focus on the interactions and interdependencies among the system components, and their potential rippleand spill-over effects on the other components and the risk-related problem of interest. The framework is therefore an appropriate tool for obtaining better background knowledge, independent of the risk problem, but the extent to which it is applied should always be seen in relation to the risk assessment context.

\section{Conclusion}

In this paper, we have suggested a framework that takes a systems approach to identify and assess the background knowledge, on which risk can be assessed. We conclude that to ensure a good quality background knowledge a systems approach is required. The framework serves the purposes of reducing the risk of missing critical knowledge elements, which might have a role to play in the background knowledge, and increasing the trustworthiness of the risk assessment, its results and recommendations. In addition, the identification and assessment of knowledge elements highlight the background knowledge that might require further attention and treatment to obtain the desired outcome of an activity/system. The core message of the paper, however, is that, to obtain good-quality background knowledge, it is often essential to take a systems approach, which captures social and technical components, interactions and interdependencies and their potential effects on the system of interest and risk assessment. In such matters, the framework presents a new approach, which explicitly assists the risk analyst in the challenging task of obtaining good-quality background knowledge. An example was included in the paper, which builds on a shorter version that was presented at the ESREL 2019 conference in Hannover, Germany [57], to illustrate the framework.

\section{CRediT authorship contribution statement}

Henrik Langdalen: Conceptualization, Methodology, Writing original draft, Visualization. Eirik Bjorheim Abrahamsen: Conceptualization, Methodology, Validation, Writing - review \& editing, Supervision. Håkon Bjorheim Abrahamsen: Conceptualization, Methodology, Validation, Writing - review \& editing, Supervision.

\section{Acknowledgements}

The authors are grateful to two anonymous reviewers for valuable comments and suggestions to an earlier version of this paper. The work (HL) has been partly funded by the Norwegian Ministry of Education and Research, which had no part in the design and or in the writing of the paper. The financial support is gratefully acknowledged.

\section{Appendix A}

Table A1 







\section{Supplementary materials}

Supplementary data associated with this article can be found, in the online version, at 10.1016/j.ress.2020.106909.

\section{References}

[1] Abrahamsen EB, Aven T, Vinnem JE, Wiencke H. Safety management and the use of expected values. Risk, Decision and Policy 2004;9(4):347-57.

[2] Abrahamsen EB, Moharamzadeh A, Abrahamsen HB, Asche F, Heide B, Milazzo MF. Are too many safety measures crowding each other out? Reliability Engineering \& System Safety 2018;174:108-13. https://doi.org/10.1016/j.ress.2018.02.011.

[3] Abrahamsen EB, Selvik JT, Berg H. Prioritising of safety measures in land use planning: on how to merge a risk-based approach with a cost-benefit analysis approach. International Journal of Business Continuity and Risk Management 2016;6(3):182-96.

[4] Amoore JN. A structured approach for investigating the causes of medical device adverse events. Journal of Medical Engineering 2014;2014. https://doi.org/10. 1155/2014/314138.

[5] Aven T. Practical implications of the new emerging risk perspectives. Reliability Engineering \& System Safety 2013;115:136-45. https://doi.org/10.1016/j.ress. 2013.02.020.

[6] Aven T. Risk, Surprises and Black Swans: Fundamental Ideas and Concepts in Risk Assessment and Risk Management. London, UK: Routledge; 2014.

[7] Aven T. Risk Analysis. 2nd ed. Chichester, UK: John Wiley \& Sons; 2015.

[8] Aven T. An emerging new risk analysis science: foundations and impacts. Risk Analysis 2018;38(5):876-88. https://doi.org/10.1111/risa.12899.

[9] Aven T, Abrahamsen EB. On the use of cost-benefit analysis in ALARP processes. International Journal of Performability Engineering 2007;3(3):345-53.

[10] Aven T, Baraldi P, Flage R, Zio E. Uncertainty in Risk Assessment: The Representation and Treatment of Uncertainties by Probabilistic and NonProbabilistic Methods. Chichester, UK: John Wiley \& Sons.; 2014.

[11] Aven T, Flage R. Risk Assessment with Broad Uncertainty and Knowledge Characterisation: An Illustrating Case. In: Aven T, Zio E, editors. Knowledge in Risk Assessment and Management. Chichester, UK: John Wiley \& Sons; 2018. p. 3-26.

[12] Aven T, Pedersen LM. On how to understand and present the uncertainties in production assurance analyses, with a case study related to a subsea production system. Reliability Engineering \& System Safety 2014;124:165-70. https://doi.org/ 10.1016/j.ress.2013.12.003.

[13] Aven T, Renn O. Risk Management and Governance: Concepts, Guidelines and Applications. Berlin, Germany: Springer Verlag; 2010.

[14] Aven T, Ylönen M. A risk interpretation of sociotechnical safety perspectives. Reliability Engineering \& System Safety 2018;175:13-8. https://doi.org/10.1016/j. ress.2018.03.004.

[15] b Aven T, Ylönen M. The Enigma of Knowledge in the Risk Field. In: Aven T, Zio E, editors. Knowledge in Risk Assessment and Management. Chichester, UK: John Wiley \& Sons; 2018. p. 27-47.

[16] Aven T, Zio E. Quality of Risk Assessment: Definition and Verification. In: Aven T, Zio E, editors. Knowledge in Risk Assessment and Management. Chichester, UK: John Wiley \& Sons; 2018. p. 297-312.

[17] Beard AN. Risk assessment assumptions. Civil Engineering and Environmental Systems 2004;21(1):19-31.

[18] Bellamy LJ, Ale BJM, Geyer TAW, Gossens LHJ, Hale AR, Oh J, Mud M, Bloemhof A, Papazoglou IA, Whiston JY. Storybuilder - A tool for the analysis of accident reports. Reliability Engineering \& System Safety 2007;92:735-44. https://doi.org/10. 1016/j.ress.2006.02.010.

[19] Benner L. Accident investigations: multilinear event sequencing methods. Journal of Safety Research 1975;7(2):67-73.

[20] Berner C, Flage R. Strengthening the quantitative risk assessments by systematic treatment of uncertain assumptions. Reliability Engineering \& System Safety 2016;151:46-59. https://doi.org/10.1016/j.ress.2015.10.009.

[21] Boin A, McConnell A. Preparing for critical infrastructure breakdowns: the limits of crisis management and the need for resilience. Journal of Contingencies and Crisis Management 2007;15(1):50-9. https://doi.org/10.1111/j.1468-5973.2007. 00504.x.

[22] Botwinick L, Bisognano M, Haraden C. Leadership Guide to Patient Safety. Cambridge, MA: Institute for Healthcare Improvement; 2006. IHI Innovation Series white paper.

[23] Brass, P., Hellmich, M., Ladra, A., Ladra, J. and Wrzosek, A. (2016). Percutaneous Techniques versus Surgical Techniques for Tracheostomy (Review). Cochrane Database for Systematic Reviews 2016, Issue 7. Art. No.: CD008045. DOI: 10.1002/ 14651858.CD008045.pub2.

[24] Campolongo F, Saltelli A. Design of Experiments. In: Saltelli A, Chan K, Scott EM, editors. Sensitivity Analysis. Chichester, UK: John Wiley \& Sons; 2000. p. 51-63.

[25] Carayon P, Hancock P, Leveson N, Noy YI, Sznelwar L, van Hootegem G. Advancing a sociotechnical systems approach to workplace safety: developing the conceptual framework. Ergonomics 2015;54(4):548-64. https://doi.org/10.1080/00140139. 2015.1015623.

[26] Carayon P, Hundt AS, Karsh BT, Gurses AP, Alvarado CJ, Smith M, Brennan PF. Work system design for patient safety: the SEIPS model. Quality and Safety in Health Care 2006;15(suppl. 1):i50-8. https://doi.org/10.1136/qshc.2005.015842.

[27] Carayon P, Wetterneck TB, Rivera-Rodriguez AJ, Hundt AS, Hoonakker P, Holden $\mathrm{R}$, Gurses AP. Human factors systems approach to healthcare quality and patient safety. Applied Ergonomics 2014;45(1):14-25. https://doi.org/10.1016/j.apergo. 
2013.04.023.

[28] Clark SC, Dunning J, Alfieri OR, Elia S, Hamilton LR, Kappetein AP, Lockowandt U, Sarris GE, Kolh PH. EACTS guidelines for the use of patient safety checklists. European Journal of Cardio-Thoracic Surgery 2012;41(5):993-1004. https://doi. org/10.1093/ejcts/ezs009.

[29] Coiera EW, Jayasuriya RA, Hardy J, Bannan A, Thorpe ME. Communication loads on clinical staff in the emergency department. Medical Journal of Australia 2002;176:415-8. https://doi.org/10.5694/j.1326-5377.2002.tb04482.x.

[30] Dekker S. Safety Differently. Boca Raton, FL: CRC Press; 2015.

[31] Dekker S, Cilliers P, Hofmeyr JH. The complexity of failure: implications of complexity theory for safety investigations. Safety Science 2011;49(6):939-45. https:// doi.org/10.1016/j.ssci.2011.01.008.

[32] Dewar JA. Assumption-Based Planning: A Tool for Reducing Avoidable Surprises. Cambridge, UK: Cambridge University Press; 2002.

[33] Donabedian A. The quality of medical care. Science 1978;200(4344):856-64.

34] Dul J, Bruder R, Buckle P, Carayon P, Falzon P, Marras WS, van der Doelen B. A strategy for human factors/ergonomics: developing the discipline and profession. Ergonomics 2012;55(4):377-95. https://doi.org/10.1080/00140139.2012.661087.

[35] Ehteshami A, Sadoughi F, Ahmadi M, Kashefi P. Intensive care information system impacts. Acta Informatica Medica 2013;21(3):185-91. https://doi.org/10.5455/ aim.2013.21.185-191.

[36] Eidesen K, Sollid SJ, Aven T. Risk assessment in critical care medicine: a tool to assess patient safety. Journal of Risk Research 2009;12(3-4):281-94.

[37] Embriaco N, Papazian L, Kentish-Barnes N, Pochard F, Azoulay E. Burnout syndrome among critical care healthcare workers. Current Opinion in Critical Care 2007;13(5):482-8. https://doi.org/10.1097/MCC.0b013e3282efd28a.

[38] Ferri M, Zygun DA, Harrison A, Stelfox HT. Evidence-based design in an intensive care unit: end-user perceptions. BMC Anesthesiology 2015;15(57). https://doi.org/ 10.1186/s12871-015-0038-4.

[39] Flage R, Aven T. Expressing and communicating uncertainty in relation to quantitative risk analysis. Reliability \& Risk Analysis: Theory \& Applications 2009;2(13):9-18.

[40] Flage R, Aven T. Emerging risks - conceptual definition and a relation to black swan type of events. Reliability Engineering \& System Safety 2016;144:61-7. https://doi. org/10.1016/j.ress.2015.07.008.

[41] Flage R, Aven T. Comments to the article by Goerlandt \& Reniers titled "On the assessment of uncertainty in risk diagrams" [Safety Sci. 84 (2016) 67-77]. Safety Science 2017;98:9-11. https://doi.org/10.1016/j.ssci.2017.04.007. (Letter to the editor).

[42] Flage R, Berner C. Treatment and Communication of Uncertain Assumptions in (Semi-)quantitative Risk Assessments. In: Aven T, Zio E, editors. Knowledge in Risk Assessment and Management. Chichester, UK: John Wiley \& Sons; 2018. p. 49-79.

[43] Flin R, Maran N. Basic concepts for crew resource management and non-technical skills. Best Practice \& Research. Clinical Anaesthesiology 2015;29(1):27-39. https://doi.org/10.1016/j.bpa.2015.02.002.

[44] Friedman Y, Fildes J, Mizock B, Samuel J, Patel S, Appavu S, Roberts R. Comparison of percutaneous and surgical tracheostomies. Chest 1996;110(2):480-5. https:// doi.org/10.1378/chest.110.2.480.

[45] Gardiner Q, White PS, Carson D, Shearer A, Frizelle F, Dunkley P. Technique training: endoscopic percutaneous tracheostomy. British Journal of Anaesthesia 1998;81:401-3. https://doi.org/10.1093/bja/81.3.401.

[46] Goerlandt F, Reniers G. On the assessment of uncertainty in risk diagrams. Safety Science 2016;84:67-77. https://doi.org/10.1016/j.ssci.2015.12.001.

[47] Haimes YY. Systems-based guiding principles for risk modelling, planning, assessment, management, and communication. Risk Analysis 2012;32(9):1451-67. https://doi.org/10.1111/j.1539-6924.2012.01809.x.

[48] Harrison MI, Koppel R, Bar-Lev S. Unintended consequences of information tech nologies in health care: an interactive sociotechnical analysis. Journal of the American Medical Informatics Association 2007;14(5):542-9. https://doi.org/10. 1197/jamia.M2384.

[49] Hettinger LJ, Kirlik A, Goh YM, Buckle P. Modelling and simulation of complex sociotechnical systems: envisioning and analysing work environments. Ergonomics 2015;58(4):600-14. https://doi.org/10.1080/00140139.2015.1008586.

[50] Holden RJ, Carayon P, Gurses AP, Hoonakker P, Hundt AS, Ozok AA, RiveraRodriguez AJ. SEIPS 2.0: a human factors framework for studying and improving the work of healthcare professionals and patients. Ergonomics 2013;56(11):1669-86. https://doi.org/10.1080/00140139.2013.838643.

[51] Hollnagel E. FRAM: The Functional Resonance Analysis Method: Modelling Complex Socio-technical Systems. UK, Farnham: Ashgate Publishing Ltd; 2012

[52] Huang DT, Clermont G, Kong L, Weissfeld LA, Sexton JB, Rowan KM, Angus DC. Intensive care unit safety culture and outcomes: a US multicenter study. International Journal for Quality in Health Care 2010;22(3):151-61. https://doi. org/10.1093/intqhe/mzq017.

[53] Jensen A, Aven T. A new definition of complexity in a risk analysis setting. Reliability Engineering \& System Safety 2018;171:169-73. https://doi.org/10. 1016/j.ress.2017.11.018.

[54] Kleiner BM. Macroergonomics: analysis and design of work systems. Applied Ergonomics 2006;37(1):81-9. https://doi.org/10.1016/j.apergo.2005.07.006.

[55] Kleiner BM, Hettinger LJ, DeJoy DM, Huang YH, Love PE. Sociotechnical attributes of safe and unsafe work systems. Ergonomics 2015;58(4):635-49. https://doi.org/ 10.1080/00140139.2015.1009175.

[56] Kloprogge P, van der Sluijs JP, Petersen AC. A method for the analysis of assumptions in model-based environmental assessments. Environmental Modelling \& Software 2011;26:289-301. https://doi.org/10.1016/j.envsoft.2009.06.009.

[57] Langdalen H, Abrahamsen EB, Abrahamsen HB. A Systems Approach to Identify Hidden Assumptions in the Background Knowledge. In: Beer M, Zio E, editors.
Proceedings of the $29^{\text {th }}$ European Safety and Reliability Conference ESREL 2019. Research Publishing; 2019.

[58] Leveson N. A new accident model for engineering safer systems. Safety Science 2004;42(4):237-70. https://doi.org/10.1016/S0925-7535(03)00047-X.

[59] Leveson N. A systems approach to risk management through leading safety indicators. Reliability Engineering and System Safety 2015;136:17-34. https://doi. org/10.1016/j.ress.2014.10.008.

[60] Leveson NG. Engineering a Safer World: Systems Thinking Applied to Safety. Cambridge, MA: The MIT Press; 2012.

[61] Lintern G. The Foundations and Pragmatics of Cognitive Work Analysis: A Systematic Approach to Design of Large-Scale Information Systems. In: Lintern Gavan, editor. Cognitive Systems Design. 2009.

[62] Marca DA, McGowan CL. SADT: Structured Analysis and Design Technique. New York: McGraw-Hill Book Co. Inc; 1988.

[63] Manser T. Teamwork and patient safety in dynamic domains of healthcare: a review of the literature. Acta Anaesthesiologica Scandinavica 2009;53:143-51. https://doi. org/10.1111/j.1399-6576.2008.01717.x.

[64] Marshall JC, Bosco L, Adhikari NK, Connolly B, Diaz JV, Dorman T, Fowler RA, Meyfroidt G, Nakagawa S, Pelosi P, Vincent J, Vollman K, Zimmerman J. What is an intensive care unit? A report of the task force of the World Federation of Societies of Intensive and Critical Care Medicine. Journal of Critical Care 2017;37:270-6. https://doi.org/10.1016/j.jcrc.2016.07.015.

[65] McElroy LM, Macapagal KR, Collins KM, Abecassis MM, Holl JL, Ladner DP, Gordon EJ. Clinician perceptions of operating room to intensive care unit handoffs and implications for patient safety: a qualitative study. American Journal of Surgery 2015;210(4):629-35. https://doi.org/10.1016/j.amjsurg.2015.05.008.

[66] Melloni G, Muttini S, Gallioli G, Carretta A, Cozzi S, Gemma M, et al. Surgical tracheostomy versus percutaneous dilatational tracheostomy: a prospective randomized study with long-term follow-up. The Journal of Cardiovascular Surgery 2002;43(1):113-21.

[67] Money AG, Barnett J, Kuljis J, Craven MP, Martin JL, Young T. The role of the user within the medical device design and development process: medical device manufacturers' perspectives. BMC Medical Informatics and Decision Making 2011;11(15). https://doi.org/10.1186/1472-6947-11-15.

[68] Mumford E. The story of socio-technical design: reflections on its successes, failures and potential. Information Systems Journal 2006;16(4):317-42. https://doi.org/ 10.1111/j.1365-2575.2006.00221.x.

[69] Pappazoglou IA, Ale BJM. A logical model for quantification of occupational risk. Reliability Engineering \& System Safety 2007;92:785-803. https://doi.org/10. 1016/j.ress.2006.04.017.

[70] Parshuram CS, Amaral ACKB, Ferguson ND, Baker GR, Etchells EE, Flintoft V, Granton J, Lingard J, Kirpalani H, Mehta S, Moldofsky H, Scales DC, Stewart TE, Willan AR, Friedrich JO. Patient safety, resident well-being and continuity of care with different resident duty schedules in the intensive care unit: a randomized trial. Canadian Medical Association Journal 2015;187(5):321-9. https://doi.org/10. 1503/cmaj.140752.

[71] Patè-Cornell E. Finding and fixing systems weaknesses: probabilistic methods and applications of engineering risk analysis. Risk Analysis 2002;22(2):319-34. https:// doi.org/10.1111/0272-4332.00025.

[72] Powell-Cope G, Nelson AL, Patterson ES. Patient Care Technology and Safety. In: Hughes RG, editor. Patient Safety and Quality: An Evidence-Based Handbook for Nurses. RockvilleMD: Agency for Healthcare Research and Quality (US); 2008 Chapter 50. Available from: https://www.ncbi.nlm.nih.gov/books/NBK2686/.

[73] Rasmussen J. Risk management in a dynamic society: a modelling problem. Safety Science 1997;27(2/3):183-213.

[74] Rasmussen J. Human factors in a dynamic information society: where are we heading? Ergonomics 2000;43:869-79. https://doi.org/10.1080/ 001401300409071.

[75] Reason J. Human Error. NY: Cambridge University Press; 1990.

[76] Reason J. Human error: models and management. British Medical Journal 2000;320(7237):768-70. https://doi.org/10.1136/bmj.320.7237.768.

[77] Reid J, Bromiley M. Clinical human factors: the need to speak up to improve patient safety. Nursing Standard 2012;26(35):35-40. https://doi.org/10.7748/ns2012.05. 26.35.35.c9084.

[78] Reiling J, Hughes RG, Murphy MR. The Impact of Facility Design on Patient Safety. In: Hughes RG, editor. Patient Safety and Quality: An Evidence-Based Handbook for Nurses. RockvilleMD: Agency for Healthcare Research and Quality (US); 20082008 Apr. Chapter 28. Available from: https://www.ncbi.nlm.nih.gov/books/NBK2633/.

[79] Renn O. Risk Governance. Coping with Uncertainty in a Complex World. 2008.

[80] Renn O, Klinke A, van Asselt. Coping with complexity, uncertainty and ambiguity in risk governance: a synthesis. Ambio 2011;40(2):231-46. https://doi.org/10.1007/ 13280-010-0134-0.

[81] Rivera-Rodriguez AJ, Karsh BT. Interruptions and distractions in healthcare: review and reappraisal. Quality and Safety in Health Care 2010;19(4):304-12. https://doi org/10.1136/qshc.2009.033282.

[82] Saltelli A. What is Sensitivity Analysis. In: Saltelli A, Chan K, Scott EM, editors. Sensitivity Analysis. Chichester, UK: John Wiley \& Sons; 2000. p. 3-13.

[83] Saltelli A, Chan K, Scott EM. Sensitivity Analysis. Chichester, UK: John Wiley \& Sons: 2000.

[84] Seamann JB, Cohen TR, White DB. Reducing the stress on clinicians working in the ICU. Journal of American Medical Association 2018;320(19):1981-2. https://doi. org/10.1001/jama.2018.14285.

[85] Simpson TP, Day CJ, Jewkes CF, Manara AR. The impact of percutaneous tracheostomy on intensive care unit practice and training. Anaesthesia 1999;54:186-9. https://doi.org/10.1046/j.1365-2044.1999.00667.x.

[86] Sollid SJM, Strand K, Søreide E. Percutanous dilatational tracheotomy in the ICU: a 
Norwegian survey focusing on perceived risk and safety attitudes. European Journal of Anaesthesiology 2008;25(11):925-32.

[87] Sørskår LIK, Abrahamsen EB, Abrahamsen HB. On the use of economic evaluation of new technology in helicopter emergency medical services. International Journal of Business Continuity and Risk Management 2019;9(1). https://doi.org/10.15054/ IJBCRM.2019.096693.

[88] Thekdi S, Aven T. A Decision Support Method for Prioritizing Investments Subject to Uncertainties. In: Aven T, Zio E, editors. Knowledge in Risk Assessment and Management. Chichester, UK: John Wiley \& Sons; 2018. p. 223-40.

[89] Tuft VL, Wagnild BR, Slyngstad OM. A Practical Approach to Risk Assessments from Design to Operation of Offshore Oil and Gas Installations. In: Aven T, Zio E, editors. Knowledge in Risk Assessment and Management. Chichester, UK: John Wiley \& Sons; 2018. p. 267-96.

[90] van der Sluijs PJ, Craye M, Funtowicz S, Kloprogge P, Ravetz J, Risbey J. Combining quantitative and qualitative measures of uncertainty in model-based environmental assessment: the NUSAP system. Risk Analysis 2005;25(2):481-92. https://doi.org/ 10.1111/j.1539-6924.2005.00604.x.

[91] Weerakkody RA, Cheshire NJ, Riga C, Lear R, Hamady MS, Moorthy K, Darzi AW, Vincent C, Bicknell CD. Surgical technology and operating-room safety failures: a systematic review of quantitative studies. BMJ Quality \& Safety 2013;22:710-8. https://doi.org/10.1136/bmjqs-2012-001778.

[92] Wilson JR. Fundamentals of ergonomics in theory and practice. Applied Ergonomics 2000;31(6):557-67.

[93] Ylönen, M., Engen, O.A., Le Coze, J.C., Heikkilä, J., Skotnes, R., Pettersen, K. et al. (2017). Sociotechnical Assessment within Three Risk Regulation Regimes: SAF€RA STARS Final Report, 295, VTT Technical Research Centre of Finland, Finland.

[94] Zio E. Challenges in the vulnerability and risk analysis of critical infrastructures. Reliability Engineering \& System Safety 2016;152:137-50. https://doi.org/10. 1016/j.ress.2016.02.009.

[95] Zio E. The future of risk assessment. Reliability Engineering and System Safety 2018;177:176-90. https://doi.org/10.1016/j.ress.2018.04.020. 



\section{Paper III}

Risk-informed decision-making with an improved approach to evaluate plug and abandonment designs

Authors: Henrik Langdalen, Eirik B. Abrahamsen, Jon T. Selvik and Hans Petter Lohne

Published in International Journal of Business Continuity and Risk Management, vol. 9 (3), 226-250, 2019. Doi: 10.1504/IJBCRM.2019.100415

Earlier version of the paper: "Improvement of the risk-based approach for evaluation of permanently plugged and abandoned oil and gas wells. In: Safety and Reliability - Safe Societies in a Changing World. Proceedings of the $28^{\text {th }}$ European Safety and Reliability Conference, ESREL 2018, 1535-1543. CRC Press"

This paper is not included in Brage for copyright reasons. 



\section{Paper IV}

A discussion on socio-economic profitability as a prerequisite for investments in security measures

Authors: Henrik Langdalen, Eirik B. Abrahamsen, Jon T. Selvik and Sissel H. Jore

Published in The Business Review, Cambridge, vol. 26 (2), 18, 2018

This paper is not included in Brage for copyright reasons. 



\section{Paper V}

On the use of the 'return of investments in safety' (ROSI) measure for decision-making in the chemical industry

Authors: Eirik B. Abrahamsen, Jon T. Selvik, Henrik Langdalen, Maria F. Milazzo, Roy E. Dahl, Håkon B. Abrahamsen and Surbhi Bansal

Submitted for possible publication in Reliability Engineering \& System Safety

This paper is not included in Brage for copyright reasons. 



\section{Paper VI}

A comparative study on the frequency of simulationbased training and assessment of non-technical skills in the Norwegian ground ambulance services and helicopter emergency medical services

Authors: Henrik Langdalen, Eirik B. Abrahamsen, Stephen J. M. Sollid, Leif I. K. Sørskår and Håkon B. Abrahamsen

Published in BMC Health Services Research, vol. 18 (509), 111, 2018. Doi: 10.1186/s12913-018-3325-1 



\title{
A comparative study on the frequency of simulation-based training and assessment of non-technical skills in the Norwegian ground ambulance services and helicopter emergency medical services
}

\author{
Henrik Langdalen ${ }^{\text {* }}$ (D), Eirik B. Abrahamsen ${ }^{1}$, Stephen J. M. Sollid ${ }^{2,3,4}$, Leif Inge K. Sørskår ${ }^{1}$
} and Håkon B. Abrahamsen 1,4

\begin{abstract}
Background: Inadequate non-technical skills (NTSs) among employees in the Norwegian prehospital emergency medical services (EMSs) are a risk for patient and operational safety. Simulation-based training and assessment is promising with respect to improving NTSs. The frequency of simulation-based training in and assessment of NTSs among crewmembers in the Norwegian helicopter emergency medical service (HEMS) has gained increased attention over recent years, whereas there has been much less focus on the Norwegian ground emergency medical service (GEMS). The aim of the study was to compare and document the frequencies of simulation-based training in and assessment of seven NTSs between the Norwegian HEMS and GEMS, conditional on workplace and occupation.

Method: A comparative study of the results from cross-sectional questionnaires responded to by employees in the Norwegian prehospital EMSs in 2016 regarding training in and assessment of NTSs during 2015, with a focus on the Norwegian GEMS and HEMS. Professional groups of interest are: pilots, HEMS crew members (HCMs), physicians, paramedics, emergency medical technicians (EMTs), EMT apprentices, nurses and nurses with an EMT licence.
\end{abstract}

Results: The frequency of simulation-based training in and assessment of seven generic NTSs was statistically significantly greater for HEMS than for GEMS during 2015. Compared with pilots and HCMs, other health care providers in GEMS and HEMS undergo statistically significantly less frequent simulation-based training in and assessment of NTSs. Physicians working in the HEMS appear to be undergoing training and assessment more frequently than the rest of the health trust employees. The study indicates a tendency for lesser focus on the assessment of NTSs compared to simulation-based training.

Conclusion: HEMS has become superior to GEMS, in terms of frequency of training in and assessment of NTSs. The low frequency of training in and assessment of NTSs in GEMS suggests that there is a great potential to learn from HEMS and to strengthen the focus on NTSs. Increased frequency of assessment of NTSs in both HEMS and GEMS is called for.

Keywords: Non-technical skills, Helicopter, Ambulance, Emergency medical service, Simulation-based training, Assessment, Learning

\footnotetext{
*Correspondence: henrik.langdalen@uis.no

'Department of Safety, Economics and Planning, University of Stavanger,

Faculty of Science and Technology, Stavanger, Norway

Full list of author information is available at the end of the article
}

(c) The Author(s). 2018 Open Access This article is distributed under the terms of the Creative Commons Attribution 4.0 International License (http://creativecommons.org/licenses/by/4.0/), which permits unrestricted use, distribution, and reproduction in any medium, provided you give appropriate credit to the original author(s) and the source, provide a link to the Creative Commons license, and indicate if changes were made. The Creative Commons Public Domain Dedication waiver (http://creativecommons.org/publicdomain/zero/1.0/) applies to the data made available in this article, unless otherwise stated. 


\section{Background}

The Norwegian prehospital emergency medical service (EMS) is an integrated part of the Norwegian preparedness system [1], dedicated to providing immediate medical attention and delivery of care outside the hospitals to the Norwegian population in the case of emergency, acute illness or critical injury [2, 3]. The helicopter emergency medical service (HEMS) and ground emergency medical service (GEMS), i.e. ambulance cars and boats, constitutes the major part of the Norwegian EMS. In Norway, commercial flight operators run the HEMS operations on behalf of the regional health trusts, whereas the regional health trusts are responsible for the EMSs in their local region. Objectives and tasks within HEMS and GEMS are similar. However, team composition, education, medical care and treatment processes (e.g. a greater number of advanced medical interventions in HEMS $[4,5])$, as well as the physical environments, differ substantially.

In both prehospital EMSs, educated, knowledgeable and skilled personnel are required to appraise the situation and adopt the appropriate approach in a vast diversity of encountered circumstances [6,7]. Intense time pressure, complex problems, uncertainties, high stakes, in addition to a number of individual challenging and interactive tasks of medical, technical and multidisciplinary character, are, among others, common denominators for EMS personnel [8]. The complexity of the prehospital EMS makes the operating environment prone to human error $[6,9,10]$.

Human factors pertain to nearly all aspects of the EMSs [11]; thus, preventing human error is paramount $[7,12]$. Poor clinical judgments by EMS personnel can reduce patient safety [13]. Efficient situation awareness is critical in the EMS domain, as routine behaviours are interspersed with adverse events that may require a higher level of attention [14]. Multidisciplinary crews require good teamwork to ensure the safety of operations and patients $[10,15,16]$. The fact that factors beyond technical skills and knowledge can cause accidents has promoted the transfer of safety management strategies developed for the aviation industry, such as crew resource management $(\mathrm{CRM})[17,18]$, into the medical domain $[19,20]$.

Specific interventions, e.g. CRM such as simulation-based training, can reduce the risk of human error by enhancing non-technical skills (NTSs) [18, 19, 21-23], ensuring safe and effective task performance [24]. NTSs complement technical "know-how" types of skills [6] and are commonly referred to as "social, cognitive and personal resource skills" [25]. Seven generic categories of NTSs are often mentioned in relation to safety [25]: decision-making, leadership, communication, situation awareness, teamwork, managing stress, and coping with fatigue.

Simulation-based training in NTSs is a central CRM intervention, recommended to improve the safety culture in prehospital domains [10], where professionals from different backgrounds practise on non-routine behaviours and tasks in safe environments [11]. The research on NTSs and simulations in a prehospital setting is sparse [13]. However, experience from other domains is promising $[26,27]$. Simulations performed by emergency medicine residents improved leadership, communication, teamwork and situation awareness [28]. Assessment of a simulation increases learning, thus potentially preventing the repetition of incorrect behaviour [29-31].

Despite the benefits documented in the literature, the effect of CRM on an organization's outcome (i.e. safety) has not been ascertained [27]. The optimum frequency of CRM interventions is also uncertain, but emerging evidence seems to support high frequency retraining [32]. The opportunity cost of CRM interventions is great, as they are resource-absorbing [33], limited by budget constraints and time to practise. Mapping the frequency of training in and assessment of NTSs is a means to identify the need for such interventions, the development of skills and the resource-effectiveness.

To the extent of our knowledge, the level of training in and assessment of NTSs in the Norwegian GEMS has not been reported in the literature. The level of simulation-based training in and assessment of NTSs in the Norwegian HEMS during 2011 has been documented in the literature [34]. The results indicated a significant difference in the frequency of training in and assessment of NTSs between employees working for the flight operator and those in the health trust.

The aim of this study was to document and compare the frequency of training in and assessment of a generic set of basic NTSs within the Norwegian HEMS and GEMS. We hypothesized that the health trust employees, compared to the flight operator employees, lacked simulation-based training in, and assessment of, NTSs. We also hypothesized that physicians working in the HEMS underwent training and assessment more frequently than the other health trust employees. Finally, we asserted that the difference in frequency of training in and assessment of NTSs between the HEMS and the GEMS has increased in recent years.

\section{Methods}

\section{Setting}

The Norwegian GEMS is considered the backbone of the Norwegian EMS [35]. The most common staffing in the Norwegian GEMS is either one paramedic and one emergency medical technician (EMT) or two EMTs [36], 
at least one of whom is an authorized EMT [3]. Norwegian EMTs ("Ambulansepersonell") undergo two years of vocational high school, followed by two years of practical on-the-job training, working as an EMT apprentice, to become authorized. The primary responsibilities of the EMT are transportation, primary survey, initiating medical care and triage on-scene. A paramedic needs an EMT licence and a university college degree of 60 to 180 European Credit Transfer and Accumulation System (ECTS) points [36]. In addition to paramedics and EMTs, physicians and nurses with or without additional authorization as an EMT or other speciality training (e.g. anaesthesia) may supplement the Norwegian GEMS staffing. Professional GEMS groups, employed by the Norwegian health trusts, of interest in the present study are paramedics, EMTs, EMT apprentices, nurses with authorizations as an EMT (referred to as EMT nurses within this paper) and nurses without an EMT certificate (referred to as nurses).

In Norway, the physician-manned HEMS supports the GEMS in emergency missions for patient care and retrieval, in addition to inter-hospital transportation of patients [34], especially when the time dimension is critical. A HEMS crew consists of three members, each of whom belongs to a different profession. The helicopter pilot acts as mission leader, primarily focusing on navigation and flight safety. The HEMS crewmember (HCM) performs rescue operations and has a supporting role in respect of the pilot and physician in different phases of the mission. The physician, who is a certified or in-training anaesthesiologist, is responsible for patient care and medical treatment, both on-scene and during transportation. The Norwegian commercial flight operator employs the pilots and HCMs, whereas the physicians are employed by the local health trusts.

\section{Questionnaire}

The basis of this study was a Norwegian Hospital Survey on Patient Safety Culture (HSOPSC) conducted in 2016, which included data regarding the self-reported frequency of training in and assessment of NTSs during 2015 among EMS professions. The primary focus of the present paper originates from two question categories addressing the extent of simulation-based training in, and assessment of, seven generic NTSs during 2015. The questions were: "How many times during 2015 did you participate in multi-professional prehospital simulation-based training in the following skill?" and "How many times during 2015 were the following of your prehospital skills systematically observed and evaluated?". In this text, the formative debriefing of systematic observation and evaluation of NTSs is referred to as the assessment of NTSs. The skills referred to are the following NTSs: decision-making, leadership, communication, situation awareness, teamwork, managing stress, and coping with fatigue. Each question item was answered across a four-point Likert scale (0, 1-2, $3-5,>5)$.

\section{Data collection}

Data were collected between October and December 2016. The survey was distributed by e-mail, with a link to a web-based questionnaire (SurveyXact), to all prehospital personnel in the Norwegian HEMS and GEMS. Non-responders received up to five reminders before they were excluded from the study. Employees in the Norwegian Search and Rescue (SAR) services and medical airplanes were not invited, thus leading to an exclusion if such occupations were found among the respondents. Questionnaires returned with unknown profession or occupation were also excluded by listwise removal.

\section{Statistical analysis}

To assess possible differences we dichotomized the question items into "some training/assessment" and "no training/assessment". Similarities, or dissimilarities, between professions or EMSs of interest are visually presented in bar charts as proportions of individuals (in \%) within the respective group.

To support the visual comparison of professional groups, the dichotomized items were used in several two-sided Fisher's exact tests. Results are presented as numbers (ratios) and $p$-values, where a $p$-value less than 0.05 is considered as statistically significant throughout the paper.

Calculated odds ratios (ORs) present the differences within all six professions working in the health trust, with physicians as the reference group. The results are presented as ORs with associated $p$-values. We used the dichotomized items as dependent variables in a series of logistic regressions, with the professional groups as explanatory variables, to obtain the p-values.

We used the freeware R 3.4.2 for calculations and visualizations of all the results presented in the present paper.

\section{Ethics, consent and participants}

This study was conducted on the approval obtained from the Norwegian Social Science Data Services (NSD; project number 45723). The Regional Committee for Medical and Health Research West-Norway (REK West) evaluated this project as "not mandatory to submit" (Ref. number 2015/2249). All the participants received information about the purpose of the study, and written consent to participate was given at the start of the study, stating that no participants could be identified in published material. The digital questionnaires were treated in confidence. 


\section{Results}

The participant flow of respondents who qualified for the statistical analysis is illustrated in Fig. 1. Of the 5124 people invited to participate in the survey, all somehow engaged in the Norwegian EMSs, 4910 and 214 worked for the GEMS and HEMS, respectively. Responders accepting the survey numbered 1384 (response rate of 27.0\%). We excluded 36 respondents, as they did not work in an EMS of interest (e.g. employees in SAR services). Among the respondents of interest, 241 respondents were excluded, due to unknown professions, irrelevant professions (e.g. ambulance assistant), and insufficient answers (less than 50\%). Of the 1107 responders qualified for statistical analysis, 998 (response rate of $20.3 \%$ ) worked for the GEMS and 109 (50.9\%) for the HEMS. The professional groups of interest are presented in the two lower boxes in Fig. 1.

Visual inspection of the frequency of simulation-based training and assessment in the HEMS and GEMS (Fig. 2) indicates that the HEMS personnel are generally exposed to training and assessment of NTSs more frequently than the GEMS personnel. These apparent differences between the two EMSs are all statistically significant, supported by two-sided Fisher's exact tests (Table 1). In other words, there is a statistically significant association between the amount of training and assessment and the two EMSs. In general, teamwork and coping with fatigue have the highest and lowest frequencies of training and assessment, respectively.

The frequency of training in and assessment of the seven NTSs among employees of the flight operator (pilots and HCMs) is statistically significantly greater than for employees of the health trust (Fig. 3 and Table 2).
Compared with the other employees of the health trust (paramedics, EMTs, EMT apprentices, EMT nurses and nurses), physicians appear to undergo training and assessment more frequently. Except for simulation-based training compared with EMT apprentices, these apparent differences are not statistically significant (Table 3).

For all the groups and EMSs included in the study, there is a clear tendency for a lower frequency of assessment across all seven generic NTSs, in comparison with the frequency of training (Figs. 2-3 and Tables 1-2).

The frequency of simulation-based training in and assessment of NTSs observed in the HEMS during 2011 [34] is statistically insignificantly different from the frequency observed in the GEMS during 2015 (Fig. 4 and Table 4), except for communication and coping with fatigue. The tendency is that GEMS underwent both training and assessment more frequently during 2015 than HEMS did in 2011.

\section{Discussion}

The assumption that training and assessment increases NTSs is reasonable based on documented experience $[28,29,37,38]$ and relevant literature $[6,11,24,25,30]$. However, direct evidence of improved outcomes or reduced amount of errors as results of training in and assessment of NTSs is sparse in the prehospital domain. The results of this study must be evaluated in respect to the lack of such evidence. The results are also hampered by the low response rate, which makes it ambitious to make strong conclusions. Nevertheless, the tendencies of frequently more training in and assessment of NTSs in HEMS than for GEMS, and that simulation-based

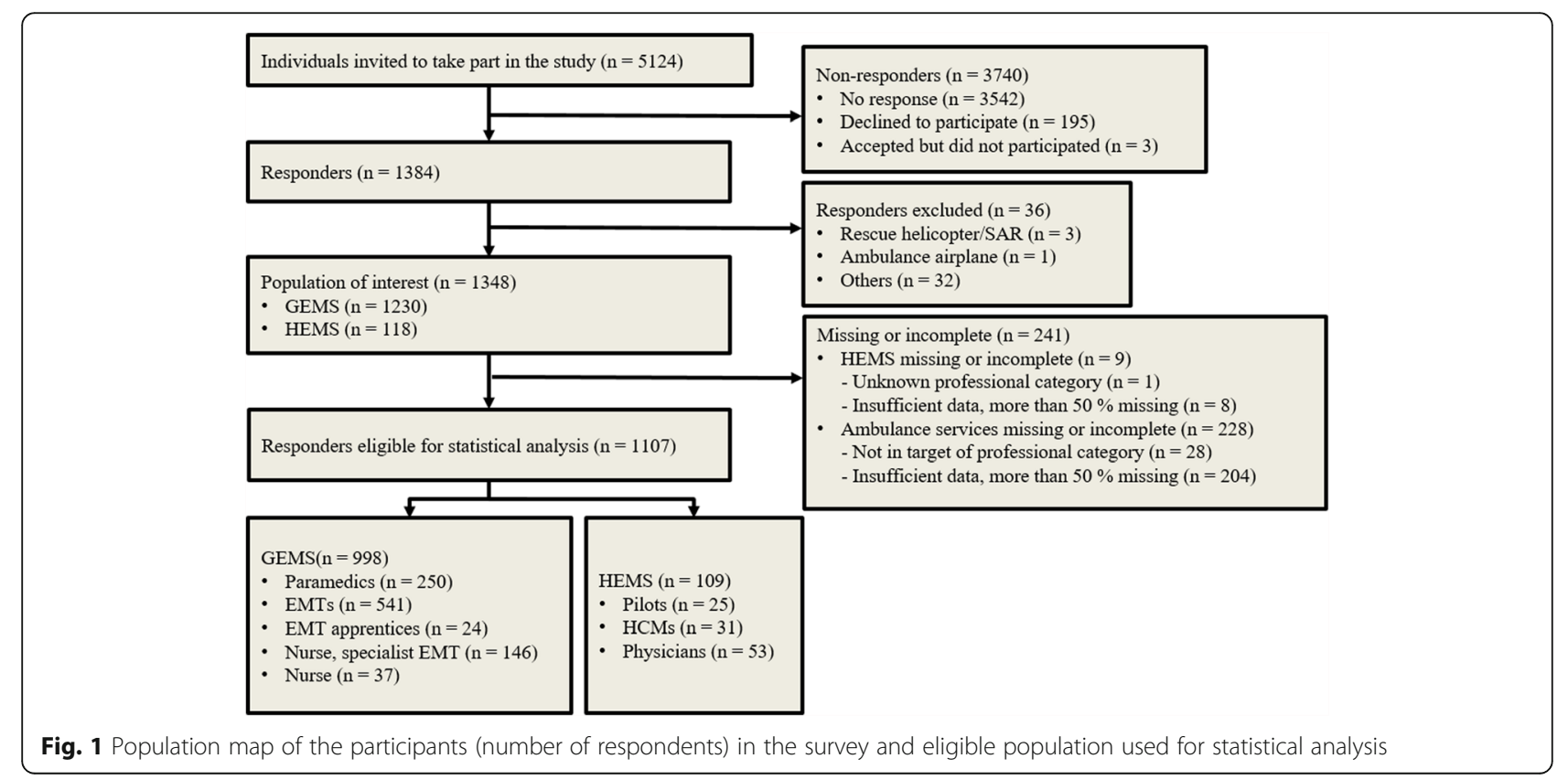




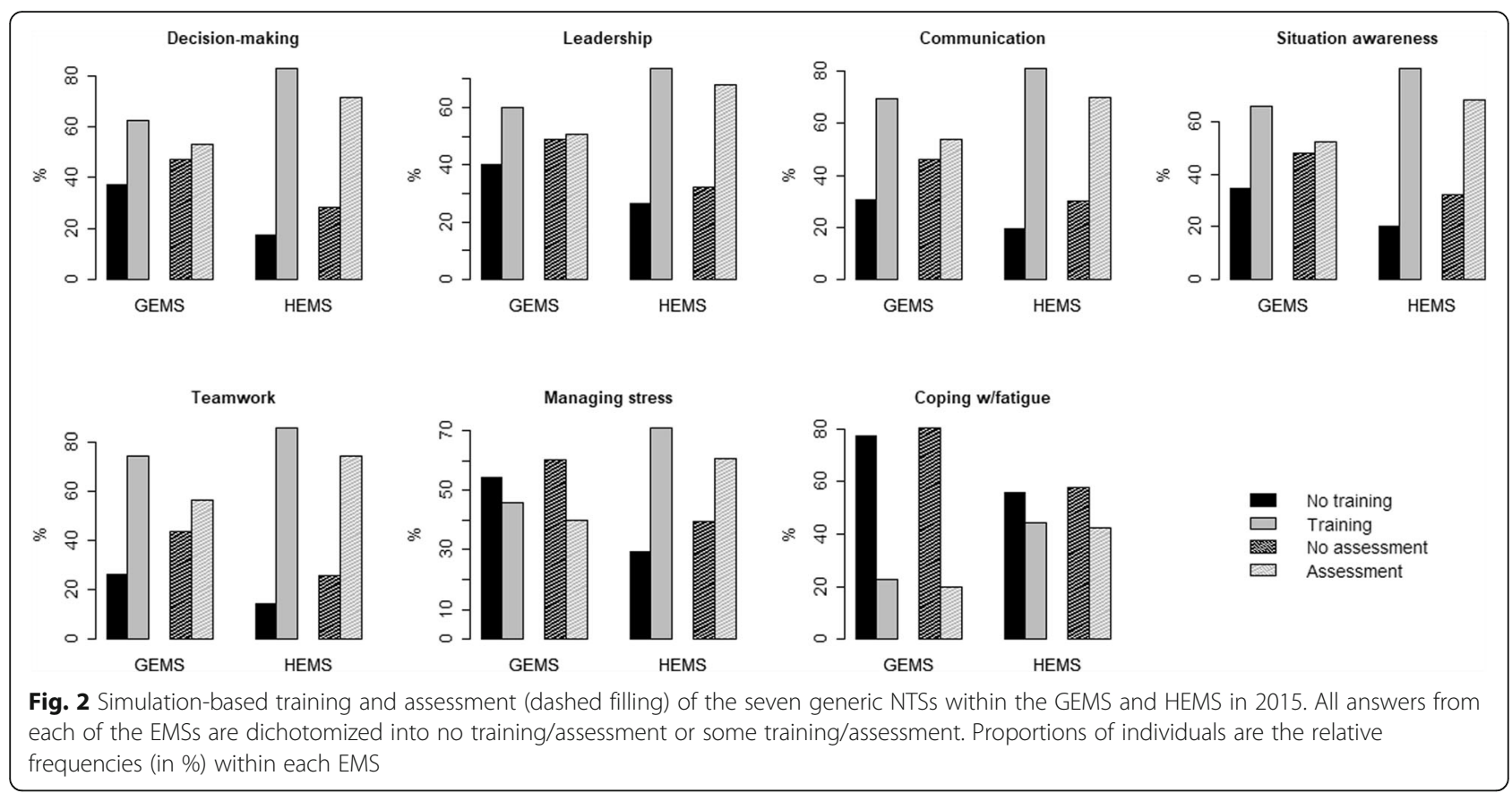

training appears to be more frequent than assessment for both the EMSs, are unambiguous.

\section{Comparison of HEMS and GEMS}

The physical environment and task-related differences between HEMS and GEMS may demand different levels of training in NTSs. However, the fact that both prehospital services perform safety-critical operations with a low tolerance of error implies a need for training [11]. One appealing reason for the observed variation in training is the safety culture. NTSs and CRM have been essential features in preventing errors in the aviation industry for a long time [11]. The acknowledgement of human limitations has promoted the need to invest resources in training in NTSs [39]. There is a lack of such strong traditions in GEMS [6], when compared with HEMS, and this may be an explanation of the observed results. Some of the aviation-related tasks performed in HEMS are claimed to be more procedure-based, thus simplifying the simulations and assessments [34]. Training on the base may also be easier to conduct for HEMS than for GEMS, due to the dynamics of the working environment [34].

Table 1 Numbers (frequencies) of GEMS and HEMS employees undertaking some training in and assessment of the seven NTSs during 2015; Fisher's exact test proving statistically significant differences

\begin{tabular}{|c|c|c|c|c|}
\hline Question category & NTS category & GEMS $(n=998)$ & HEMS $(n=109)$ & $p$-value \\
\hline & Decision-making & $624(62.5 \%)$ & $90(82.6 \%)$ & $<0,001$ \\
\hline \multirow[t]{6}{*}{ Simulation-based training of NTSS } & Leadership & $599(60.0 \%)$ & $80(73.4 \%)$ & 0,007 \\
\hline & Communication & $693(69.4 \%)$ & $88(80.7 \%)$ & 0,015 \\
\hline & Situation awareness & $652(65.6 \%)$ & 87 (79.8\%) & 0,003 \\
\hline & Teamwork & 739 (74.0\%) & $93(85.3 \%)$ & 0,010 \\
\hline & Managing stress & $457(45.8 \%)$ & 77 (70.6\%) & $<0,001$ \\
\hline & Coping with fatigue & $226(22.6 \%)$ & $48(44.0 \%)$ & $<0,001$ \\
\hline \multirow[t]{7}{*}{ Assessment of NTSs } & Decision-making & $529(53.0 \%)$ & $78(71.6 \%)$ & $<0,001$ \\
\hline & Leadership & $508(50.9 \%)$ & $74(67.9 \%)$ & $<0,001$ \\
\hline & Communication & $539(54.0 \%)$ & $76(69.7 \%)$ & 0,002 \\
\hline & Situation awareness & $521(52.2 \%)$ & $74(67,9 \%)$ & 0,002 \\
\hline & Teamwork & $563(56.4 \%)$ & $81(74.3 \%)$ & $<0,001$ \\
\hline & Managing stress & 398 (39.9\%) & $66(60.6 \%)$ & $<0,001$ \\
\hline & Coping with fatigue & 199 (19.9\%) & $46(42.2 \%)$ & $<0,001$ \\
\hline
\end{tabular}




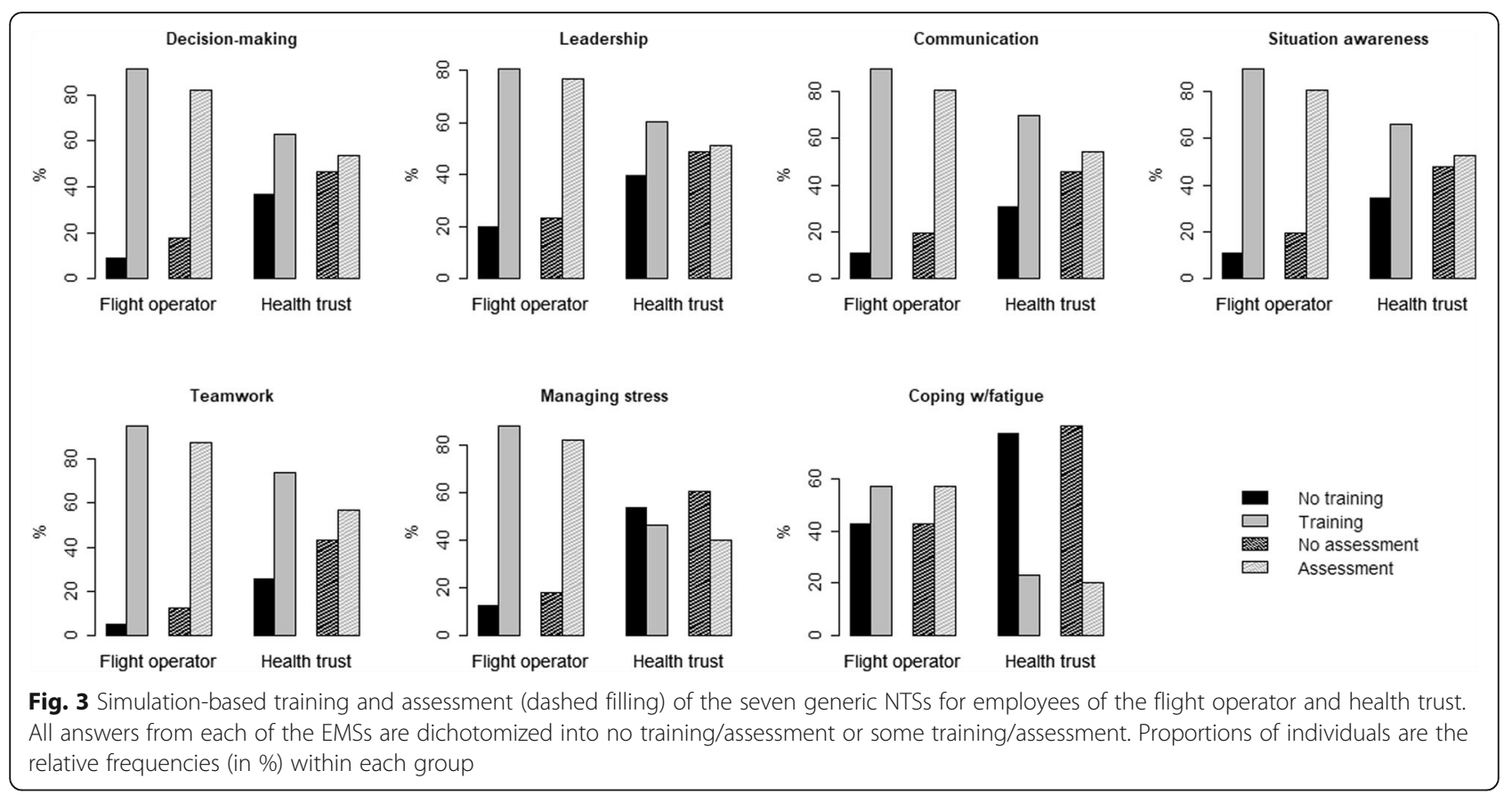

\section{Lack of assessment}

In both HEMS and GEMS, our findings show a tendency of less assessment of NTSs than simulation-based training. Just as the effect of simulation-based training should not be underestimated [11], neither should the effect of assessment. Incorrect behaviour, which is not detected, induces the likelihood of errors that could have been prevented [29]. Many of the tasks executed in the EMS are routines, which need to be corrected if they are wrong. Frameworks and tools exist to assess the NTSs in medical teams [37, 40].
However, none are custom-made for the prehospital environment [6]. Proper training without any feedback from qualified personnel can limit the value and learning [41]. In addition to maximize training outcomes, systematic assessment of the NTSs (i.e. debriefing) may detect CRM issues and improve the simulation-based training [42].

\section{The greater and lesser focus in the Norwegian HEMS and GEMS}

Within both EMSs, the frequency of training in and assessment of teamwork appears to be greater than

Table 2 Numbers (frequencies) of flight operator and health trust employees undertaking some training in and assessment of the seven NTSs during 2015; Fisher's exact test proving statistically significant differences

\begin{tabular}{|c|c|c|c|c|}
\hline Question category & NTS category & Flight operator employee $(n=56)$ & Health trust employee $(n=1051)$ & $p$-value \\
\hline & Decision-making & $51(91.1 \%)$ & $663(63.1 \%)$ & $<0,001$ \\
\hline \multirow[t]{6}{*}{ Simulation-based training of NTSs } & Leadership & $45(80.4 \%)$ & $634(60.3 \%)$ & 0,003 \\
\hline & Communication & $50(89.3 \%)$ & $731(69.6 \%)$ & $<0,001$ \\
\hline & Situation awareness & $50(89.3 \%)$ & $692(65.8 \%)$ & $<0,001$ \\
\hline & Teamwork & $53(94.6 \%)$ & 779 (74.1\%) & $<0,001$ \\
\hline & Managing stress & $49(87.5 \%)$ & $485(46.1 \%)$ & $<0,001$ \\
\hline & Coping with fatigue & $32(57.1 \%)$ & $242(23.0 \%)$ & $<0,001$ \\
\hline \multirow[t]{7}{*}{ Assessment of NTSs } & Decision-making & $46(82.1 \%)$ & $561(53.4 \%)$ & $<0,001$ \\
\hline & Leadership & $43(76.8 \%)$ & $539(51.3 \%)$ & $<0,001$ \\
\hline & Communication & $45(80.4 \%)$ & $570(54.2 \%)$ & $<0,001$ \\
\hline & Situation awareness & $45(80.4 \%)$ & $550(52.3 \%)$ & $<0,001$ \\
\hline & Teamwork & $49(87.5 \%)$ & $592(56.6 \%)$ & $<0,001$ \\
\hline & Managing stress & $46(82.1 \%)$ & $418(39.8 \%)$ & $<0,001$ \\
\hline & Coping with fatigue & $32(57.1 \%)$ & 213 (20.3\%) & $<0,001$ \\
\hline
\end{tabular}


Table 3 ORs with $p$-values, for health trust employees having undergone simulation-based training in and assessment of seven generic NTSs during 2015, compared with the group of physicians $(n=53)$; $p$-values are calculated from logistic regressions

\begin{tabular}{|c|c|c|c|c|c|c|c|c|c|c|c|}
\hline \multirow[t]{2}{*}{$\begin{array}{l}\text { Question } \\
\text { category }\end{array}$} & \multirow[t]{2}{*}{$\begin{array}{l}\text { NTS } \\
\text { category }\end{array}$} & \multicolumn{2}{|c|}{$\begin{array}{l}\text { EMT } \\
(n=541)\end{array}$} & \multicolumn{2}{|c|}{ Nurse EMT $(n=146)$} & \multicolumn{2}{|c|}{$\begin{array}{l}\text { Nurse } \\
(n=37) \\
\end{array}$} & \multicolumn{2}{|c|}{ Paramedic $(n=250)$} & \multicolumn{2}{|c|}{ EMT apprentice $(n=24)$} \\
\hline & & $\overline{O R}$ & $p$-value & $\overline{\mathrm{OR}}$ & $p$-value & $\overline{\mathrm{OR}}$ & $p$-value & $\overline{O R}$ & $p$-value & $\overline{O R}$ & $p$-value \\
\hline \multirow{7}{*}{$\begin{array}{l}\text { Simulation- } \\
\text { based training } \\
\text { of NTSs }\end{array}$} & Decision-making & 0.59 & 0.107 & 0.55 & 0.087 & 0.75 & 0.536 & 0.67 & 0.242 & 0.30 & 0.021 \\
\hline & Leadership & 0.77 & 0.397 & 0.64 & 0.183 & 0.44 & 0.060 & 1.09 & 0.782 & 0.17 & 0.001 \\
\hline & Communication & 0.88 & 0.699 & 0.76 & 0.430 & 1.43 & 0.476 & 1.06 & 0.870 & 0.40 & 0.068 \\
\hline & Situation awareness & 0.88 & 0.688 & 0.74 & 0.376 & 0.90 & 0.821 & 0.82 & 0.556 & 0.37 & 0.048 \\
\hline & Teamwork & 0.94 & 0.853 & 0.89 & 0.757 & 1.18 & 0.749 & 0.99 & 0.978 & 0.38 & 0.065 \\
\hline & Managing stress & 0.76 & 0.344 & 0.74 & 0.342 & 1.05 & 0.909 & 0.74 & 0.313 & 0.54 & 0.215 \\
\hline & Coping w/fatigue & 0.80 & 0.478 & 0.62 & 0.191 & 0.54 & 0.231 & 0.54 & 0.066 & 0.21 & 0.050 \\
\hline \multirow{7}{*}{$\begin{array}{l}\text { Assessment } \\
\text { of NTSs }\end{array}$} & Decision-making & 0.73 & 0.285 & 0.73 & 0.339 & 0.77 & 0.550 & 0.80 & 0.458 & 0.47 & 0.130 \\
\hline & Leadership & 0.72 & 0.255 & 0.69 & 0.253 & 0.60 & 0.242 & 0.89 & 0.700 & 0.36 & 0.044 \\
\hline & Communication & 0.86 & 0.616 & 0.77 & 0.421 & 0.75 & 0.503 & 0.85 & 0.587 & 0.60 & 0.303 \\
\hline & Situation awareness & 0.92 & 0.777 & 0.87 & 0.676 & 0.87 & 0.753 & 0.93 & 0.799 & 0.59 & 0.291 \\
\hline & Teamwork & 0.88 & 0.666 & 0.87 & 0.656 & 0.69 & 0.396 & 0.82 & 0.524 & 0.66 & 0.395 \\
\hline & Managing stress & 1.13 & 0.648 & 1.09 & 0.799 & 1.40 & 0.437 & 0.99 & 0.985 & 0.99 & 0.984 \\
\hline & Coping w/fatigue & 0.85 & 0.632 & 0.63 & 0.224 & 0.65 & 0.410 & 0.42 & 0.018 & 0.73 & 0.600 \\
\hline
\end{tabular}

that of the other NTSs. Strong teamwork is considered fundamental to patient safety and thus, not surprisingly, a major focus, independent of profession and EMS [43]. Each member of an EMS team needs to be aware of his/her own and the other team members' roles and tasks, to ensure effective and safe patient care, as the safety in the EMS domain relies on mutual understanding among the team members [25].
Our data indicate that less training in and assessment of coping with fatigue, compared to the other NTSs, is present in both HEMS and GEMS, which was also observed in HEMS during 2011 [34]. The previous study [34], reflected on coping with fatigue as not being an explicit NTS category per se but rather an influencer affecting the other NTSs. This study supports such an argument. Fatigue, which is common in the EMS environment [44], ultimately threatens the other NTSs [45],

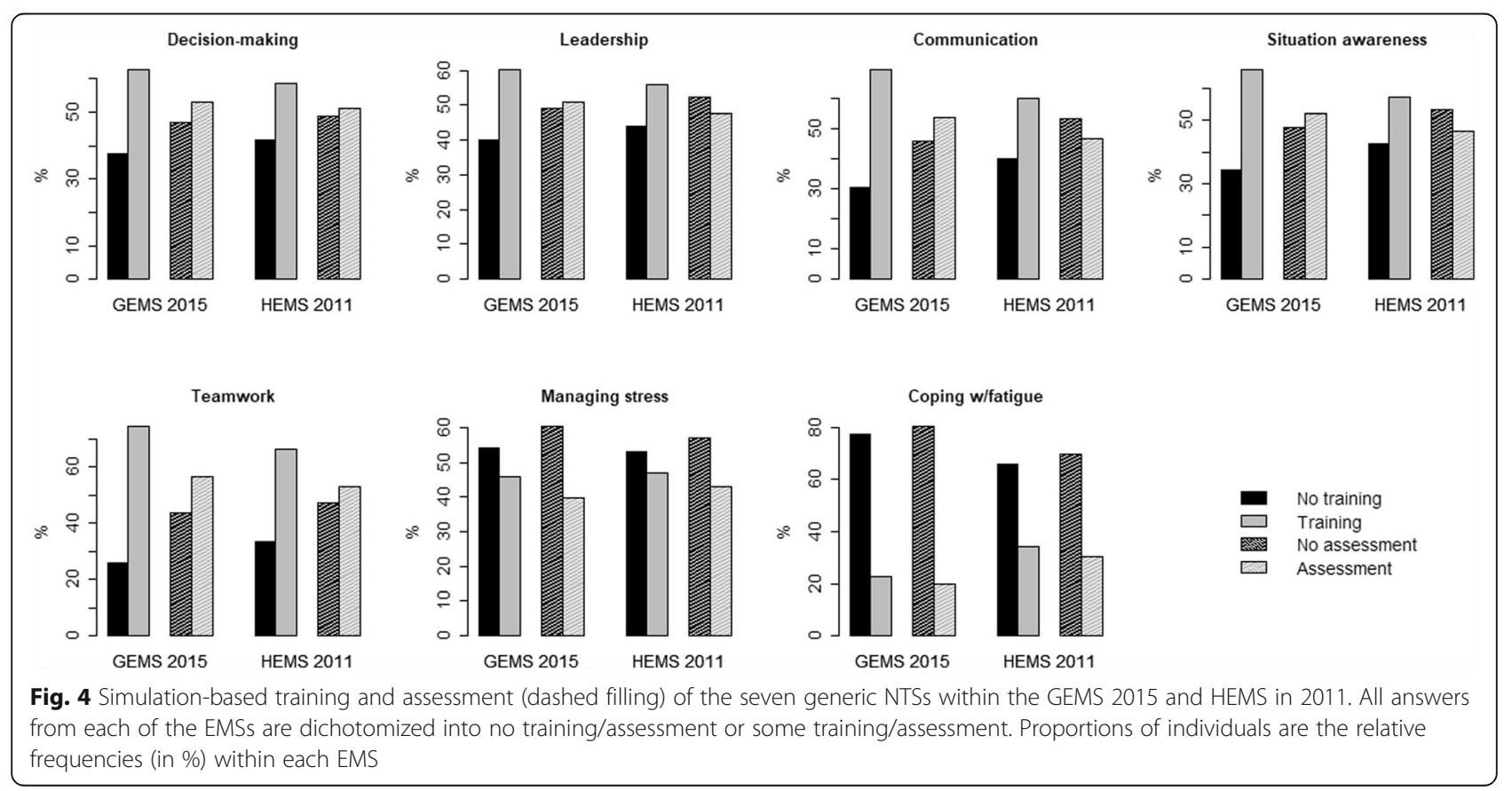


Table 4 Numbers (frequencies) of GEMS employees during 2015 and HEMS employees during 2011 [34] undertaking some training in and assessment of the seven NTSs; Fisher's exact test proving statistically significant differences

\begin{tabular}{|c|c|c|c|c|}
\hline Question category & NTS category & $\begin{array}{l}\text { GEMS } 2015 \\
(n=998)\end{array}$ & $\begin{array}{l}\text { HEMS } 2011 \\
(n=155)\end{array}$ & $p$-value \\
\hline & Decision-making & $624(62.5 \%)$ & $87 / 149(58.4 \%)$ & 0,366 \\
\hline \multirow[t]{6}{*}{ Simulation-based training of NTSs } & Leadership & $599(60.0 \%)$ & $84 / 150(56.0 \%)$ & 0,373 \\
\hline & Communication & $693(69.4 \%)$ & $90 / 150(60.0 \%)$ & 0,024 \\
\hline & Situation awareness & $655(65.6 \%)$ & $86 / 159(57.3 \%)$ & 0,054 \\
\hline & Teamwork & $739(74.0 \%)$ & $99 / 149(66.4 \%)$ & 0,060 \\
\hline & Managing stress & $457(45.8 \%)$ & $80 / 151(53.0 \%)$ & 0,793 \\
\hline & Coping with fatigue & $226(22.6 \%)$ & $50 / 146(34.2 \%)$ & 0,004 \\
\hline \multirow[t]{7}{*}{ Assessment of NTSS } & Decision-making & $529(53.0 \%)$ & $76 / 149(51.0 \%)$ & 0,661 \\
\hline & Leadership & $508(50.9 \%)$ & $71 / 149(47.7 \%)$ & 0,483 \\
\hline & Communication & $539(54.0 \%)$ & $69 / 148(46.6 \%)$ & 0,095 \\
\hline & Situation awareness & $521(52.2 \%)$ & $69 / 148(46.6 \%)$ & 0,218 \\
\hline & Teamwork & $563(56.4 \%)$ & $79 / 149(53.0 \%)$ & 0,479 \\
\hline & Managing stress & $398(39.9 \%)$ & $64 / 149(43.0 \%)$ & 0,475 \\
\hline & Coping with fatigue & 199 (19.9\%) & $44 / 146(30.1 \%)$ & 0,007 \\
\hline
\end{tabular}

such as teamwork [40]. Therefore, the post-assessment of simulations that comprise fatigue is important, to exploit the full potential of the simulations.

\section{Comparison of the health trust and flight operator}

Compared with flight operator employees, i.e. pilots and HCMs, our data indicate that personnel in the health trust undergo training and assessment significantly less frequently. A possible explanation is the difference in safety culture, as already mentioned. However, a strong safety culture is not a persistent quality that a group achieves automatically. It is a result of focus, resources and commitment over time. In the Norwegian HEMS, significant amounts of resources have been allocated in recent years to enhance training and NTSs [46]. Daily clinical duties in the health trust appear to be less suitable for simulation-based training [34], as it will be too time-consuming and costly, hampering the amount of CRM interventions. However, in situ simulation-based training during on-call hours in the Norwegian HEMS has proven to be feasible [47]. Future research may address the possibility for the health trust to learn from HEMS and adopt similar interventions in their daily duties.

\section{Professional requirements}

The greater frequency of training in and assessment of NTSs observed among flight operator employees, compared to health trust employees, is no surprise. This tendency was also identified in the study from 2011 [34]. Major disincentives of performing simulation-based training are associated with time-consumption, interruption of daily duties and increased overall expenses [48]. Standards that specify requirements of training may inhibit these natural disincentives, and promote participation in training among the EMS personnel.

In the Norwegian HEMS, standards related to the competency of each profession (i.e. pilot, HCM [49], anaesthesiologist [50]) are established. Within these standards, regular interdisciplinary training is emphasised to achieve high quality health care [49]. The standards are perceived as guiding norms [2], that intend to ensure adequate skills among the personnel in the Norwegian HEMS. In the Norwegian GEMS, basic requirements related to education and skills of each profession are also established [2], but without any further specifications on training, frequency of training, and development of the necessary prehospital skills of GEMS personnel. We call for more research related to establishing such standards in GEMS, which can be motivated by the ones in HEMS.

\section{Comparison of health trust employees}

Among the health trust employees, physicians appear to undergo the greatest amount of training in and assessment of NTSs. The intuitive explanation is the close relationship these physicians have to the aviation safety culture through their experience from HEMS. Although the anaesthesiologists are not obligated to participate in the training conducted in HEMS, which is mandatory for the pilots and HCMs, it is strongly recommended. Opportunities to participate in training and being a member of a culture with a focus on NTSs may have induced an awareness of training and assessment among the physicians. 
Equal backgrounds and similarities in responsibility may hamper the development and learning within the team. Diversity in a team can raise awareness of differences and has a positive effect on learning [51, 52]. For GEMS, it can be beneficial to establish a closer relationship with HEMS, with respect to training, in order to promote awareness of their own capabilities and NTSs.

There is an ongoing debate in the Norwegian prehospital domain regarding EMT apprentices conducting on-the-job practice (following the first draft of the Norwegian prehospital emergency medicine regulation [3]), as they are still pursuing their licence. If NTSs are considered to be one of the vaguely stated "required qualities" in the Norwegian prehospital emergency medicine regulation for EMS personnel [3], we may question whether EMT apprentices are eligible to participate in emergency missions. The frequency of training in and assessment of NTSs for EMT apprentices indicates a substantial lack of focus on NTSs and CRM interventions in their education. Our data imply a potential for improvement of simulation-based training in and assessment of NTSs among the EMT apprentices, which the educational programmes in Norway need to be aware of.

\section{An opportunity for GEMS}

There has been an increasing focus on the importance of NTSs and simulations to ensure safety within the Norwegian HEMS over recent years. Specific initiatives have been launched to increase the frequency of training in and assessment of NTSs. In 2011, the Norwegian air ambulance foundation established Camp Torpomoen [53], which is an intensive training programme, in which pilots, HCMs and anaesthesiologists practise together on rare and challenging tasks in safe environments. Another NTS-related initiative in HEMS is the Fatigue Risk Management Programme, initiated in 2013, with the purpose of documenting the physical impact of the working environment and sleep deprivation.

Interestingly, our data imply that the frequency of simulation-based training and assessment observed in HEMS during 2011 [34] is statistically insignificantly different from the frequency observed in GEMS during 2015 (Fig. 4 and Table 4), except for the cases of communication and coping with fatigue. The tendency is that GEMS underwent both training and assessment more frequently during 2015 than HEMS did in 2011. Before the great NTSs-offensive in the Norwegian HEMS, the data indicate that there was no particular association between working in either HEMS or GEMS and the frequency of simulation-based training in and assessment of NTSs. Based on this study, there are now reasons to think otherwise. The potential for learning across the EMSs appears to be present, and it may be a great opportunity for GEMS to gain experience from
HEMS. However, the practice applied in HEMS should be adjusted to better fit the GEMS environment, as simulations need to be specifically designed to incorporate significant differences across the two domains $[6,20]$.

\section{Limitations and strengths of the study}

The response rate among HEMS employees was substantially lower than for the previous study in 2011. This calls into question the representativeness of the 2015 HEMS population. Only one fourth of the GEMS population was included in this study. It is ambitious not to consider non-respondents bias having an impact on the results. However, the observed trends are consistent and unambiguous.

The number of respondents who answered "Other" about their profession, due to having achieved/executing more than one, was significant $(n=63)$. Respondents with "Other" as a profession were categorized manually based on specifications in a free text answer. We had also omitted "EMT apprentice" in the predefined professions in the questionnaire. 24 respondents wrote "EMT apprentice" ("Ambulanselærling") in a free text field, which we manually categorized as a unique group.

Comparing professions in HEMS and GEMS involves a challenge in sample sizes. It is reasonable to believe that the smaller sub-populations, e.g. pilots, have affected the significance of some results. On the other hand, non-parametric statistical tests, such as the Fisher's exact test and odds ratio, are resilient to different sample size, strengthening our results.

Dichotomizing the question items into no training/ assessment and some training/assessment, reduced the possibility of over- or underreporting, due to respondents not remembering how many times they actually underwent training or assessment.

The questionnaire was tested on a group of seven prehospital healthcare workers to ensure correct terminology. We assumed that all the respondents understood the questions, as no additional explanations and definitions were provided. HEMS employees are more familiar with CRM training and may have better understood what the questions were referring to. The possibility that respondents did not report truthfully is also present.

A weakness of the study, which was not the intention, is the possibility of making strong conclusions regarding the quality of NTSs among the EMSs in Norway. Ultimately, it is the quality, and not the frequency of training and assessment, of the NTSs that the individuals possess which is important.

\section{Conclusion}

The study may help to inform future practice of simulation-based training and assessment in the Norwegian prehospital EMSs, particularly in GEMS. The 
observed difference in frequency of simulation-based training in and assessment of NTSs in HEMS, compared to GEMS, implies a potential for learning across domains. In both EMSs, the frequency of assessment was significantly lower than for simulation-based training. Special emphasis on how to increase the frequency of assessment is called for to increase the benefits of simulation-based training in NTSs.

\section{Abbreviations}

ALS: Advanced Life Support; CRM: Crew Resource Management:

ECTS: European Credit Transfer and Accumulation System; EMS: Emergency Medical Service; EMT: Emergency Medical Technician; GEMS: Ground Emergency Medical Service; HCM: HEMS Crew Member; HEMS: Helicopter Emergency Medical Service; HSOPSC: Hospital Survey on Patient Safety Culture; NTS: Non-Technical Skill; OR: Odds Ratio; SAR: Search and Rescue

\section{Acknowledgements}

The authors would like to thank the healthcare providers and local leaders in the Norwegian GEMS and HEMS for participating. We are also grateful to the reviewers of an earlier version of this paper.

\section{Funding}

$\mathrm{HL}$ received funding from the Norwegian Ministry of Education and Research. The funders had no part in the design of the study, collection, analysis, interpretation of data or in the writing of the manuscript.

\section{Availability of data and materials}

Data generated and analysed in the present paper are not publicly available, as further papers may be written based on the data, but are available from LIKS on reasonable request.

\section{Authors' contributions}

HL, EBA and HBA conceived of and designed the study. LIKS, HBA and SJMS performed the data collections. HL performed the data analysis. EBA and HBA contributed to the interpretation. HL drafted the manuscript. EBA, SJMS, HBA contributed to and revised the manuscript for intellectual content. All authors read and approved the final draft.

\section{Ethics approval and consent to participate}

This study was conducted on the approval obtained from the Norwegian Social Science Data Services (NSD; project number 45723). The Regional Committee for Medical and Health Research West-Norway (REK West) evaluated this project as "not mandatory to submit" (Ref. number 2015/2249). Al the participants received information about the purpose of the study, and written consent to participate was given at the start of the study, ensuring that no individual participants could be identified in published material. The digital questionnaires were treated in confidence.

\section{Consent for publication}

Not applicable.

\section{Competing interests}

The authors declare that they have no competing interests.

\section{Publisher's Note}

Springer Nature remains neutral with regard to jurisdictional claims in published maps and institutional affiliations.

\section{Author details}

'Department of Safety, Economics and Planning, University of Stavanger, Faculty of Science and Technology, Stavanger, Norway. ${ }^{2}$ Department of Quality and Health Technology, University of Stavanger, Faculty of Health Sciences, Stavanger, Norway. ${ }^{3}$ Prehospital Division, Stavanger University Hospital, Stavanger, Norway. ${ }^{4}$ Department of Anaesthesiology and Intensive Care, Stavanger University Hospital, Stavanger, Norway.
Received: 6 March 2018 Accepted: 25 June 2018

Published online: 03 July 2018

\section{References}

1. Zakariassen E, Uleberg O, Røislien J. Helicopter emergency medical services response times in Norway: do they matter? Air Med J. 2015;34(2):98-103.

2. Norges offentlige utredninger [Official Norwegian reports]. Først og fremst. Et helhetlig system for håndtering av akutte sykdommer og skader utenfor sykehus [Primarily. A comprehensive system for dealing with acute diseases and injuries outside hospitals]. NOU 2015:17. Norwegian Government Security and Service Organization 2015. https://www.regjeringen.no/no/ dokumenter/nou-2015-17. Accessed 29 Jan 2018.

3. Akuttforskriften. Forskrift om krav til akuttmedisinske tjenester utenfor sykehus [Regulation on pre-hospital Emerg Med services]. 2015. https:// lovdata.no/dokument/LTI/forskrift/2015-03-20-231. Accessed 29 Jan 2018.

4. Dissmann PD, Le Clerc $\mathrm{S}$. The experience of Teesside helicopter emergency services: doctors do not prolong prehospital on-scene times. Emerg Med J. 2007;24(1):59-62.

5. Roberts K, Blethyn K, Foreman M, Bleetman A. Influence of air ambulance doctors on on-scene times, clinical interventions, decision-making and independent paramedic practice. Emerg Med J. 2009;26(2):128-34.

6. Shields A, Flin R. Paramedics' non-technical skills: a literature review. Emerg Med J. 2013;30:350-4.

7. Myers JA, Powell DMC, Psirides A, Hathaway K, Aldington S, Haney MF. Nontechnical skills evaluation in the critical care air ambulance environment: introduction of an adapted rating instrument - an observational study. Scand J Trauma Resusc Emerg Med. 2016; https://doi.org/10.1186/s13049016-0216-5.

8. St Pierre M, Hofinger G, Buerschaper C, Simon R. Crisis management in acute care settings: human factors, team psychology, and patient safety in a high stakes environment. 2nd ed. Berlin: Springer; 2011.

9. Seymour CW, Kahn JM, Schwab CW, Fuchs BD. Adverse events during rotary-wing transport of mechanically ventilated patients: a retrospective cohort study. Crit Care. 2008;12(3):R71

10. Manser T. Teamwork and patient safety in dynamic domains of healthcare: a review of the literature. Acta Anaesthesiol Scand. 2009;53(2):143-51.

11. Gordon M, Darbyshire D, Baker P. Non-technical skills training to enhance patient safety: a systematic review. Med Educ. 2012;46(11):1042-54.

12. O'Connor RE, Slovis CM, Hunt RC, Pirrallo RG, Sayre MR. Eliminating errors in emergency medical services: realities and recommendations. Prehosp Emerg Care. 2002;6(1):107-13.

13. Atack L, Maher J. Emergency medical and health providers' perceptions of key issues in prehospital patient safety. Prehosp Emerg Care. 2010;14(1):95-102.

14. Blandford A, Wong WBL. Situation awareness in emergency medical dispatch. Int J Hum-Compu St. 2004;61(4):421-52.

15. Weller J, Frengley R, Torrie J, Shulruf B, Jolly B, Hopley L, et al. Evaluation of an instrument to measure teamwork in multidisciplinary critical care teams. BMJ Qual Saf. 2011;20(3):216-22.

16. Welp A, Manser T. Integrating teamwork, clinician occupational well-being and patient safety - development of a conceptual framework based on a systematic review. BMC Health Serv Res. 2016; https://doi.org/10.1186/ s12913-016-1535-y.

17. Helmreich RL. Managing human error in aviation. Sci Am. 1997;276(5):62-7.

18. O'Connor P, Campbell J, Newton J, Melton J, Salas E, Wilson K. Crew resource management training effectiveness: a meta-analysis and some critical needs. Int J Aviat Psychol. 2008;18(4):353-68.

19. Gaba DM. Anaesthesiology as a model for patient safety in health care. BMJ. 2000;320:785.

20. Grote G. Safety management in different high-risk domains - all the same? Safety Sci. 2012;50(10):1983-92.

21. Winkelmann M, Friedrich L, Schröter C, Flemming A, Eismann H, Sieg L, Mommsen P, Krettek C, Zeckey C. Simulator-based air medical training program Christoph life: from concept to course. Air Med J. 2016;35(4):242-6.

22. Barger LK, Runyon MS, Renn ML, Moore CG, Weiss PM, Condle JP, et al. Effect of fatigue training on safety, fatigue, and sleep in emergency medical services personnel and other shift workers: a systematic review and metaanalysis. Prehosp Emerg Care. 2018; https://doi.org/10.1080/10903127.2017. 1362087.

23. Batchelder AJ, Steel A, Mackenzie R, Hormis AP, Daniels TS, Holding N. Simulation as a tool to improve the safety of pre-hospital anaesthesia - a pilot study. Anaesthesia. 2009;64(9):978-83. 
24. Flin R, Maran N. Basic concepts for crew resource management and nontechnical skills. Best Pract Res Clin Anaesthesiol. 2015;29(1):27-39.

25. Flin $\mathrm{RH}, \mathrm{O}^{\prime}$ Connor $\mathrm{P}$, Crichton M. Safety at the sharp end: a guide to nontechnical skills. Farnham: Ashgate Publishing; 2008.

26. Hesselink G, Berben S, Beune T, Schoonhoven L. Improving the governance of patient safety in emergency care: a systematic review of interventions. BMJ Open. 2016; https://doi.org/10.1136/bmjopen-2015-009837.

27. Salas E, Wilson KA, Burke CS, Wightman DC. Does crew resource management training work? An update, an extension, and some critical needs. Hum Factors. 2006; https://doi.org/10.1518/001872006777724444.

28. Parson JR, Crichlow A, Ponnuru S, Shewokis PA, Goswami V, Griswold S. Filling the gap: simulation-based crisis resource management training for emergency medicine residents. West J Emerg Med. 2018;19(1):205-10.

29. Gardner A, Rich M. Error management training and simulation education. Clin Teach. 2014;11(7):537-40.

30. Wisborg T, Manser T. Assessment of non-technical skills in the operating room-one assessment tool per specialty. Acta Anaesthesiol Scand. 2014 https://doi.org/10.1111/aas.12352.

31. Ballangrud R, Husebø SE, Hall-Lord ML. Cross-cultural validation and psychometric testing of the Norwegian version of the TeamSTEPPS ${ }^{\circledR}$ teamwork perceptions questionnaire. BMC Health Serv Res. 2017;17(1):799.

32. Mayer CM, Cluff L, Lin W-T, Willis TS, Stafford RE, Williams C, et al. Evaluating efforts to optimize TeamSTEPPS implementation in surgical and pediatric intensive care units. Jt Comm J Qual Patient Saf. 2011;37(8):365-74.

33. Al-Elq AH. Simulation-based medical teaching and learning. J Family Community Med. 2010;17(1):35-40.

34. Abrahamsen HB, Sollid SJM, Öhlund LS, Røislien J, Bondevik GT. Simulationbased training and assessment of non-technical skills in the Norwegian helicopter emergency medical services: a cross-sectional survey. Emerg Med J. 2015;32(8):647-53.

35. Langhelle A, Lossius HM, Silfvast T, Björnsson HM, Lippert FK, Ersson A, et al. International EMS systems: the Nordic countries. Resuscitation. 2004; 61(1):9-21.

36. Grusd E, Kramer-Johansen J. Does the Norwegian emergency medical dispatch classification as non-urgent predict no need for pre-hospital medical treatment? An observational study. Scand J Trauma Resusc Emerg Med. 2016; https://doi.org/10.1186/s13049-016-0258-8.

37. Lyk-Jensen H, Jepsen R, Spanager L, Dieckmann P, Østergaard D. Assessing nurse anaesthetists' non-technical skills in the operating room. Acta Anaesthesiol Scand. 2014;58(7):794-801.

38. Bamford R, Langdon L, Rodd CA, Eastaugh-Waring S, Coulston JE. Core trainee boot camp-a method for improving technical and non-technical skills of novice surgical trainees. A before and after study. Int J Surg. 2018; https://doi.org/10.1016/j.ijsu.2018.03.083

39. Sexton JB, Thomas EJ, Helmreich RL. Error, stress, and teamwork in medicine and aviation: cross sectional surveys. BMJ. 2000;320:745-9.

40. Patterson PD, Weaver MD, Weaver SJ, Rosen MA, Todorova G, Weingart LR, et al. Measuring teamwork and conflict among emergency medical technician personnel. Prehosp Emerg Care. 2012; https://doi.org/10.3109/ 10903127.2011.616260

41. Ryoo EN, Ha EH. The importance of debriefing in simulation-based learning: comparison between debriefing and no debriefing. Comput Inform Nurs. 2015:33(12):538-45.

42. Bredmose PP, Habig K, Davies G, Grier G, Lockey DJ. Scenario based outdoor simulation in pre-hospital trauma care using a simple mannequin model. Scand J Trauma Resusc Emerg Med. 2010; https://doi.org/10.1186/ 1757-7241-18-13.

43. Williams KA, Rose WD, Simon R. Teamwork in emergency medical services. Air Med J. 1999;18(4):149-53.

44. Patterson PD, Suffoletto BP, Kupas DF, Weaver MD, Hostler D. Sleep quality and fatigue among prehospital providers. Prehosp Emerg Care. 2010; https://doi.org/10.3109/10903120903524971.

45. Myers JA, Powell DMC, Aldington S, Sim D, Psirides A, Hathaway K, et al. The impact of fatigue on the non-technical skills performance of critical care air ambulance clinicians. Acta Anaesthesiol Scand. 2017;61(10):1305-13.

46. Stiftelsen Norsk Luftambulanse [The Norwegian Air Ambulance Foundation] Årsrapport for 2016 [Annual Report 2016]. 2017. https://norskluftambulanse. no/arsrapporter/. Accessed 27 Apr 2018.

47. Bredmose PP, Sollid S. Weekly simulation for an on call helicopter emergency medical crew: feasible or impossible? Scand J Trauma Resusc Emerg Med. 2015; https://doi.org/10.1186/1757-7241-23-S2-A23.
48. Pietsch U, Knapp J, Ney L, Berner A, Lischke V. Simulation-based training in mountain helicopter emergency medical service: a multidisciplinary team training concept. Air Med J. 2016; https://doi.org/10.1016/j.amj.2016.05.006.

49. The Norwegian Ministry of Justice and Public Security, The Norwegian Ministry of Health and Care Services. Nasjonal standard for redningsmenn innen Luftambulasetjenesten, redningshelikoptertjenesten og SAR offshore [National standards for HCM within the air ambulance, emergency helicopter services and SAR offshore]. 2010. http://www.luftambulanse.no/ system/files/internett-vedlegg/nasjonal_standard_for_redningsmenn_ revidert_18._juli_2010.pdf. Accessed 1 May 2018.

50. Luftambulansetjenesten [National Air Ambulance Services of Norway]. Nasjonal standard for luftambulanseleger (helikopter) [National standard requirements helicopter emergency medical services physicians]. 2013. http://www.luftambulanse.no/system/files/internett-vedlegg/nasjonal_ standard for_luftambulanseleger_25.08.2011_rev_helsekrav.pdf. Accessed 27 Apr 2018.

51. Eisenmann D, Stroben F, Gerken JD, Machner M, Hautz WE. Interprofessiona emergency training leads to changes in the workplace. West J Emerg Med. 2018; https://doi.org/10.5811/westjem.2017.11.35275.

52. Frykman M, Hasson $\mathrm{H}$, Muntlin Athlin $\AA$, von Thiele Schwarz U. Functions of behavior change interventions when implementing multi-professional teamwork at an emergency department: a comparative case study. BMC Health Serv Res. 2014; https://doi.org/10.1186/1472-6963-14-218.

53. Martinsen J. Observation and rating HEMS Crew in non-Technical Skills, CRM medical simulation in Norwegian air ambulance. Scand J Trauma, Resusc Emerg Med. 2015;23(2):A21.

\section{Ready to submit your research? Choose BMC and benefit from:}

- fast, convenient online submission

- thorough peer review by experienced researchers in your field

- rapid publication on acceptance

- support for research data, including large and complex data types

- gold Open Access which fosters wider collaboration and increased citations

- maximum visibility for your research: over $100 \mathrm{M}$ website views per year

At BMC, research is always in progress.

Learn more biomedcentral.com/submissions 



\section{Paper VII}

Training and assessment of non-technical skills in Norwegian helicopter emergency services: a crosssectional and longitudinal study

Authors: Kristen Rasmussen, Henrik Langdalen, Stephen J. M. Sollid, Eirik B. Abrahamsen, Leif I. K. Sørskår, Gunnar T. Bondevik and Håkon B. Abrahamsen

Published in Scandinavian Journal of Trauma, Resuscitation and Emergency Medicine, vol. 27, 1-10, 2019. Doi: 10.1186/s13049-018-0538-1 



\title{
Training and assessment of non-technical skills in Norwegian helicopter emergency services: a cross-sectional and longitudinal study
}

Kristen Rasmussen ${ }^{1,2,3^{*}}$ (D) Henrik Langdalen ${ }^{4}$, Stephen J. M. Sollid ${ }^{1,5}$, Eirik Bjorheim Abrahamsen ${ }^{4}$, Leif Inge K. Sørskår ${ }^{4}$ Gunnar Tschudi Bondevik ${ }^{6,7}$ and Håkon B. Abrahamsen ${ }^{4,8}$

\begin{abstract}
Background: Deficient non-technical skills (NTS) among providers of critical care in helicopter emergency medical services (HEMS) is a threat to patient and operational safety. Skills can be improved through simulation-based training and assessment. A previous study indicated that physicians underwent less frequent training compared to pilots and HEMS crew members (HCM) and that all professional groups in Norwegian HEMS received limited training in how to cope with fatigue. Since then, training initiatives and a fatigue risk management project has been initiated. Our study aimed to explore if the frequency of simulation-based training and assessment of NTS in Norwegian HEMS has changed since 2011 following these measures.

Methods: A cross-sectional web-based survey from October through December 2016, of physicians, HCM and pilots from all civilian Norwegian HEMS-bases reporting the overall extent of simulation-based training and assessment of NTS.

Results: Of 214 invited, 109 responses were eligible for analysis. The frequency of simulation-based training and assessment of NTS has increased significantly for all professional groups in Norwegian HEMS, most prominently for the physicians. For all groups, the frequency of assessment is generally lower than the frequency of training.

Conclusions: Physicians in Norwegian HEMS seem to have adjusted to the NTS training culture of the other crew member groups. This might be a consequence of improved NTS training programs. The use of behavioural marker systems systematically in HEMS should be emphasized.
\end{abstract}

Keywords: Air ambulances, Helicopter, Communication, Leadership, Non-technical skills, Simulation-based training

\section{Introduction}

Pre-hospital critical care and transport of critically ill or injured patients involve a significant risk of adverse events [1]. Studies investigating the factors contributing to critical incidents and adverse events in highly dynamic domains of healthcare, such as emergency medicine, have shown that teamwork plays an important role [2]. Team leadership is a critical skill for emergency

\footnotetext{
* Correspondence: kristen.rasmussen@norskluftambulanse.no

${ }^{1}$ Faculty of Health Sciences, University of Stavanger, Stavanger, Norway

${ }^{2}$ Department of Research and Development, Norwegian Air Ambulance

Foundation, Oslo, Norway

Full list of author information is available at the end of the article
}

medicine physicians directly affecting team performance and the quality of patient care $[3,4]$. Poor communication has been found to be a significant factor in adverse events in air ambulance transports [5, 6], but overall, research on the causes of human errors in helicopter emergency medical services (HEMS) is still sparse [7].

Systematic training and assessment of non-technical skills (NTS) in HEMS have received little attention in the past $[8,9]$. NTS can be defined as the cognitive and interpersonal skills needed to deliver safe care [10]. Seven generic categories of NTS have been suggested: situation awareness, decision-making, communication,

(c) The Author(s). 2019 Open Access This article is distributed under the terms of the Creative Commons Attribution 4.0 International License (http://creativecommons.org/licenses/by/4.0/), which permits unrestricted use, distribution, and 
teamwork, leadership, managing stress and coping with fatigue [11].

To document the level of simulation-based training and assessment of non-technical skills in 2011 among crew members of the Norwegian HEMS, Abrahamsen and co-workers performed a cross-sectional survey [8]. The main findings from this study was a lack of simulation-based training and assessment for all professional groups in Norwegian HEMS, that physicians underwent significantly less frequent training and assessment compared to pilots and HEMS Crew Members (HCM), and that all groups received limited training in how to cope with fatigue even though they were on call for extended hours. Since then, the Norwegian Air Ambulance Foundation has implemented a crew training camp concept for the Norwegian HEMS [12], initiated a research project of in situ simulation training during on-call hours with the implementation of weekly simulation training at several HEMS bases in Norway [13], and conducted a fatigue risk management project in Norwegian HEMS.

Our study aimed to explore if the frequency of simulation-based training and assessment of nontechnical skills in Norwegian HEMS has changed following the training initiatives mentioned above. Our hypothesis is that the frequency of simulation-based training and assessment of NTS has increased in all the three professional groups.

\section{Methods}

\section{Setting}

Since the previous survey, one additional HEMS base has been established in Norway. The 12 HEMS bases all have helicopters staffed with a pilot, a HEMS crew member $(\mathrm{HCM})$ and a physician running 24/7 services. One HEMS base is staffed with an additional flight nurse, but because the number of nurses is low, full anonymity could not be guaranteed and this professional group was not included in the previous study. This also applies to the current survey. All Norwegian HEMS physicians are certified or soon-to-be certified anaesthesiologists and employed by the local health enterprise. HCMs and pilots are employed by one of the two flight operators, Norsk Luftambulanse AS and Lufttransport RW AS.

\section{Questionnaire}

Eight question categories regarding education and training in NTS were attached to a patient safety climate questionnaire (Additional file 1). Except for a minor adaptation in wording to also fit ground ambulance organization, the questionnaire was identical to the previous survey [8]. Similarly, our study focused on the two question categories reporting the overall extent of simulation-based training (question category I6) and assessment (question category I7) in the previous year on a four-point ordinal scale $(0,1-2$, $3-5,>5$ times per year) for each of the seven generic NTS categories. The questionnaire also contained seven background variables relating to the respondents' work characteristics; work area, geographic location, field of competence, patient contact, work hours, experience in the prehospital area and seniority in position.

\section{Data collection}

All physicians, HCMs and pilots working in the civilian Norwegian HEMS were invited to participate in an anonymous, cross-sectional web-based survey (SurveyXact ${ }^{\mathrm{m}}$, Rambøll Management Consulting, Oslo, Norway). A link to the survey was distributed via e-mail and five reminders were sent non-responders. The survey was open from October through December 2016.

\section{Statistical analysis}

All answers related to simulation-based training and assessment were dichotomized into "some training/ assessment" and "no training/assessment". To visualize the development in training and assessment, ratios of the percentages from 2015 divided by the corresponding percentages from 2011, were calculated and are presented in bar charts across an ordinal scale. A ratio greater than 1 , indicates a positive development in the frequency of training and assessment. To support the visuals, a series of two-sided Fisher's exact test of the dichotomized items were performed. A $p$-value less than 0.05 should imply a rejection of the null hypothesis, which was no association between the two groups of interest and level of training and assessment. The freeware R 3.1.3 was used for all calculations and visualization producing the results presented in this paper.

\section{Ethical considerations}

The study was approved by the Norwegian Centre for Research Data (Ref. no. 2016/45723) and was exempted from ethical approval by the Regional Committee for Medical and Health Research Western Norway (Ref. no. 2015/2249). The participants received information regarding the purpose of the study and that the questionnaires were to be treated in confidence, and their written consent to participate in the study was given at the start of the survey.

\section{Results}

In total, 214 physicians, $\mathrm{HCMs}$ and pilots in the Norwegian civilian HEMS were invited to participate in the survey. We received 118 responses, yielding a 
response rate of $55.1 \%$. Nine responses were excluded due to either missing core data, or because respondents stated search and rescue services (SAR) or fixed wing air ambulance as their main job, giving 109 responses eligible for analysis. Of these, 49\% (53) were from physicians, 28\% (31) from HCM and 23\% (25) from pilots. In 2011, the corresponding distribution among the professional groups was 53,27 and $20 \%$, respectively (Table 1, Fig. 1).

Overall training and assessment of NTS in Norwegian HEMS When evaluating the results for all personnel in Norwegian HEMS as a whole, the frequency of both simulation-based training and assessment for all NTS categories have increased from 2011 to 2015. By statistical testing, we found that all changes were significant except for simulation-based training in "coping with fatigue" (Table 2).

\section{Training and assessment for each professional group}

Physicians were the professional group with most categories with significant increase in training and assessment from 2011 to 2015. The frequency of simulation-based training of decision-making, leadership, communication, situation awareness and managing stress has increased significantly, and physicians have been assessed significantly more frequently for all NTS

Table 1 Demographic and professional characteristics of the study populations in 2011 and 2015

$2011(n=155) \quad 2015(n=109)$

$\%$

Professional group

$\begin{array}{lll}\text { Physician } & 53 & 49 \\ \text { Pilot } & 20 & 23 \\ \text { HCM } & 27 & 28\end{array}$

Regional health trust

$\begin{array}{lll}\text { North } & 14 & 18 \\ \text { Mid-Norway } & 22 & 21 \\ \text { West } & 26 & 21 \\ \text { South-East } & 36 & 39 \\ \text { Other } & 3 & <1\end{array}$

Prehospital experience

Less than 1 year

1 to 5 years

6 to 10 years

11 to 15 years

16 to 20 years

21 years or more

\section{$\%$}

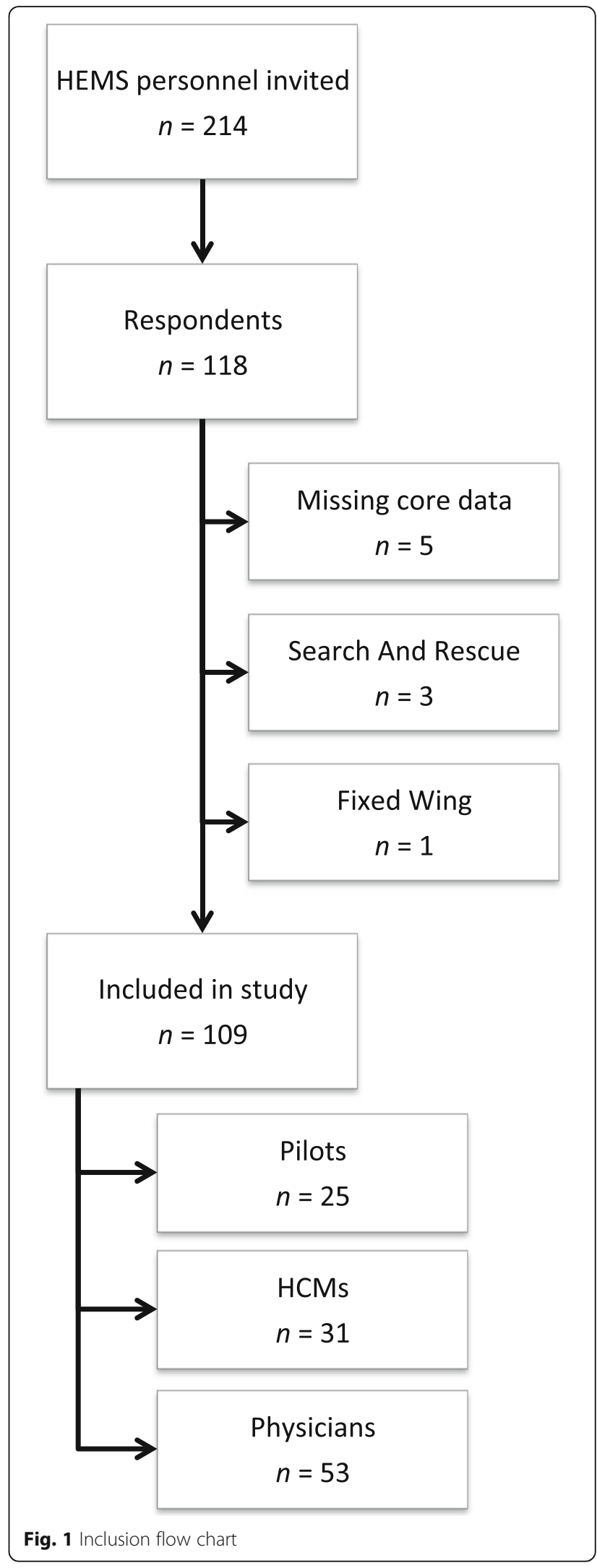


Table 2 Norwegian HEMS personnel with simulation-based training in and assessment of non-technical skills

\begin{tabular}{|c|c|c|c|c|c|}
\hline Question category & NTS category & $2015(n=109)$ & $2011(n=155)$ & $P$-value & \\
\hline \multirow[t]{7}{*}{ Simulation-based training of NTS } & 1. Decision-making & $90 / 109$ (82.6\%) & $87 / 149(58.4 \%)$ & $<0.001$ & * \\
\hline & 2. Leadership & 29/109 (73.4\%) & $84 / 150(56.0 \%)$ & 0.004 & * \\
\hline & 3. Communication & $21 / 109$ (80.7\%) & $90 / 150(60.0 \%)$ & $<0.001$ & * \\
\hline & 4. Situation awareness & 22/109 (79.8\%) & $86 / 150(57.3 \%)$ & $<0.001$ & * \\
\hline & 5. Teamwork & $16 / 109$ (85.3\%) & $99 / 149$ (66.4\%) & $<0.001$ & * \\
\hline & 6. Managing stress & $32 / 109(70.6 \%)$ & 71/151 (47.0\%) & $<0.001$ & * \\
\hline & 7. Coping with fatigue & $61 / 109(44.0 \%)$ & $50 / 146(34.2 \%)$ & 0.120 & \\
\hline \multirow[t]{7}{*}{ Assessment of NTS } & 1. Decision-making & 78/109 (71.6\%) & 76/149 (51.0\%) & 0.001 & * \\
\hline & 2. Leadership & $74 / 109$ (67.9\%) & $71 / 149(47.7 \%)$ & 0.001 & * \\
\hline & 3. Communication & 76/109 (69.7\%) & $69 / 148(46.6 \%)$ & $<0.001$ & * \\
\hline & 4. Situation awareness & $74 / 109(67.9 \%)$ & 69/148 (46.6\%) & $<0.001$ & * \\
\hline & 5. Teamwork & $81 / 109$ (74.3\%) & 79/149 (53.0\%) & $<0.001$ & * \\
\hline & 6. Managing stress & $66 / 109$ (60.6\%) & 64/149 (43.0\%) & 0.006 & * \\
\hline & 7. Coping with fatigue & 46/109 (42.2\%) & $44 / 146$ (30.1\%) & 0.048 & * \\
\hline
\end{tabular}

Number and proportion (\%) of Norwegian HEMS personnel having undergone simulation-based training (question category 16) and assessment (question category 17) of seven (1-7) generic non-technical skills (NTS) in 2011 and 2015. ${ }^{*}$-values less than 0.05 from the two-sided Fisher exact test comparing the proportions in 2011 and 2015

except managing stress and coping with fatigue (Table 3, Fig. 2).

In 2011, pilots reported to be assessed more frequently than physicians, while no significant difference was found regarding simulation-based training [8]. The bar plots indicate a further increase in the frequency of training and assessments for the pilots, but these changes were not significant with the exception of training and assessment of "situation awareness" and "managing stress" (Table 4, Fig. 2).

HCMs appeared to be the professional group with the highest frequency of training and assessment in 2011, although not significantly different from the pilots [8]. We found a further and significant increase in the frequency of HCMs of simulation-based training in decision-making, communication, teamwork and managing stress. No

Table 3 Physicians with simulation-based training in and assessment of non-technical skills

\begin{tabular}{|c|c|c|c|c|c|}
\hline Question category & NTS category & $2015(n=53)$ & $2011(n=82)$ & $P$-value & \\
\hline \multirow[t]{7}{*}{ Simulation-based training of NTS } & 1. Decision-making & $39 / 53(73.6 \%)$ & $37 / 76(48.7 \%)$ & 0.006 & * \\
\hline & 2. Leadership & $35 / 53(66.0 \%)$ & $37 / 78$ (47.4\%) & 0.049 & * \\
\hline & 3. Communication & 38/53 (71.7\%) & 40/77 (51.9\%) & 0.029 & * \\
\hline & 4. Situation awareness & $37 / 53(69.8 \%)$ & $37 / 77$ (48.1\%) & 0.019 & * \\
\hline & 5. Teamwork & 40/53 (75.5\%) & 44/76 (57.9\%) & 0.060 & \\
\hline & 6. Managing stress & 28/53 (52.8\%) & 24/78 (30.8\%) & 0.018 & * \\
\hline & 7. Coping with fatigue & 16/53 (30.2\%) & 18/78 (23.1\%) & 0.419 & \\
\hline \multirow[t]{7}{*}{ Assessment of NTS } & 1. Decision-making & $32 / 53(60.4 \%)$ & 29/77 (37.7\%) & 0.013 & * \\
\hline & 2. Leadership & $31 / 53(58.5 \%)$ & 27/77 (35.1\%) & 0.012 & * \\
\hline & 3. Communication & $31 / 53(58.5 \%)$ & 25/76 (32.9\%) & 0.007 & * \\
\hline & 4. Situation awareness & 29/53 (54.7\%) & $24 / 77(31.2 \%)$ & 0.011 & * \\
\hline & 5. Teamwork & $32 / 53(60.4 \%)$ & 30/77 (39.0\%) & 0.020 & * \\
\hline & 6. Managing stress & 20/53 (37.7\%) & 21/77 (27.3\%) & 0.250 & \\
\hline & 7. Coping with fatigue & $14 / 53(26.4 \%)$ & 14/77 (18.2\%) & 0.284 & \\
\hline
\end{tabular}

Number and proportion (\%) of physicians working in Norwegian helicopter emergency medical services (HEMS) who have undergone simulation-based training (question category 16) and assessment (question category 17) of seven (1-7) generic non-technical skills (NTS) in 2011 and $2015 .{ }^{*} P$-values less than 0.05 from the two-sided Fisher exact test comparing the proportions in 2011 and 2015 


\section{A: Simulation-based training}
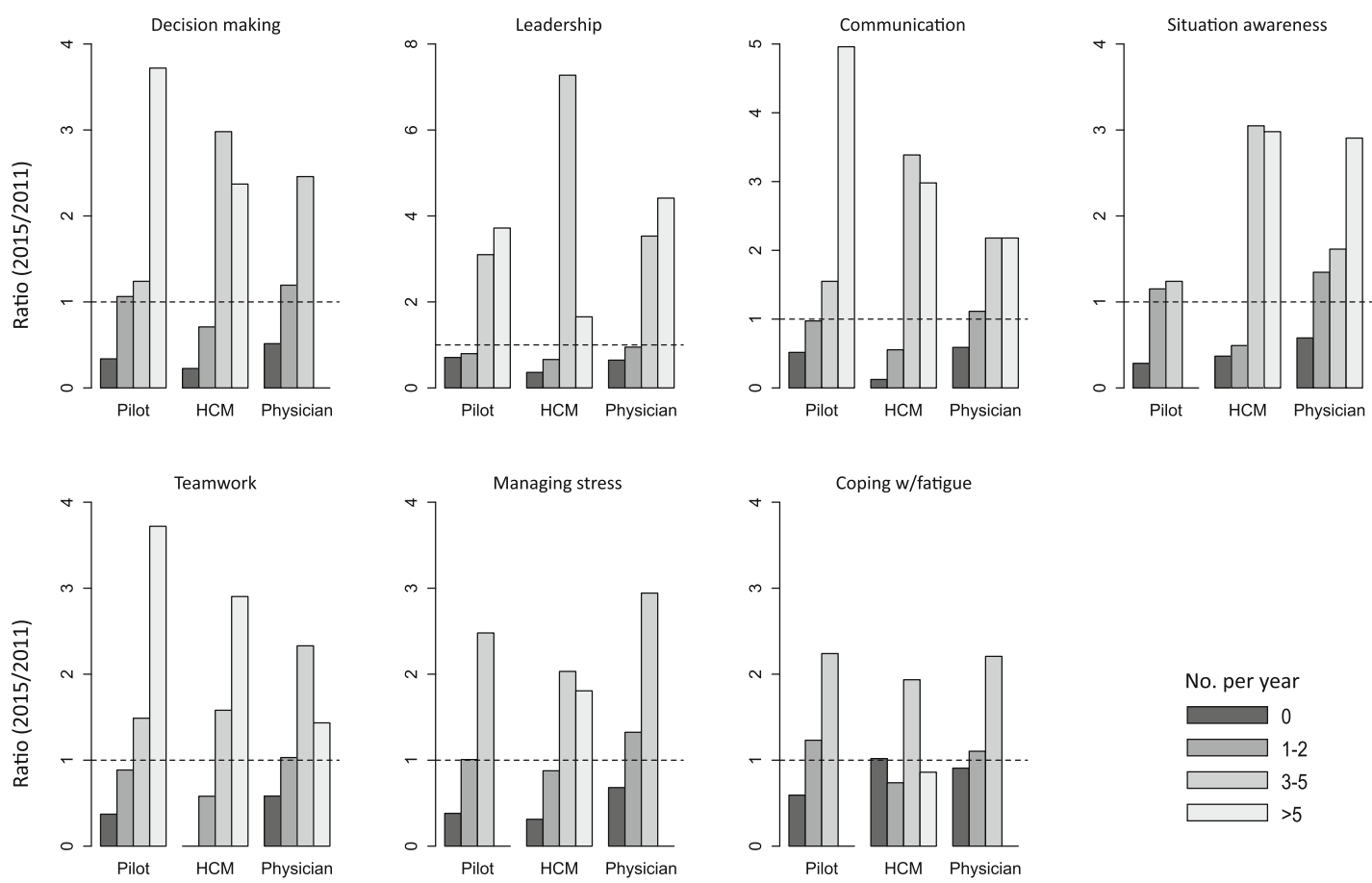

No. per year
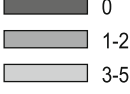

B: Assessment
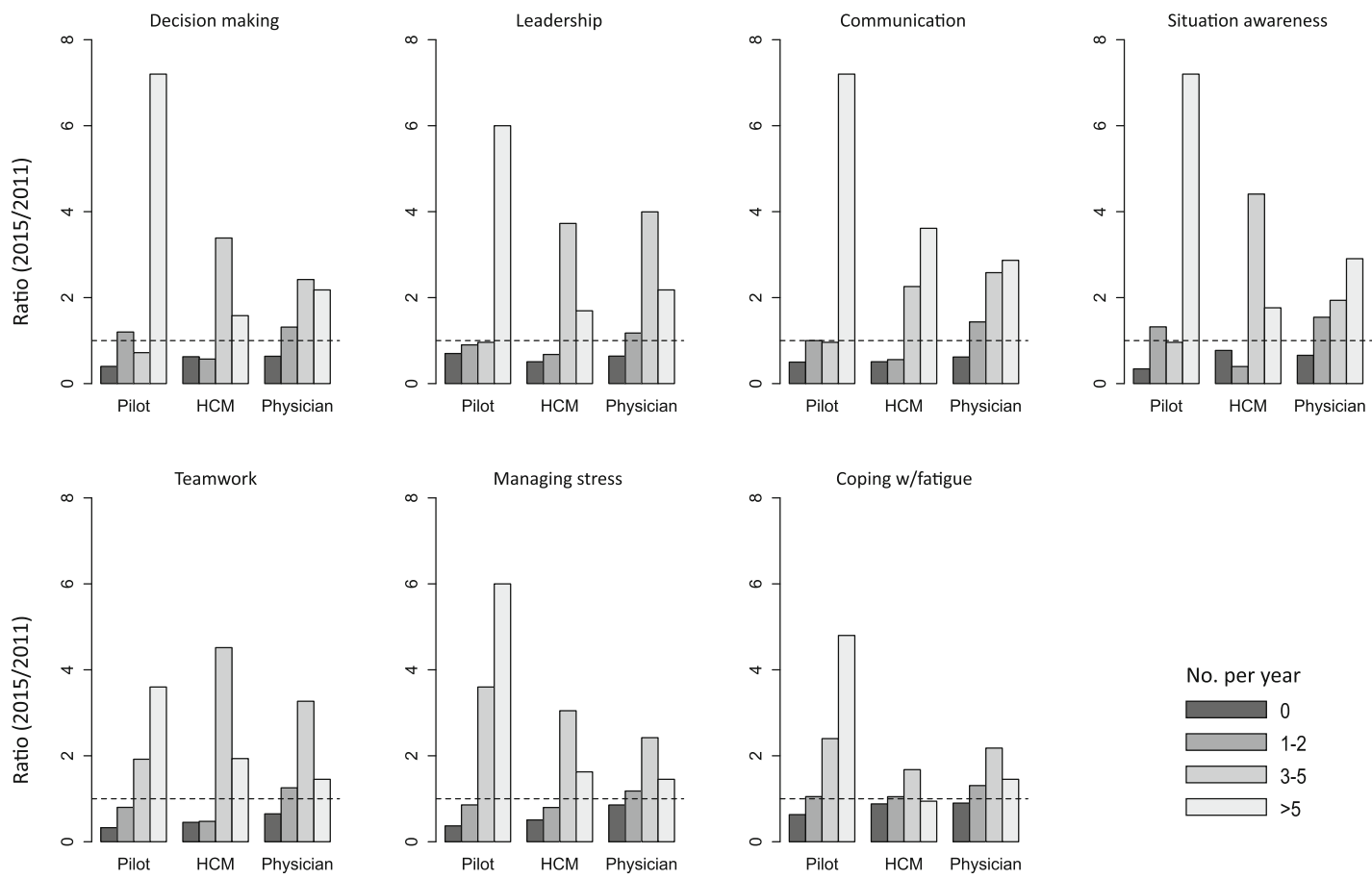

No. per year

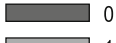

$\square 1-2$

$\square-5$

Fig. 2 (See legend on next page.) 
(See figure on previous page.)

Fig. 2 The changes in (a) simulation-based training in and (b) assessment of the generic non-technical skills within each professional group from 2011 to 2015. The ratios represent the relative frequencies (\%) of 2015 divided by the relative frequencies (\%) of 2011 across all four ordinal categories, with a ratio $=1$ (dashed line) indicating no change in relative frequency and a ratio $<1$ or $>1$ respectively a decrease or an increase in frequency. Missing bars are due to categories with no data in one or both of the years surveyed, and thus, no computable ratio

significant changes were noted for assessment of any of the NTS categories. (Table 5, Fig. 2).

\section{Training and assessment based on employer}

The crew members can be separated with respect to employer. Of the respondents, $49 \%$ were employed by the flight operator (HCMs and pilots) and $51 \%$ were working for the health enterprise (physicians) compared to 47 and $53 \%$, respectively in the previous survey [8].

In 2011, health enterprise employees experienced significantly less frequent training and assessment than flight operator personnel for all NTS categories [8]. In our study, flight operator employees were reporting a significant increase in the frequency of both training and assessment of all NTS except "leadership" and "coping with fatigue" (Table 6). Even though the physicians were the group with most categories with significant increase in training and assessment in the period (Table 3), the significant differences based on employment status still exist for all categories except "leadership" (Table 6).

\section{Discussion}

\section{Training of non-technical skills}

To deliver high quality of care and patient safety, training in technical skills is important to be competent in critical care procedures [14]. Non-technical skills are essential to complement the technical skills in a work setting such as HEMS. Deficiencies in communication and teamwork are frequent contributors to adverse events in health care [15]. There is also increasing awareness about the positive influence of teamwork on clinical performance $[16,17]$ and clinical outcomes $[18,19]$.

Even though the theoretical basis and the evidence regarding educational methods to enhance patient safety using NTS training are still limited [10], both simulation and classroom-based training has been found to improve teamwork processes [15]. An interdisciplinary team training program using in-situ simulation gave a statistically significant and persistent improvement in perinatal morbidity [20]. Similar results have been found in surgical outcome after team training of operating room personnel [19]. Simulation-based team training seems to be the most prominent mode of training in the literature [15].

Duration and frequency of training varies, and there is currently limited, but emerging, evidence that provides insight into the frequency of retraining needed to maintain effective teamwork skills [15]. Significant improvement has been found for critical care providers at 6 and 12 months post-training [21], and studies on simulation based training in neonatal resuscitation seems to favour

Table 4 Pilots with simulation-based training in and assessment of non-technical skills

\begin{tabular}{|c|c|c|c|c|c|}
\hline Question category & NTS category & $2015(n=25)$ & $2011(n=31)$ & $P$-value & \\
\hline \multirow[t]{7}{*}{ Simulation-based training of NTS } & 1. Decision-making & $22 / 25(88.0 \%)$ & $20 / 31(64.5 \%)$ & 0.064 & \\
\hline & 2. Leadership & 17/25 (68.0\%) & 17/31 (54.8\%) & 0.412 & \\
\hline & 3. Communication & $20 / 25(80.0 \%)$ & 19/31 (61.3\%) & 0.155 & \\
\hline & 4. Situation awareness & $22 / 25(88.0 \%)$ & 18/31 (58.1\%) & 0.018 & * \\
\hline & 5. Teamwork & $22 / 25(88.0 \%)$ & 21/31 (67.7\%) & 0.112 & \\
\hline & 6. Managing stress & $21 / 25(84.0 \%)$ & 18/31 (58.1\%) & 0.045 & * \\
\hline & 7. Coping with fatigue & $16 / 25(64.0 \%)$ & 11/28 (39.3\%) & 0.101 & \\
\hline \multirow[t]{7}{*}{ Assessment of NTS } & 1. Decision-making & $21 / 25(84.0 \%)$ & 18/30 (60.0\%) & 0.075 & \\
\hline & 2. Leadership & 18/25 (72.0\%) & $18 / 30(60.0 \%)$ & 0.404 & \\
\hline & 3. Communication & $20 / 25(80.0 \%)$ & 18/30 (60.0\%) & 0.147 & \\
\hline & 4. Situation awareness & $21 / 25(84.0 \%)$ & 16/30 (53.3\%) & 0.022 & * \\
\hline & 5. Teamwork & $22 / 25(88.0 \%)$ & 19/30 (63.3\%) & 0.061 & \\
\hline & 6. Managing stress & $21 / 25(84.0 \%)$ & $17 / 30(56.7 \%)$ & 0.041 & * \\
\hline & 7. Coping with fatigue & $15 / 25$ (60.0\%) & $11 / 30(36.7 \%)$ & 0.108 & \\
\hline
\end{tabular}

Number and proportion (\%) of pilots working in Norwegian helicopter emergency medical services (HEMS) who have undergone simulation-based training (question category 16) and assessment (question category 17) of seven (1-7) generic non-technical skills (NTS) in 2011 and $2015 .{ }^{*} P$-values less than 0.05 from the two-sided Fisher exact test comparing the proportions in 2011 and 2015 
Table 5 HEMS crew members (HCM) with simulation-based training in and assessment of non-technical skills

\begin{tabular}{|c|c|c|c|c|c|}
\hline Question category & NTS category & HCM $2015(n=31)$ & HCM $2011(n=42)$ & $P$-value & \\
\hline \multirow[t]{7}{*}{ Simulation-based training of NTS } & 1. Decision-making & $29 / 31(93.5 \%)$ & $30 / 42(71.4 \%)$ & 0.033 & * \\
\hline & 2. Leadership & 28/31 (90.3\%) & $30 / 41(73.2 \%)$ & 0.080 & \\
\hline & 3. Communication & 30/31 (96.8\%) & $31 / 42(73.8 \%)$ & 0.010 & * \\
\hline & 4. Situation awareness & 28/31 (90.3\%) & $31 / 42(73.8 \%)$ & 0.131 & \\
\hline & 5. Teamwork & $31 / 31(100.0 \%)$ & $34 / 42(81.0 \%)$ & 0.018 & * \\
\hline & 6. Managing stress & 28/31 (90.3\%) & 19/42 (69.0\%) & 0.044 & * \\
\hline & 7. Coping with fatigue & $16 / 31(51.6 \%)$ & $21 / 40(52.5 \%)$ & 1.000 & \\
\hline \multirow[t]{7}{*}{ Assessment of NTS } & 1. Decision-making & $25 / 31(80,6 \%)$ & 29/42 (69.0\%) & 0.295 & \\
\hline & 2. Leadership & $25 / 31(80,6 \%)$ & 26/42 (61.9\%) & 0.122 & \\
\hline & 3. Communication & 25/31 (80,6\%) & 26/42 (61.9\%) & 0.122 & \\
\hline & 4. Situation awareness & $24 / 31(77,4 \%)$ & 29/42 (69.0\%) & 0.596 & \\
\hline & 5. Teamwork & 27/31 (87,1\%) & $30 / 42(71.4 \%)$ & 0.154 & \\
\hline & 6. Managing stress & 25/31 (80,6\%) & 26/42 (61.9\%) & 0.122 & \\
\hline & 7. Coping with fatigue & $17 / 31(54,8 \%)$ & 19/39 (48.7\%) & 0.638 & \\
\hline
\end{tabular}

Number and proportion (\%) of HEMS crew members (HCM) working in Norwegian helicopter emergency medical services (HEMS) who have undergone simulation-based training (question category 16) and assessment (question category 17) of seven (1-7) generic non-technical skills (NTS) in 2011 and 2015.

*P-values less than 0.05 from the two-sided Fisher exact test comparing the proportions in 2011 and 2015

low dose, high frequency training [22]. This points in the direction of at least annual training, similar to common practice for crew resource management (CRM) training in aviation.

The content and schedule of training in technical skills need to be tailored due to variations in mission profiles and exposure to different procedures [14]. Human errors, on the other hand, are not limited to inexperienced clinicians, and NTS training is therefore equally important to all. So far, a consensus regarding the content of team training has not been achieved, but the most commonly targeted teamwork competencies are communication,

Table 6 Flight operator employees and health enterprise employees with simulation-based training in and assessment of nontechnical skills

\begin{tabular}{|c|c|c|c|c|c|c|c|c|}
\hline Question category & NTS category & $\begin{array}{l}\text { Flight } 2015 \\
(n=56)\end{array}$ & $\begin{array}{l}\text { Flight } 2011 \\
(n=73)\end{array}$ & \multicolumn{2}{|l|}{$\begin{array}{l}P \text {-value } \\
\text { A }\end{array}$} & $\begin{array}{l}\text { Health } 2015 \\
(n=53)\end{array}$ & \multicolumn{2}{|l|}{$\begin{array}{l}P \text {-value } \\
B\end{array}$} \\
\hline \multirow[t]{7}{*}{ Simulation-based training of NTS } & 1. Decision-making & $51 / 56(91.1 \%)$ & $50 / 73(68.5 \%)$ & 0.002 & * & $39 / 53(73.6 \%)$ & 0.022 & * \\
\hline & 2. Leadership & $45 / 56(80.4 \%)$ & $47 / 72(65.3 \%)$ & 0.075 & & $35 / 53(66.0 \%)$ & 0.129 & \\
\hline & 3. Communication & $50 / 56(89.3 \%)$ & $50 / 73(68.5 \%)$ & 0.006 & * & $38 / 53(71.7 \%)$ & 0.028 & * \\
\hline & 4. Situation awareness & $50 / 56(89.3 \%)$ & $49 / 73(67.1 \%)$ & 0.003 & * & $37 / 53(69.8 \%)$ & 0.016 & * \\
\hline & 5. Teamwork & $53 / 56(94.6 \%)$ & $55 / 73(75.3 \%)$ & 0.003 & * & $40 / 53(75.5 \%)$ & 0.006 & * \\
\hline & 6. Managing stress & $49 / 56(87.5 \%)$ & $47 / 73(64.4 \%)$ & 0.004 & * & $28 / 53(52.8 \%)$ & $<0.001$ & * \\
\hline & 7. Coping with fatigue & $32 / 56(57.1 \%)$ & $32 / 68(47.1 \%)$ & 0.284 & & $16 / 53(30.2 \%)$ & 0.007 & * \\
\hline \multirow[t]{7}{*}{ Assessment of NTS } & 1. Decision-making & $46 / 56(82.1 \%)$ & $47 / 72(65.3 \%)$ & 0.045 & * & $32 / 53(60.4 \%)$ & 0.019 & * \\
\hline & 2. Leadership & $43 / 56(76.8 \%)$ & 44/72 (61.1\%) & 0.085 & & $31 / 53(58.5 \%)$ & 0.064 & \\
\hline & 3. Communication & $45 / 56(80.4 \%)$ & $44 / 72(61.1 \%)$ & 0.021 & * & $31 / 53(58.5 \%)$ & 0.021 & * \\
\hline & 4. Situation awareness & $45 / 56(80.4 \%)$ & 45/71 (63.4\%) & 0.049 & * & $29 / 53(54.7 \%)$ & 0.007 & * \\
\hline & 5. Teamwork & $49 / 56(87.5 \%)$ & 49/72 (68.1\%) & 0.012 & * & $32 / 53(60.4 \%)$ & 0.002 & * \\
\hline & 6. Managing stress & $46 / 56(82.1 \%)$ & $43 / 72(59.7 \%)$ & 0.007 & * & $20 / 53(37.7 \%)$ & $<0.001$ & * \\
\hline & 7. Coping with fatigue & $32 / 56(57.1 \%)$ & $30 / 69(43.5 \%)$ & 0.152 & & $14 / 53(26.4 \%)$ & 0.002 & * \\
\hline
\end{tabular}

Number and proportion (\%) of Norwegian HEMS personnel employed by the flight operator and health enterprise who have undergone simulation-based training (question category 16) and assessment (question category 17) of seven (1-7) generic non-technical skills (NTS).* $P$-values less than 0.05 from the two-sided Fisher exact test comparing (A) the proportions of flight operator employees in 2011 and 20 and (B) flight operator employees with health enterprise employees in 2015 
situational awareness and leadership [15]. In addition to these, decision-making, teamwork, managing stress and coping with fatigue are often included in non-technical skills evaluation schemes.

\section{Assessment versus training}

Assessment is the process of observing, recording, interpreting and evaluating individual performance and serves different purposes: to audit the level of skills of individuals or units, but also to evaluate training programs [11]. A number of non-technical skills rating frameworks, behavioural marker systems, have been developed for health-care domains closely related to the air ambulance setting [23-26], but a tool for assessment of non-technical skills for HEMS such as the AeroNOTS, has just recently been developed and yet not fully validated [27]. Generally, the frequency of assessment was lower than the frequency of simulation-based training for all three professional groups in our study. This result underlines the undone work in using assessment tools systematically in HEMS.

\section{Training in Norwegian HEMS}

Norwegian HEMS providers have a contractual mandatory training program in rescue and flight operative procedures, including recurrent flight simulator training for pilots and HCMs. Medical training, simulation-based or otherwise, depend on local initiative and commitment. In the study of Abrahamsen, physicians underwent significantly less frequent simulation-based training compared to the other groups [8]. In our study, physicians were the one group with a significant increase in most NTS categories, and thus, an important contributor to the overall increase in the frequency of training in the Norwegian HEMS. The before-mentioned initiatives with in-situ simulation [13] and the all crew training camp [12] may be one explanation to this result. The proportion of physicians training currently seems to be at the level of the other groups in 2011, but they still train significantly less than flight operative employees. Thus, a great potential for simulation-based training still exists among the HEMS physicians.

\section{Coping with fatigue}

The results from the different professional groups were inconsistent regarding each of the generic NTS, and with the limitation in response rate and sample size in our survey, these results should not be over-interpreted. For coping with fatigue, on the other hand, we did not find significant increase for any professional group, despite the finding from 2011 where all professional groups received limited training. This may be seen as a paradox since the non-technical performance of critical care air transfer clinicians is impaired when they are fatigued
[28], and fatigue training seems to improve safety and health outcome for EMS personnel [29]. Fatigue and stress management are usually included in training programs, although it has been questioned whether it is appropriate to include these topics in assessment schemes of NTS. Both can be difficult to detect and rate unless extreme symptoms are displayed, in which other skills will be affected [11]. Another influencing factor may be the lack of a consensus on the definition of fatigue and a standardized survey instrument to measure fatigue among EMS worker groups. Only a limited number of tools used in other settings for assessment of fatigue exist, and research focused on development and testing of fatigue survey instruments tailored specifically for emergency medical services is needed [30]. The on-going research project in Norwegian HEMS in fatigue risk management will hopefully contribute to developing useful tools for fatigue training and assessment.

\section{Limitations}

Our study was part of a combined survey of both ground and air ambulance with more than 5000 invited participants, and thus, the same follow up with personal reminders to all invited as the survey of Abrahamsen [8], was not feasible. Our response rate is therefore noticeably lower, but the distribution in professional groups, prehospital experience and geographical location was largely similar (Table 1 ). We do not know, however, if personnel who have undergone training were more likely to respond to our survey or not, which could result in a non-responder bias and possibly more significant changes than otherwise. The results should be interpreted according to these limitations with an emphasis on the major lines and not detailed results.

In both surveys, respondents were asked to report exclusively on the frequency of interdisciplinary prehospital simulation training. We cannot, nevertheless, exclude that pilots and HCMs may have reported on mandatory flight operative training and that this may explain the better results for these groups in both surveys. We also cannot exclude that physicians may have reported on intra-hospital training.

When asked retrospective to specify the number of training sessions and assessments, some uncertainty must be expected. We have mainly based our conclusions on the dichotomized data, "no training" or "some training", which we have assumed more reliable. Ideally, a longer period between the two surveys would be preferable. This was not possible as our study was a part of a larger research project.

Finally, as discussed earlier, in order to fully understand the effect of simulation training on patient outcome, further research is needed. 


\section{Conclusion}

The frequency of simulation-based training and assessment of NTS has increased significantly in Norwegian HEMS. Physicians seem to be adjusting to the training culture of other professional groups in HEMS, but still, there is a great potential for improving training frequency and volume among the HEMS physicians. Systematic assessment of NTS, including fatigue management, should be a future focus area in HEMS.

\section{Additional file}

Additional file 1: Questionnaire (English translation). (PDF $180 \mathrm{~kb}$ )

\section{Abbreviations}

AeroNOTS: Aeromedical non-technical skills; HCM: HEMS Crew Member; HEMS: Helicopter Emergency Medical Service; NTS: Non-technical skills; SAR: Search and rescue

\section{Acknowledgements}

The authors would like to thank Lufttransport RW AS, Norsk Luftambulanse AS and the medical leaders for their help in distributing and promoting the survey.

\section{Funding}

This study received no specific funding. KR received research grants from Norwegian Air Ambulance Foundation and Møre and Romsdal Hospital Trust and $\mathrm{HL}$ received funding from the Norwegian Ministry of Education and Research. The funders did not take part in any part of the study or manuscript.

\section{Availability of data and materials}

The datasets supporting the conclusions of this article are available from the corresponding author on reasonable request.

\section{Authors' contributions}

KR, HBA, EBA, SJMS: Study design; LIKS, KR, HBA, SJMS, GTB: data collection; KR, HL: data analysis; KR: draft of the manuscript; all authors revised the manuscript and approved the final version.

\section{Ethics approval and consent to participate}

The study was approved by the Norwegian Centre for Research Data (Ref. no. 2016/45723) and was exempted from ethical approval by the Regional Committee for Medical and Health Research Western Norway (Ref. no. 2015/

2249). Consent to participate in the study was given at the start of the survey.

\section{Consent for publication}

Not applicable.

\section{Competing interests}

The authors declare that they have no competing interests.

\section{Publisher's Note}

Springer Nature remains neutral with regard to jurisdictional claims in published maps and institutional affiliations.

\footnotetext{
Author details

${ }^{1}$ Faculty of Health Sciences, University of Stavanger, Stavanger, Norway. ${ }^{2}$ Department of Research and Development, Norwegian Air Ambulance Foundation, Oslo, Norway. ${ }^{3}$ Division of Critical Care, Møre and Romsdal Hospital Trust, Ålesund, Norway. ${ }^{4}$ Department of Safety, Economics and Planning, University of Stavanger, Stavanger, Norway. ${ }^{5}$ Division of Prehospital Medicine, Stavanger University Hospital, Stavanger, Norway. ${ }^{6}$ Department of Global Public Health and Primary Care, University of Bergen, Bergen, Norway. ${ }^{7}$ National Centre for Emergency Primary Health Care, Uni Research Health, Bergen, Norway. ${ }^{8}$ Department of Anaesthesiology and Intensive Care, Stavanger University Hospital, Stavanger, Norway.
}

Received: 8 August 2018 Accepted: 28 December 2018

Published online: 07 January 2019

\section{References}

1. Parmentier-Decrucq E, Poissy J, Favory R, Nseir S, Onimus T, Guerry M-J, Durocher A, Mathieu D. Adverse events during intrahospital transport of critically ill patients: incidence and risk factors. Ann Intensive Care. 2013;3(1):10 https://doi.org/10.1186/2110-5820-3-10.

2. Manser T. Teamwork and patient safety in dynamic domains of healthcare: a review of the literature. Acta Anaesthesiol Scand. 2009;53:143-51 https:// doi.org/10.1111/j.1399-6576.2008.01717.x.

3. Künzle $B$, Kolbe M, Grote $G$. Ensuring patient safety through effective leadership behaviour: a literature review. Safety Sci. 2010;48:1-17 https://doi. org/10.1016/j.ssci.2009.06.004.

4. Rosenman ED, Branzetti JB, Fernandez R. Assessing team leadership in emergency medicine: the milestones and beyond. J Grad Med Educ. 2016 8(3):332-40 https://doi.org/10.4300/JGME-D-15-00400.1.

5. MacDonald RD, Banks BA, Morrison M. Epidemiology of adverse events in air medical transport. Acad Emerg Med. 2008;15:923-31 https://doi.org/10. 1111/j.1553-2712.2008.00241.x.

6. Dalto JD, Weir C, Thomas F. Analyzing communication errors in an air medical transport service. Air Med J. 2013;32(3):129-37 https://doi.org/10. 1016/j.amj.2012.10.019

7. Bigham BL, Buick JE, Brooks SC, Morrison M, Shojania KG, Morrison LJ. Patient safety in emergency medical services: a systematic review of the literature. Prehospital Emerg Care. 2012;16:20-35 https://doi.org/10.3109/ 10903127.2011.621045.

8. Abrahamsen HB, Sollid SJM, Öhlund LS, Røislien J, Bondevik GT. Simulationbased training and assessment of non-technical skills in the Norwegian helicopter emergency medical services: a cross-sectional survey. Emerg Med J. 2015;32:647-53 https://doi.org/10.1136/emermed-2014-203962.

9. Winkelmann M, Friedrich L, Schroter C, Flemming A, Eismann H, Sieg L, et al. Simulator-based air medical training program Christoph life: from concept to course. Air Med J. 2016;35(4):242-6 https://doi.org/10.1016/j.amj. 2016.03.002.

10. Gordon M, Darbyshire D, Baker P. Non-technical skills training to enhance patient safety: a systematic review. Med Educ. 2012;46(11):1042-54 https:// doi.org/10.1111/j.1365-2923.2012.04343.x.

11. Flin R, O'Connor P, Crichton M. Safety at the sharp end. A guide to nontechnical skills. Aldershot: Ashgate; 2008.

12. Martinsen J. Observation and rating HEMS crew in non-technical skills, CRM medical simulation in Norwegian air ambulance. Scand J Trauma Resusc Emerg Med. 2015;23(2):A21 https://doi.org/10.1186/1757-7241-23-S2-A21.

13. Bredmose P, Sollid SJM. Weekly simulation for an on call helicopter emergency medical crew: feasible or impossible? Scand J Trauma Resusc Emerg Med. 2015;23(2):A23 https://doi.org/10.1186/1757-7241-23-S2-A23.

14. Sollid SJM, Bredmose P, Nakstad AR, Sandberg M. A prospective survey of critical care procedures performed by physicians in helicopter emergency medical service: is clinical exposure enough to stay proficient? Scand J Trauma Resusc Emerg Med. 2015;23(45) https://doi.org/10.1186/s13049-0150128-9.

15. Weaver SJ, Dy SM, Rosen MA. Team-training in healthcare: a narrative synthesis of the literature. BMJ Qual Saf. 2014;23(5):359-72 https://doi.org/ 10.1136/bmjqs-2013-001848

16. Schmutz J, Manser T. Do team processes really have an effect on clinical performance? A systematic literature review. Br J Anaesth. 2013;110(4):529-44 https://doi.org/10.1093/bja/aes513.

17. Gjeraa K, Moller TP, Østergaard D. Efficacy of simulation-based trauma team training of non-technical skills. A systematic review. Acta Anaesthesiol Scand. 2014;58(7):775-87 https://doi.org/10.1111/aas.12336.

18. Salas E, Rosen MA. Building high reliability teams: progress and some reflections on teamwork training. BMJ Qual Saf. 2013;22(5):369-73 https:// doi.org/10.1136/bmjqs-2013-002015.

19. Neily J, Mills PD, Young-Xu Y, Carney BT, West P, Berger DH, et al. Association between implementation of a medical team training program and surgical mortality. JAMA. 2010;304(15):1693-700 https://doi.org/10.1001/ jama.2010.1506.

20. Riley W, Davis S, Miller K, Hansen H, Sainfort F, Sweet R. Didactic and simulation nontechnical skills team training to improve perinatal patient outcomes in a community hospital. Jt Comm J Qual Patient Saf. 2011;37(8):357-64 https://doi.org/10.1016/S1553-7250(11)37046-8. 
21. Mayer CM, Cluff L, Lin W-T, Willis TS, Stafford RE, Williams C, et al. Evaluating efforts to optimize TeamSTEPPS implementation in surgical and pediatric intensive care units. Jt Comm J Qual Patient Saf. 2011;37(8):365-74 https://doi.org/10.1016/S1553-7250(11)37047-X.

22. Mduma E, Ersdal $H$, Svensen E, Kidanto H, Auestad B, Perlman J. Frequent brief on-site simulation training and reduction in 24-h neonatal mortality —an educational intervention study. Resuscitation. 2015;93:1-7 https://doi.org/10.1016/j.resuscitation.2015.04.019.

23. Flin R, Patey R, Glavin R, Maran N. Anaesthetists' non-technical skills, Br J Anaesth. 2010;105(1):38-44 https://doi.org/10.1093/bja/aeq134.

24. Flin R, Maran N. Identifying and training non-technical skills for teams in acute medicine. Quality \& safety in health care. 2004;13:180-4 https://doi. org/10.1136/qshc.2004.009993.

25. Ummenhofer W, Amsler F, Sutter PM, Martina B, Martin J, Scheidegger D. Team performance in the emergency room: assessment of inter-disciplinary attitudes. Resuscitation. 2001;49(1):39-46 https://doi.org/10.1016/S03009572(00)00304-X.

26. Robertson ER, Hadi M, Morgan LJ, et al. Oxford NOTECHS II: a modified theatre team non-technical skills scoring system. Roma PG, ed PLoS ONE. 2014;9(3):e90320 https://doi.org/10.1371/journal.pone.0090320.

27. Myers JA, Powell DMC, Psirides A, Hathaway K, Aldington S, Haney MF. Non-technical skills evaluation in the critical care air ambulance environment introduction of an adapted rating instrument--an observational study. Scand J Trauma Resusc Emerg Med. 2016;24:24 https://doi.org/10.1186/ s13049-016-0216-5.

28. Myers JA, Powell DMC, Aldington S, Sim D, Psirides A, Hathaway K, et al. The impact of fatigue on the non-technical skills performance of critical care air ambulance clinicians. Acta Anaesthesiol Scand. 2017;61(10):1305-13 https://doi.org/10.1111/aas.12994.

29. Barger LK, Runyon MS, Renn ML, Moore CG, Weiss PM, Condle JP, et al. Effect of fatigue training on safety, fatigue, and sleep in emergency medical services personnel and other shift workers: a systematic review and metaanalysis. Prehosp Emerg Care. 2018;22(sup1):58-68 https://doi.org/10.1080/ 10903127.2017.1362087.

30. Patterson PD, Weaver MD, Fabio A, Teasley EM, Renn ML, Curtis BR, et al. Reliability and validity of survey instruments to measure work-related fatigue in the emergency medical services setting: a systematic review. Prehosp Emerg Care. 2018;22(sup1):17-27 https://doi.org/10.1080/10903127. 2017.1376134

Ready to submit your research? Choose BMC and benefit from:

- fast, convenient online submission

- thorough peer review by experienced researchers in your field

- rapid publication on acceptance

- support for research data, including large and complex data types

- gold Open Access which fosters wider collaboration and increased citations

- maximum visibility for your research: over $100 \mathrm{M}$ website views per year

At $\mathrm{BMC}$, research is always in progress.

Learn more biomedcentral.com/submissions 